\title{
Dynamics of peri-urban agricultural development and farmers' adaptive behaviour in the emerging megacity of Hyderabad, India
}

\section{DISSERTATION}

zur Erlangung des akademischen Grades

Doctor rerum agriculturarum

(Dr. rer. agr.)

Eingereicht an der

Landwirtschaftlich-Gärtnerischen Fakultät

der Humboldt-Universität zu Berlin

von

M.Sc. Zakir Hussain Shaik

Präsident der Humboldt-Universität zu Berlin

Prof. Dr. Jan-Hendrik Olbertz

Dekan der Landwirtschaftlich-Gärtnerischen Fakultät

Prof. Dr. Dr. h.c. Frank Ellmer

\section{Gutachter}

1. Prof. Dr. Markus Hanisch

2. Prof. Dr. Michael Mann

3. Prof. Dr. K.P.R. Chowdary

Datum der Promotion: 01.10.2013 


\section{Summary}

In recent past two decades India is experiencing a dramatic growth in urban population. The latest censes (2011) specifies that there is 32 per cent of the population lives in cities which makes a growth of 5 per cent in comparison with 2001 census. Apart from the demographic growth, it is the spatial growth which directed various disciplines', among them political, historical, sociological and agricultural sciences attention to the dynamic transformation processes taking place in the urban periphery.

These dramatic changes underpin that due to spatial expansion of cities and town various transformations happen in urban peripheries to a large extent. These transformations in urban peripheries are driven largely on the one hand towards land grabbing building industry providing additional space for real estate, on the other a growing demand for fresh fruits and vegetables for feeding the increasing population. The growing pressure on natural resources like land and water puts also pressure on the economic spaces of peri-urban agriculture forcing them to develop strategies which enable them to react on these challenges. The dissertation describes this brief wider social setting where the main objective of the dissertation provide ramification of the relationship between urbanization and the pattern of change taking place in the peri-urban farming. In addition the dissertation has put forth arguments about understanding the sustainability by various agricultural actors in the peri-urban agriculture that could prompt agricultural communities in these areas to collectively seek more sustainable development and recoup certain social innovations in the process of achieving sustainability. The individual research papers in this dissertation exclusively shed light on various perspectives connected to the establishment of sustainable peri-urban agriculture. 
The literature review unpacks various trajectories of peri-urban agricultural development in different parts of the world such as Europe, North America, South-east Asia and South Africa. ${ }^{1}$ It explores ramifications of rapid urbanization on food production in urban peripheries along with the overview of typical changes which farmers adapt in response to urbanization across the world.

It emphasizes the key drivers of urbanization and their relation to and impacts on peri-urban farming in general and the different trajectories of development around the world in particular. Finally, it outlines the underlying questions that need to be explored within the context of the Greater Hyderabad Area.

Subsequently, Chapter $\mathbf{1}$ applies the findings from the literature review to the case of Greater Hyderabad area. It explores the structural change drivers along with most common types of adaptations realized by the peri-urban farmers and the corresponding environmental impacts. It explores the ramification of rapid urbanization on food production in urban peripheries across the world. It promises some kind of guidelines for a better management and better political action plans concerning the future development of peri-urban zones of Hyderabad.

Sustainability is the magic word with respect to almost everything regarding human behaviour and action for more than two decades now is the natural resources, forestry energy etc., globally much of the attention allocated to sustainability discourses relates to the macro level. Little attention has been paid to understand what different criteria of sustainability mean to farmers themselves (micro level). Therefore in Chapter 2 a Multi-Criteria Decision

\footnotetext{
${ }^{1}$ Thanks to Professor Dr. Michael Mann for summarizing
} 
Analysis with AHP is employed in order to capture the stakeholders' perceptions of sustainability as well as their discernment on various sustainability dimensions. The analysis helps identifying mayor trade-offs amongst different dimensions of sustainability in the farmers' point of view and provides insights for policy makers to better tailor projects in support of sustainable peri-urban agriculture.

About $5 \%$ of agricultural land of the GHA is allocated to Integrated Crop Management and Organic Farming. Growing environmental problems give rise to the question as to how higher adoption rates of sustainable agricultural practices can be achieved. Chapter $\mathbf{3}$ analyses a case in which an entire village has adopted organic farming and draws conclusions for policy makers and urban planners. ${ }^{2}$ Another finding is that the ecological challenge procured community (collective) action and thus promoted environmental sustainability as well as social sustainability. This confirms the theoretical claim that collective action and effective community participation are core elements of social innovation which might help to shape future politics in urban fringes of Hyderabad.

At the end of the dissertation the results of the individual papers are related to each other and their relevance for achieving higher adoption rates for sustainable agriculture in the peri-urban farming is discussed. Finally conclusions for further research and policy recommendations with respect to peri-urban farming in Greater Hyderabad area, India are formulated.

\footnotetext{
${ }^{2}$ Thanks to Professor Dr. Michael Mann again for the key thoughts
} 


\section{Acknowledgements}

This book is dedicated to my beloved deceased parents whose blessings from heaven have had helped me to reach this stage. This research is an outcome of the Project "Climate and Energy in a Complex Transition Process towards Sustainable Hyderabad - Mitigation and adaptation strategies by changing institutions, governance structures, lifestyles and consumption patterns." It was so edifying to author this dissertation which has substantially explicated my understanding about the farmers' issues in the urban periphery of the growing megacity of Hyderabad, India. Also, it was exciting to understand the immense transformations and associated dynamics with the ongoing urbanization besides the multifarious challenges they bring about for the farmers as well as Indian authorities.First, I would like to mention my supervisor Professor Dr. Markus Hanisch, who offered me a great opportunity to conduct my research within the above mentioned project. Professor Hanisch helped me to find my intellectual pathway without steering me and, at times, he fatherly supported my endeavor to creatively re-invent my doubts. His remarkable talent for combining essayistic beauty with the pragmatic demands of daily academic life has taught me many a lesson. Thank you for your relentless willingness to share and reflect. I am grateful for his constant encouragement to pursue my research interest and constructive efforts while writing the research papers in this dissertation. He substantially helped me to clarify various concepts and theories in many conversations.Likewise, I consider it as an honor to thank Prof. Dr. Dr. h.c. Konrad Hagedorn for his constructive suggestions during the research colloquium at the Division of Resource Economics, which has significantly helped to reconcile my research in various stages. Also, I am highly thankful to my second and third supervisors Prof. Dr. Michael Mann and Prof. Dr. K. R. Chowdary for their valuable suggestions and guidance to finally ship-shape my dissertation. In similar vein I would like to appreciate the support of all my defense committee members.

I would like to express my heartfelt thanks to Mr. Reinhold Wilhelm, for his support during the entire research period. I am also indebted to my many colleagues from the Division of Cooperative Sciences especially Saikumar Bharamappanavara, Rajeshwari Mallegowda, Jennifer Meyer-Ueding, Jens Rommel, Sophia Opperskalski, Julian Sagebiel, Malte Müller and Hanna Höfer for their constant support, comments, and encouragement during the 
research period. Similarly I am gratified to all other colleagues from the Division of Resource Economics for their constructive suggestions. Also, I greatly acknowledge the support of my Indian interview partners, the farmers and respondents for sharing their knowledge and opinions with me. Without their cooperation, my fieldwork and research would not have been possible. In the same manner, I would like to thank all those anonymous reviewers from the editorial departments of journals for their valuable comments to my published and papers and to those which are currently under review, Their comments significantly helped me to improve my manuscripts. I greatly appreciate the financial support from the German Academic Exchange Service (DAAD) and the German Federal Ministry for Education and Research (BMBF) that first made my research possible. Furthermore, I am grateful to Humboldt University of Berlin for their financial support from March to June 2013, which enabled me to finalize this dissertation.Finally, I want to express my deepest gratitude for the constant support, encouragement, and love from my wife Shabana Kauser and my two loving daughters Saakhiya and Nida. They had to bear my absence from India during long periods of my research and without them I could not have achieved this goal. Diction is not enough to express my gratitude to my parents though they are not with me anymore. It was their endless blessings from heaven that have carried me through the entire research period. 


\section{Contents}

Summary ....................................................................................................................

Acknowledgements........................................................................................... vi

List of Abbreviations............................................................................................... xiv

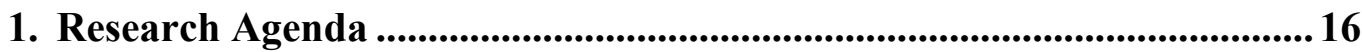

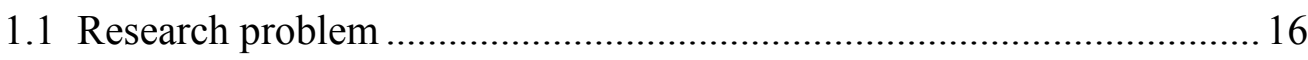

1.2 Conceptual and theoretical framework of the research ............................ 17

1.2.1 Farm adaptations in peri-urban area ............................................ 17

1.2.2 Sustainability and farmers perceptions ........................................ 19

1.2.3 Social innovations and community participation .......................... 19

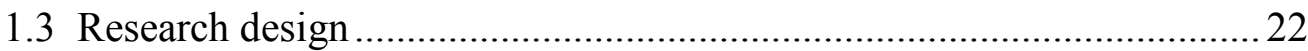

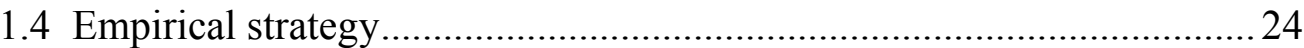

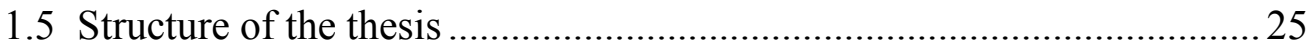

1.5.1 Chapter 1: Dynamics of peri-urban agricultural development-concepts, approaches and diversities around the world: A Literature Review .........................................2 27

1.5.2 Chapter 2: Dynamics of peri-urban agricultural development and farmers' adaptive behavior in the emerging megacity of Hyderabad, India (Published in Journal of Environmental Planning and Management)

1.5.3 Chapter 3: Farmers' discernment about sustainability in the peri-urban farming using Multi-Criteria Decision Analysis with AHP

1.5.4 Chapter 4: Fostering Sustainability in peri-urban farming through societal innovations and community participation: A case about the entire village adoption of organic farming in peri-urban Hyderabad, India........................30

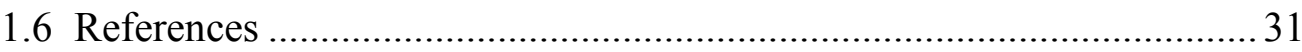

2. Dynamics of peri-urban agricultural development-

A literature review.............................................................................................36

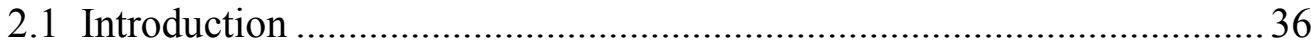

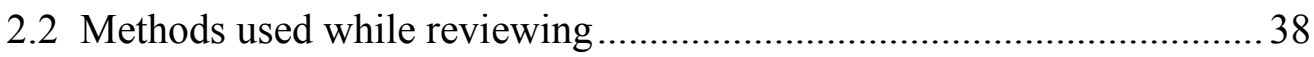

2.3 Studies on peri-urban agricultural development..................................... 42

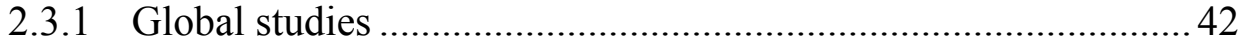

2.3.2 Urban and peri-urban agriculture in India .................................... 44 
2.4 Theorizing agriculture change and adaptation in the urban fringe

2.5 Agricultural development theories and associated discourses

2.5.1 Studies related to farmers' perceptions, attitudes and beliefs.

2.5.2 Community approaches, innovations .54

2.6 Research agenda .57

2.7 References . 57

3. Dynamics of peri-urban agricultural development and farmers' adaptive behaviour in the emerging megacity of Hyderabad, India. .74

3.1 Introdution .75

3.2 Urbanisation in Hyderabad .76

3.3 Adaptation behaviour of peri-urban farmers ....................................... 77

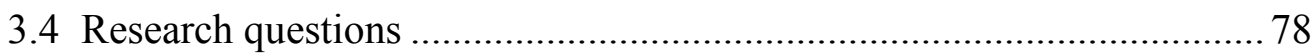

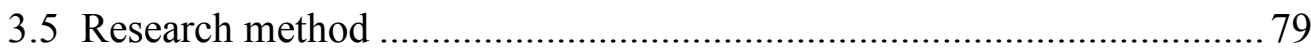

3.6 Causes and effects of urbanization on agriculture................................. 83

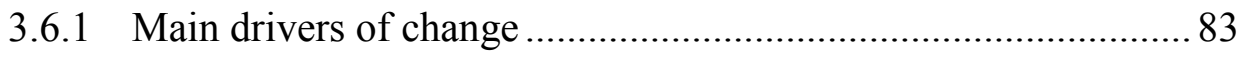

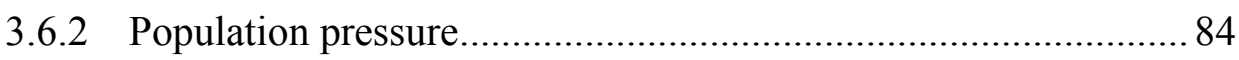

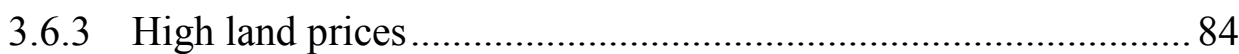

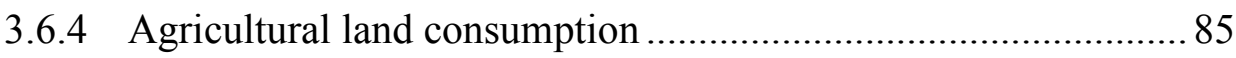

3.6.5 Land tenancy rates and in-migration ..................................... 85

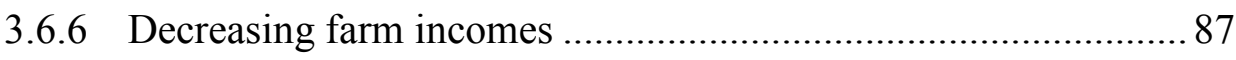

3.7 Farmer perceptions on profitability and sustainability in

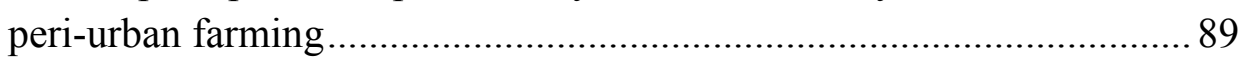

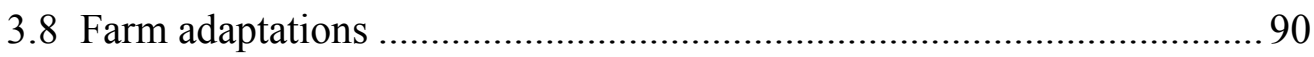

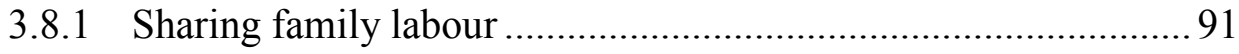

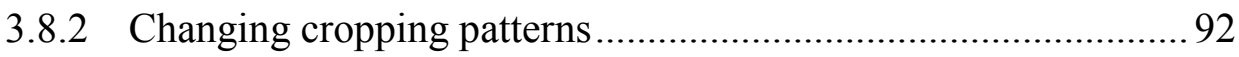

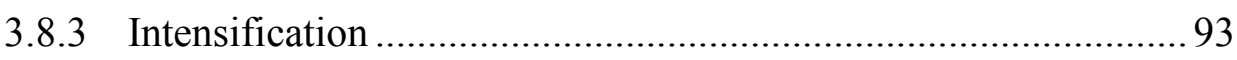

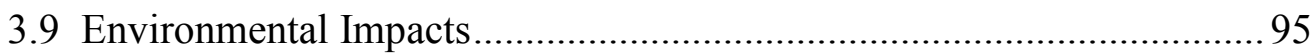

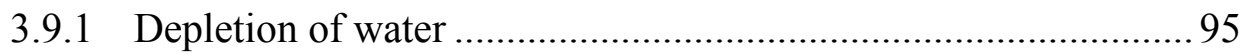

3.9.2 Nitrogen leaking and chemical residues .................................. 96

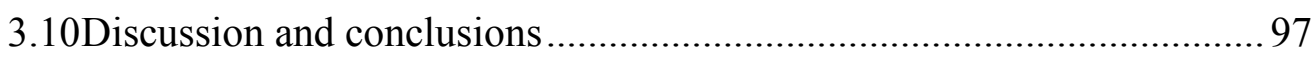

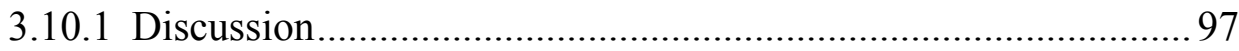

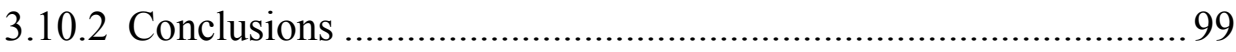

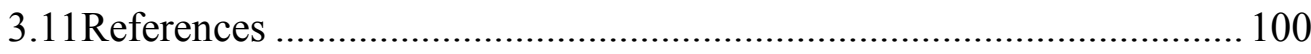


4. Megacity development and farmers' discernment about s ustainability. A Multi-Criteria Decision Analysis in South India's Greater Hyderabad Area .......................................................... 104

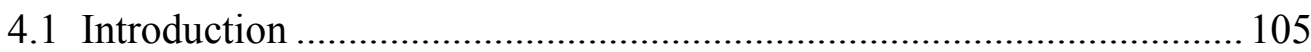

4.1.1 Sustainability, social discourse and perception ........................ 106

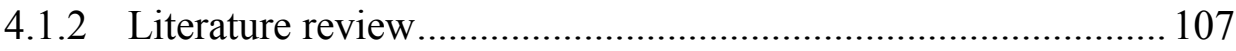

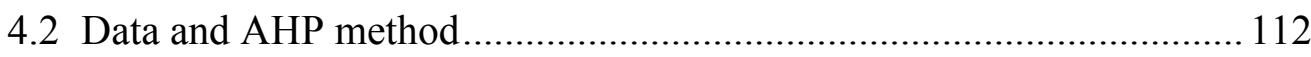

4.2.1 Criteria selection for conducting sustainability

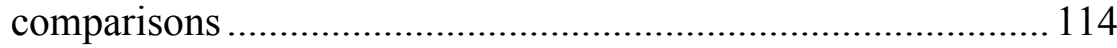

4.3 Structuring the hierarchy and pair-wise comparisons with Analytical Hierarchy Process ............................................................ 116

4.3.1 Data collection and analysis ................................................ 117

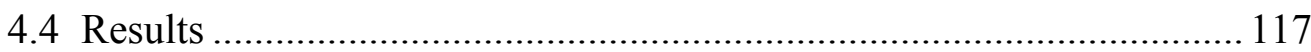

4.4.1 Farmers' perceptions on three dimensions of

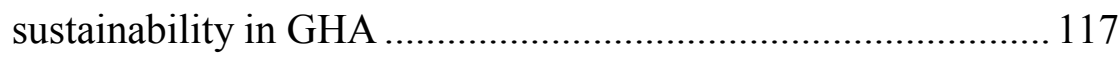

4.4.2 Farmers' perceptions on the environmental criteria

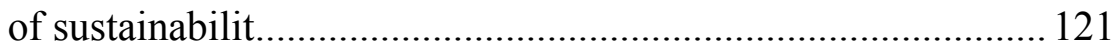

4.4.3 Farmers' perception on different social criteria ....................... 122

4.5 Discussion and Conclusion....................................................................... 124

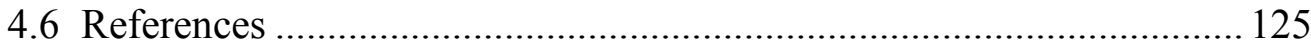

5. Sustainability and Social innovation - A case study of the adoption of organic farming in the Greater Hyderabad

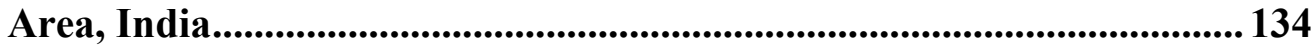

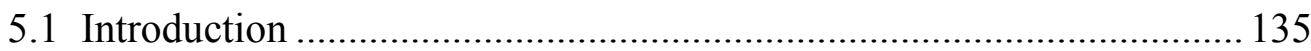

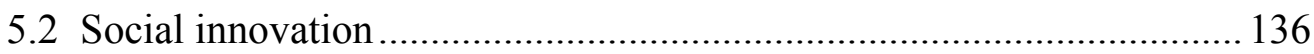

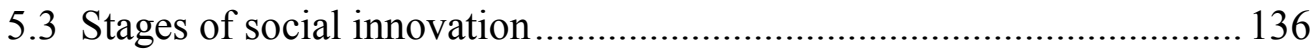

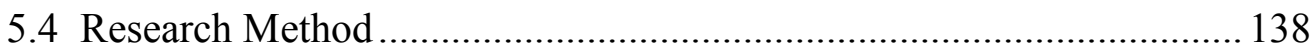

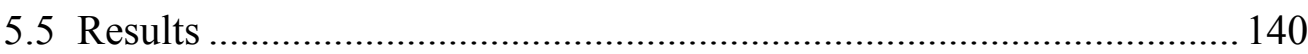

5.5.1 Determinants of crisis in-Enabavi ........................................... 140

5.5.2 The beginning of transformation (Problematization) ................ 142

5.5.3 Expression of interest and coordination ................................. 142

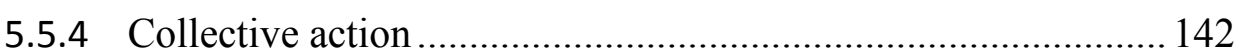

5.5.5 The household level factor analysis...................................... 147

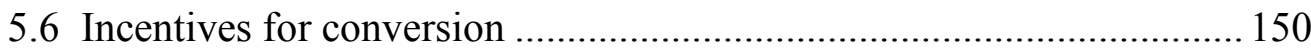

5.6.1 Exchange of goods and services among the villagers .............. 151

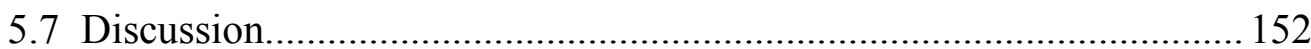

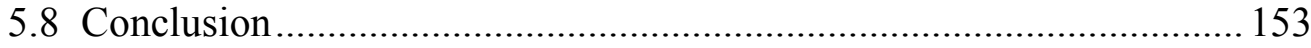


5.9 References

153

6. Conclusion and Research outlook ............................................................. 158

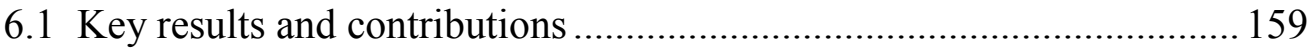

6.2 Limitations of the thesis and indications for further research ............... 167

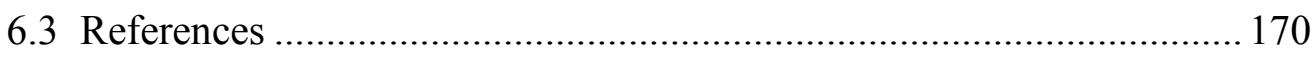

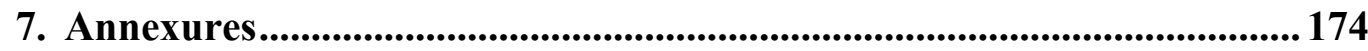




\section{List of Figures}

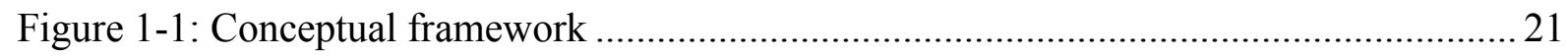

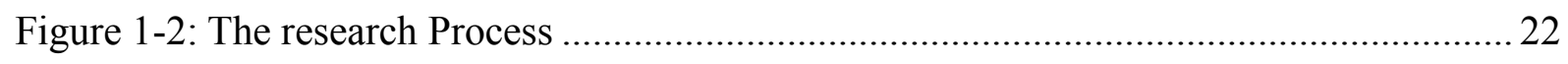

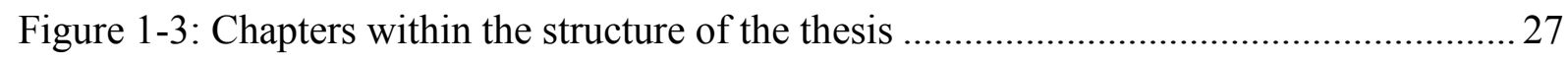

Figure 2-1: Key drivers and thrust areas on PUA across the world ...................................... 43

Figure 3-1: Map indicating mandals selected for study in GHA ........................................ 81

Figure 3-2: Farmers' perception on continuity and profitability of PUA ............................... 90

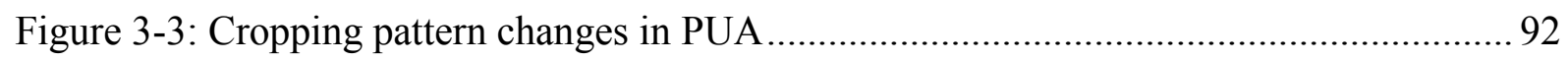

Figure 4-1: Analytical background for understanding farmers'

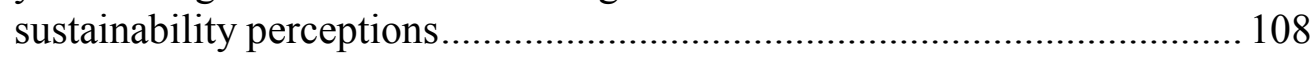

Figure 4-2: Performance sensitivity of different dimensions of sustainability ..................... 119

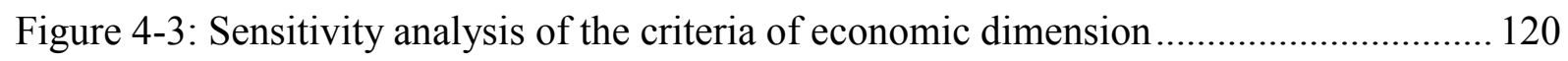

Figure 4-4: Sensitivity analysis of the criteria of environmental dimension ......................... 122

Figure 4-5: Farmers' ranking related to different criteria of social dimension....................... 123

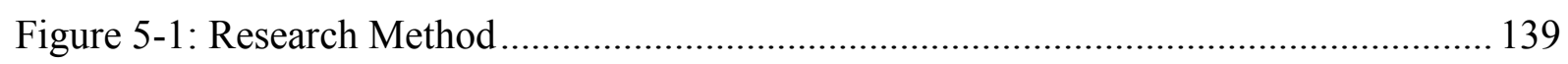

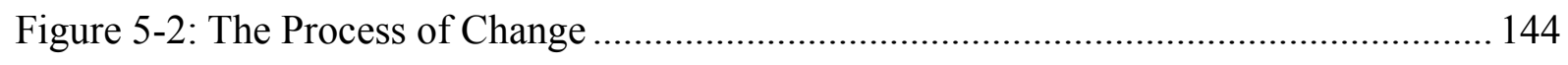

Figure 5-3: Factor loading graph of participation factors ............................................... 148

Figure 5-4: Factor loading graph on trust and community enforcement............................. 150 


\section{List of tables}

Table 2-1: Studies related to peri-urban areas on various themes in India.............................. 45

Table 2-2: Studies related to peri-urban areas on various themes in India-2 …..................... 46

Table 2-3: Various paths of peri-urban agricultural development .......................................... 51

Table 3-1: Characteristics of selected administrative areas in GHA ..................................... 82

Table 3-2: Agricultural land value (USD/Ha) in selected administrative units....................... 85

Table 3-3: Tenancy rates/ha in different administrative units of GHA .................................. 86

Table 3-4: Economics of production for peri-urban vegetables ............................................ 88

Table 3-5: Average costs for inputs in Paddy production and revenues

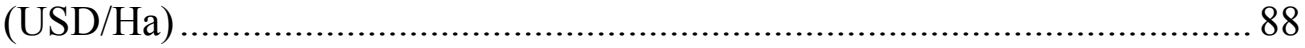

Table 3-6: Pesticide use in GHA (Number of sprays/Ha) ..................................................... 93

Table 3-7: Fertilizer use in GHA peri-urban farming (Number of Bags/Ha; 1 bag=50Kg)..... 94

Table 4-1: Classification of farming based on intensive input use ..................................... 113

Table 4-2: Production area under different farming systems in GHA ................................. 114

Table 4-3: Different criteria selected from the literature for pair-wise c omparison in economic and environmental dimensions........................... 115

Table 4-4: Different criteria selected under social dimension from the literature for pair-wise comparison ........................................................ 116

Table 4-4: Summary of farmers' preferences related to three dimensions of sustainability .. 118

Table 4-6: Farmers' ranking on different environmental criteria ......................................... 121

Table 4-7: Farmers ranking on different social criteria ....................................................... 123

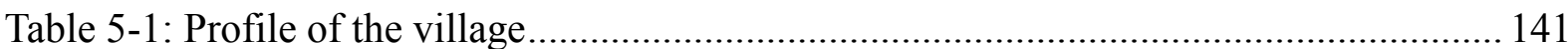

Table 5-2: Historical Matrix of change in the village .......................................................... 145

Table 5-3: Villagers attribution of importance to various organizations about trust and

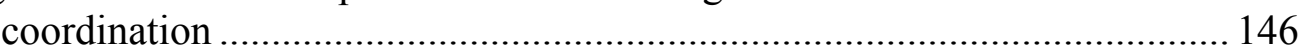

Table 5-4: Factor results on participation and collective action....................................... 147

Table 5-5: Factor results of Trust and community interactions.......................................... 149

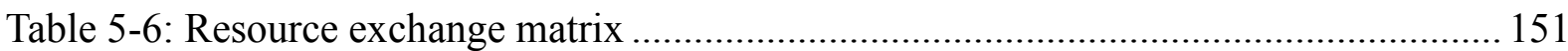

Table 6-1: Summary of various studies related to peri-urban agriculture ............................. 174 


\section{List of Abbreviations}

APA

AFN

AHP

AP

ANGRAU

CAP

CSA

CGWD

CHPC

DEFRA

FAO

FDI

FAOSTAT

FYM

GHA

GOI

HMDA

HUDA

Ha

IDEA

ICRISAT

IAC

JNNURM

Km

LNA

MNREGA

MCDA

$\mathbf{M}^{3}$

Mt

NIN

NAU
American Planning Association

Alternative Food Networks

Analytical Hierarchy Process

Andhra Pradesh

Acharaya N G Ranga Agricultural University

Common Agricultural Policy

Community Supported Agriculture

Central Groundwater Board

City of Hyderabad Population Census

Department of Environment, Food and Rural Affairs

Food and Agriculture Organization

Foreign Direct Investment

FAO Statistics

Farm Yard Manure

Greater Hyderabad Area

Government of India

Hyderabad Metropolitan Development Authority

Hyderabad Urban Development Authority

Hectares

Indicateurs de durabilite des exploitations agricoles

International Crop Research Institute for Semi-Arid Tropics

Integrated Agent Centered Framework

Jawahar Lal Nehru National Urban Renewable Mission

Kilo Meters

Land Put to Non-Agricultural Use

Mahatma Gandhi National Rural Employment Guarantee Act

Multi-Criteria Decision Analysis

Cubic Meters

Metric Tons

National Institute of Nutrition

Non-Agricultural Use 
NGO

PUA

QMP

RISE

RHC

SSA

SEZ

SCAR

UNFAO

UNHABITAT

UPA

USD

USA

WFP
Non-Governmental Organization

Peri-urban Agriculture

Quality Management Program

Response Inducing Sustainability Evaluation

Red Hairy Caterpillars

Sub Saharan Africa

Special Economic Zones

Standing Committee of Agricultural Research

United Nations Food and Agricultural Organization

United Nations Humans Settlements Program

Urban and Peri-urban Agriculture

US Dollars

United States of America

World Food Program 


\section{Research Agenda}

“(...) urban poverty tends to be fuelled by people migrating towards the cities in an attempt to escape the deprivations associated with rural livelihoods. Partly due to the rural decline, the world is urbanizing at a fast pace and it will not be long before a greater part of developing country populations is living in large cities. Therefore, urban food security and its related problems should also be placed high on the agenda on the years to come" (Jacques Diouf, FAO 2011).

\subsection{Research problem}

Cities represent a dynamic human constructs that constantly undergo structural changes and, redevelopment. The speed of structural change in cities often causes disparities in the urban periphery. These peri-urban areas are unambiguously described in literature with various synonymous descriptions especially as "peri-urban zones/PUI (peri-urban interface), 'transitional zones', 'rural-urban fringes', 'urban fringes', 'suburbs' etc.,(Forsyth 2012, FAO 2007). The process of urbanization and structural change has relatively drawn much attention from researchers, development agencies and policy makers (Zasada 2011). Farming in the peri-urban areas have has to confront increasing competition on the land market caused by non-agricultural land uses such as housing, industrial purposes with high bid rent (Robinson 2004; Seto et al.2011). These issues have raised various concerns about the sustainability of peri-urban agriculture and connected debates to reconcile whether peri-urban agriculture has a chance to survive (van der Falk et al. 2009). In Asia and the developing world technological innovation was long described as the main driver of structural changes in agriculture, this is especially true in scenarios where rapid urbanization threatens agricultural production (Hayami and Ruttan 1971).In addition to this another important factor that has its fair influence on farming in peri-urban areas is both "structural" and "technological lock-in effects that have to do with path dependency, cultural influences on farm practices and the often long term investments related to agriculture (Wilson 2012). Growing public concerns with sustainability motivate the exploration as to how the process of rapid urbanization does impact agricultural adaptation and in how far growing sustainability concerns are justified. Literature on peri-urban farming reports changes in area, intensity and value of agricultural 
production in the vicinity of large metropolitan areas (Lawrence 1988; Coughlin 1979; Furuseth and Pierce 1982).

In addition the peri-urban conditions could contribute both positive and negative effects on farming in these areas. For example, Tzoulas et al. (2007) find that urban peripheries may also positively contribute to the urban environment by providing "green lungs" to absorb emissions and help urban residents recuperate from physical and psychological stress. In a similar vein, Sharp and Smith (2003) describe a situation in which the development of new types of neighbourly relations and social capital, for instance when land-owning agriculturists develop relations with their non-farm neighbours, may serve as mitigation strategies for otherwise marginalized peri-urban farmers.

Currently there is growing trend of counter narratives emphasizing the difficult relationship between urbanization and agricultural change in the peri-urban areas. The dramatic transformations in land use change nearby urban metropolitan areas also influence the values and preferences of the urban society as well as those of peri-urban farmers. A better understanding of theconstruction and change of values and perceptions of farmers in relation to the main sustainability dimension could fruitfully inform the management of these spaces. The literature indicates that the meaning of sustainability in general varies in different spatial scales in general and from person to person in particular (Mudroch et al. 2003). The peri-urban agriculture albeit has its high potentiality to generate public goods that in turn has the image of a problem rather than a solution for policy makers and urban planners. (Kirschemann 2000).A clear understanding of the determinants of this image is a prerequisite for well-tailored policies towards more sustainable peri urban production systems.

\subsection{Conceptual and theoretical framework of the research}

\subsubsection{Farm adaptations in peri-urban area}

In the literature Bryant and Johnston (1992) indicates two imperative farm adaptation scenarios in the urban peripheries where the 'off-farm diversification', of which generally involves increased reliance of farmers on non-farm employment in the urban peripheries, and "on-farm diversification", characterized by "changes in production practices or management 
approaches. In similar vein, Smither and Jhonson (2004) describes four possible farm level trajectories - especially "growth and decline", "intensification", "persistence" and "deintensification" as a consequence of changing pattern of land, labor, capital use. "Growth and decline" describes a scenario in which aggregate increase or decrease in scale of production occurs, without a fundamental restructuring of the relationship between the main agricultural inputs and the intensity of production process. 'Intensification' defines a scenario in which the main agricultural inputs, such as labour and capital are increased. 'Persistence' refers to a status quo -preserving condition. Finally, 'de-intensification' characterizes a situation in which agriculture is no longer competitive with other sector uses, and farmers react by reducing their main agricultural inputs, eventually leading to farm closures.

Jhonston and Bryant (1987) proposed three divergent types of farm changes in the urban-rural interface considering the internal and external farm conditions. These changes include "positive adaptations that enhance farm production" (e.g. urban oriented direct marketing, or intensifying traditional production), another farm change include "normal or managerial adjustments" (farm changes consistent with changes occurring across the agricultural sector including the adoption of new agricultural technologies to increase efficiency) and finally " negative adaptations" (such as reducing production intensity or farm investments, perhaps in anticipation of a future sale to developers). The adaption models developed by Johnston and Bryant (1986) and Smithers and Jhonson (2004) observes the farm adaptation strategies that emerge from complex interplay between farm household and farm business in rural-urban interface. In addition Smithers and Jhonson (2004) distinguishes the role of 'farmer agency' in managing change and impart credence to the farm family acting and contributing to farm decision making.

In addition, Pierce (1994) indicated a diverse range of "survival" strategies of farmers" response to structural change and uncertainty in the urban fringes. One prominent path in his opinion could represent a typical accumulation strategy pursued by "highly capital intensive enterprises". He further indicates another adaptive strategy involving some form of "diversification" with some changes in production strategies including few petrochemical inputs and processing inputs. There are numerous examples of these kinds of development indicating development and marketing of specialized crops and direct sales of produce. Another common adaption represents "selling of the farms for conversion to urban use or 
amenity". This has something to do with opportunity cost and location of the farmland. Furthermore an alternative adaptation is "redeployment of farm resources -hobby farms, golf courses, amenity agriculture". Another option could be "conservational reserves" particularly to preserve biological resources in the urban fringes. Other strategy represents "a dramatic shift in culture of production from agro-industrial mode towards sustainable and organic mode of production".

\subsubsection{Sustainability and farmers perceptions}

Sustainability is constructed in discourses among social actors (Berger and Luckmann 1966³ : Kosterman and Cramer 2007). Subsequently, Bennett (1968) emphasizes that social structure is articulated in farming practice where the economic behavior of farmers is not only restricted to market, but also to the exchange of goods and services among themselves that enhances the social connections. The urbanization triggers certain trade-offs among the farmers' when making day to day decisions. The adoption of particular farming system in these areas is seen as the expressions of farmers 'participation in the social discourses about agricultural production. These discourses eventually verbalize into different perceptions through possible actions that could enable them to strategically adopt a particular farming system in the peri-urban area.

\subsubsection{Social innovations and community participation}

Peri-urban agriculture could significantly represent most widespread human environmental interactions in the rural- urban continuum. These areas highly manifest the construction of sustainability due to uncertainty in farming and resource degradation. These debates about values and the governing ethics should proceed into certain actions. The societal innovations fairly indicates the ethical behavior that negotiates the reasons in relation to peoples view of doing right or wrong, good or bad, fair and unfair (Rollin 1999). The

\footnotetext{
${ }^{3}$ Berger and Luck man (1966, pp. 1ff) understand that "reality" as beliefs that we have about this world and that is our conception of reality and not reality itself. They developed a second thesis in chapters 2 and 3 and stated that 'Social institutions and persons are created in social interaction'. They combine these two and finally said "The belief about reality, which is constructed in social interaction play an important role in the (re)construction of institutions and persons.
} 
enduring crisis in the peri-urban farming prompt the need for novel approaches to address these challenges. They should allow the society to innovate, participate and do things according to their choice. Agriculture requires an ethic that discriminates the human obligation (a moral claim) in manner that acknowledges the human-ecological and social relations that makes farming a sustainable (Krischermann 2004). In other words creating sustainability cannot just an agriculturist responsibility but it is social responsibility. The commonly found normative link between social innovation and socially esteemed values ignores the fact that different purposes and interest can indeed be pursued by social innovations.

There is growing concerns related to understanding the role of societal innovations in enhancing the societal capabilities in order to achieve sustainability. Various authors often consider sustainability as a process of searching and learning. Sustainability always opens a window for exploring a novel approaches in dealing things either at farm level or at community level facilitating bottom up approaches in rural development. The argument put forth in this dissertation is that - the growing crisis in agriculture could prompt communities to collectively seek more sustainable development and recoup certain social innovations4in the process of achieving sustainability. This implies that "the need to change in the society or communities due to demographic imbalance and structural adjustments could relatively setoff certain social innovations. These kinds of innovations enhance better participation of the communities in order to effectively tackle the crisis in farming. Comparably, literature indicates that when "Social innovations" are combined with concepts of social empowerment, inclusion, social capital and cohesion could fairly enhance the people's participation towards more sustainable development. Thus theoretically social innovations are based on collective action which forms the central core element for any social innovation to happen. They are unique outcome of a collaborative action among the network of actors associated with similar interests and are highly related to the existence of social capital available (Neumier 2011).

\footnotetext{
${ }^{4}$ For details on concept of social innovations see Chapter 4
} 


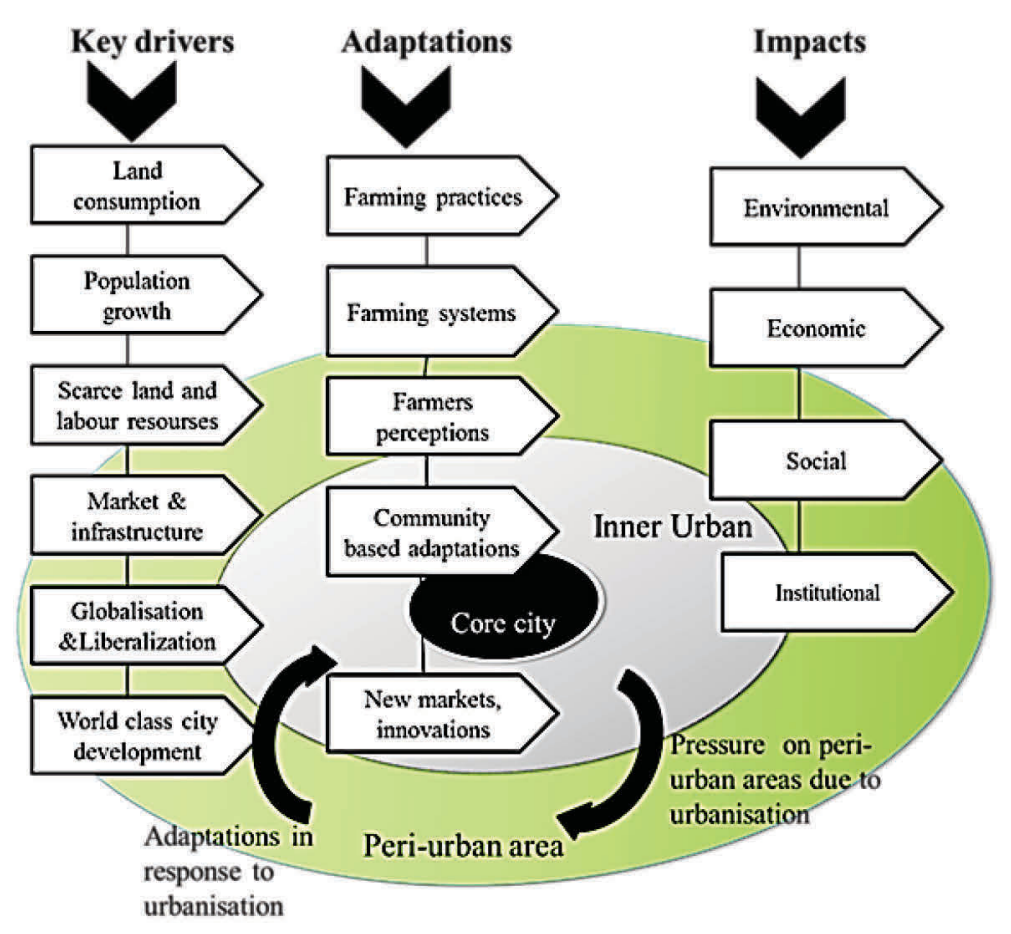

Figure 1-1: Conceptual framework

Source: Author's own compilation

Implying the above theoretical and conceptual interpretations, I explore the pattern of development paths and adaptations in the context of GHA fuelled by the drivers of megacity development. Various authors in the literature indicate that the farmers' responses to uncertainty are diverse and arbitrary within the dominant forces of structural change (Pierce 2010). The study seeks to explore how the key drivers of megacity development trigger different adaptations among the farmers in the urban periphery. The main structural change drivers recognized across the world from various studies includes, changes in land consumption accompanied by changes in land rent, population growth, pressure on land and labour resources, access to market. In the diagram he key drivers of change are indicated on the left hand side, subsequently the middle stream represents the alternative adaptations in response to the urbanization which depicts the major research focus of this dissertation especially the changes in farming practices, farmers' perceptions and adoption of farming systems, community based adaptations. On the right hand side, the corresponding 
environmental impacts, including the impacts on social, economic and institutional are indicated related to peri-urban areas

\subsection{Research design}

As indicated in Figure 1-2, I carry on with my research especially through analyzing various dynamics of peri-urban agricultural development and the corresponding farmers' adaptations in the peri-urban Hyderabad. To

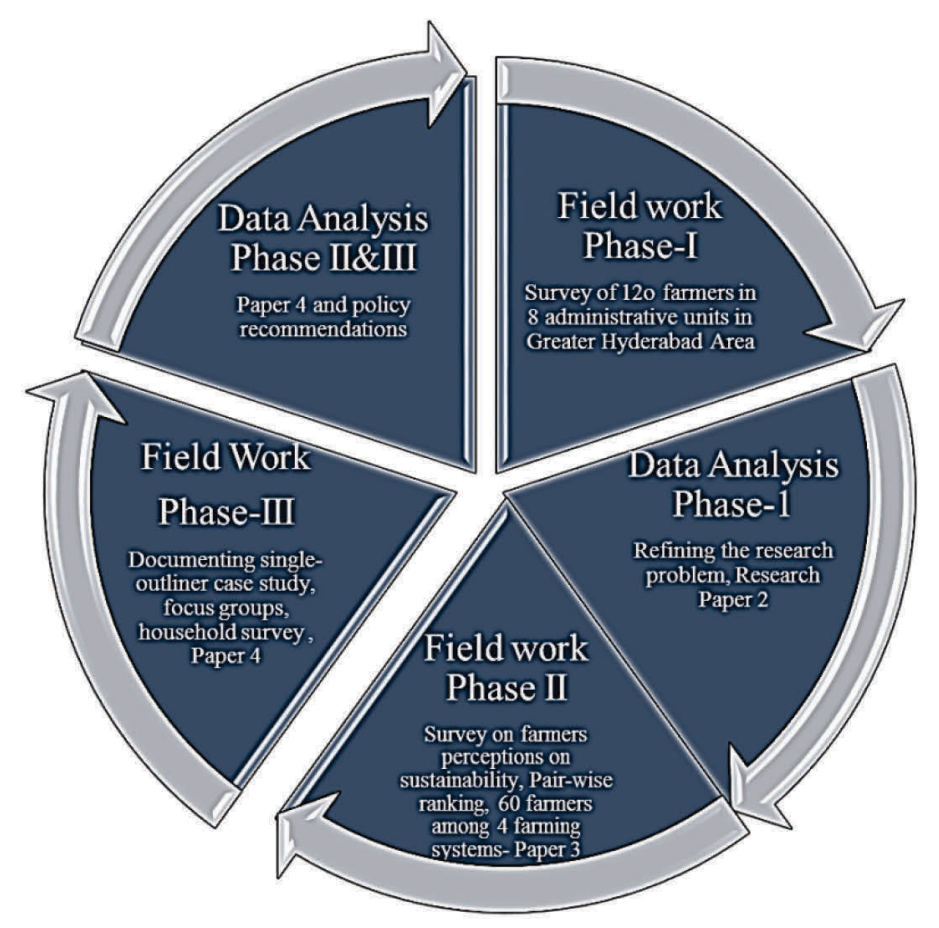

Figure 1-2: The research Process

accomplish this task, selected a total number of 120 farmers $^{5}$ from 8 administrative units (Mandals), in GHA consisted of 15 farmers from each administrative unit during 2011.The data was collected through semi-structure interviews where the qualitative data targeted towards measurable components of these changes such as the cost of production and

\footnotetext{
${ }^{5}$ More details on research method and sampling procedure is available in paper 2
} 
use of major agricultural inputs. Similarly the qualitative data targeted the farmers' main perceptions on drivers of change.

The Phase II in the research process has explicitly focused on analyzing the farmers' perceptions on sustainability dimensions in the GHA. Considering the official data on cropping patterns from the department of agriculture and Horticulture, I broadly categorized the farming systems in GHA into four essential types. They are Conventional farmers, Better management, High resource use Paddy farmers and Organic group of farmers. Amidst these I selected 15 farmers from each group and the farmers' preferences are recorded on pair-wise ranking exercise especially designed for Analytical Hierarchy Process ${ }^{6}$.

The data analysis was carried out (Data analysis Phase I) and the empirical experience has provided me with an unblemished understanding of various dynamics of peri-urban agricultural development and the corresponding farmers' adaptations to the process of structural change. Field work of Phase III documents an eccentric case of a village where all the farmers in the village have spurned using chemicals in their farming. In this phase, I have organized focus group discussion, key informant interviews to gather the data on the process of change towards this kind of transformation. Furthermore I interviewed all the household heads to obtain the individual data especially related to various forms of participation and collective action along with trust variables.

The data obtained from the field work phase II and III was analyzed in the subsequent data analysis phase and considering the outcomes of these above phases, I wrote two papers especially Chapter 3 that describes the farmers' discernment about sustainability dimension in the peri-urban Hyderabad.

Similarly the Chapter 4 narrates the case about the process of social innovation, where farmers under distress espouse novel ways of doing farming. Further I recommended policies in support of peri-urban agricultural development and sustainability in the context of megacity of Hyderabad emphasizing the need for a more integrated development approach. The dissertation finally concludes based on the findings from the different papers.

\footnotetext{
${ }^{6}$ The detail information on the method is available in Chapter 3
} 


\subsection{Empirical strategy}

The purpose of this research is to characterize the main drivers of change, observable adaptation scenarios and corresponding impact of urbanisation on agriculture in the GHA. This study delineates the primary drivers of change, actual rate and scale of urbanisation, effective demographic changes and population pressures coupled with land prices and land rents. In addition it explores the farmers' perceptions on profitability of important crops over time. Then, it throws some light on the main adaptation scenarios, taking into account of the farmers' perceptions and their willingness with respect to get on with or abandons the agriculture in GHA. Finally various kinds of adaptations in the production system in GHA due to megacity development are described and conclusions are drawn in order to better integrating peri-urban agriculture in urban planning.

To empirically substantiate the dynamics of change in the peri-urban framing in GHA, I decided to apply both qualitative and quantitative methods. To collect the data I interviewed 120 farmers in GHA, where the qualitative variables includes the perceptions of farmers on crop changes, continuity and viability of agriculture in the urban fringes, perception on labour crisis. The quantitative data is substantiated with descriptive statistics where I collected data on changes in cost of production, land rent and input use. Subsequently the data has beencross checked with key informants in the villages, extension officials, input agencies and experts and official statistical data.

Similarly in order to study farmers perceptions related to sustainability dimension in GHA (Chapter 3), I decided to use a research method namely Analytical Hierarchy Process (AHP), which is a tool in Multi-criteria Decision Making (MCDA). This method is appropriate to analyze the decision-making problems involving multiple goals in relation to three dimensions of sustainability (Sadok et al. 2008; Mwana et al. 1996). AHP is used to support decision making process which involves different dimensions while conflicting economic, environmental and social objectives are pursued. Different researchers have demonstrated the appropriateness of Multi-criteria Decision Analysis with AHP (Mwana et al. 1996; Tiwari et al. 1999; Strassert and Tony 2002; Munda et al. 1994) in various sustainability assessment studies. I collected farmers' responses from each group based on pair-wise comparisons and the data is aggregated to calculate the "geometric mean" of each 
group of 15 farmers. Further, the data is dispensed into a matrix in the software called "Expert choice ${ }^{\circledR} "$ to simplify the methodological algorithm. The software evaluates the consistency of the survey data from the input matrices. Further it generates the weights based on the ranking given by farmers, engine value, and engine vector as well along with the inconsistency ratio. Thus, it is the inconsistency ratio that determines the accuracy of the data from the software. If the inconsistency ratio is more than $0.1(10 \%)$ that indicates the farmers have not appropriately made the judgment and we should repeat the whole process of data collection.

To document the case study (Chapter 4) I relied on mixed method of analysis for where the qualitative methods basically seek to understand the process of transformation, historical evolution and the implicit desire to change towards alternative methods of farming practice in this village. For this purpose I carried out in-depth interviews with different stakeholders involved in the process of transformation. Concomitantly, I organized focus group discussions in the village to understand the perceptions, views and experiences among the community. Similarly to facilitate focus group discussions, I employ the "Historical matrices" adopted from Thompson and Freudenberger (1997) to interrupt the changes in the

community during the social innovation process. In addition I draw upon the"Resource Exchange Matrix" from Kuehnast and Dudwick (2004), to get feed- back on every day interactions in the real life conditions through exchange of goods and services during the focus group discussions in relation to the level of social capital. The quantitative data is better substantiated with an individual survey with all 50 household heads with semi-structured interviews. To explore the most influencing variables among all chosen variables for the process of change, I have adopted "Factor analysis" with strata. Furthermore to support my findings I have analyzed information through local newspaper articles and reports prepared by the facilitating organizations.

\subsection{Structure of the thesis}

The entire dissertation is structured into five chapters. All the five chapters of the thesis contribute to the overall research goal and explore the answers to the guiding research questions outlined within the context of peri-urban agricultural development in megacity of 
Hyderabad. The first paper (chapter 1) provides an understanding on the current developments, conceptual and theoretical understanding and the pace of development approaches concerned to peri-urban agriculture around the world. The second chapter (chapter 2) analyzes typical pathways and the various dynamics of peri-urban agricultural development in the context of Hyderabad megacity growth and farmers' adaptations in the urban fringe of Hyderabad highlighting the corresponding environmental impacts. (This paper is published in Journal of Environmental Planning and Management).The subsequent paper (chapter 3) disentangles, the farmers' perceptions concerned to the sustainability dimensions in the peri-urban areas. The chapter is motivated to analyze the influence of social discourses on sustainability and the ways in which the meaning of sustainability is constructed among the farmers in the urban fringes where the sustainability in general seems to be a contested issue due to structural change and urbanization forces.

Furthermore, the manifestations of peri-urban areas for sustainability in farming due to loss of land ethics and fading community sense prompted us to explore the community based adaptations in agriculture that provide a strong sense for fabricating these issues in policy frameworks. I found such a case in the suburb of Hyderabad. I explore the cause and effect in the transformation process of that change to make it a case in point for better policy formulation. The chapter 4 (Paper 4) unveils the social innovation process behind the blanket adoption of sustainable agriculture in the nearby village of Hyderabad using mixed methods of research. In the end, policy recommendations are drawn in order to better integrate farming in the peri-urban areas in the current Indian agricultural policies. I explore various agricultural policies and their implicit linkage to farming in peri-urban area and finally draw a conclusion that provides insights for sustainable peri-urban agricultural development. 


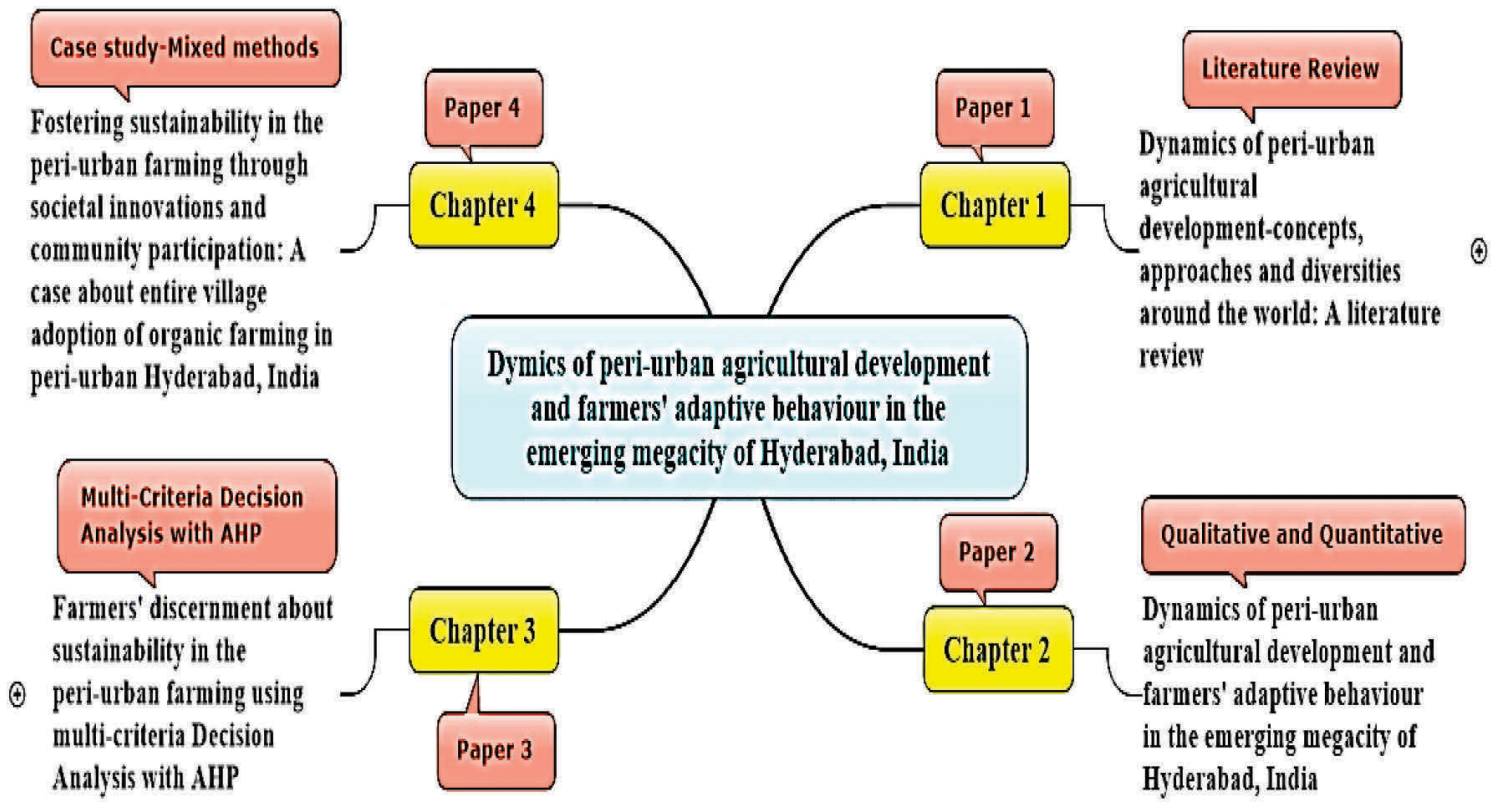

Figure 1-3: Chapters within the structure of the thesis

In the following I outline the sub-research questions along with various approaches adopted and the contribution of each of the four papers at the end of each session. The main results of these papers and the implications of these results towards a feasible strategy for sustainable peri-urban agricultural development and policy making with limitations and further research are discussed in the conclusion chapter.

\subsubsection{Chapter 1: Dynamics of peri-urban agricultural development-concepts, approaches and diversities around the world: A Literature Review}

As indicated in the previous chapter, the first chapter of my thesis provides an overview of various concepts, approaches amenably related to peri-urban agricultural development across the world. The review has considerably focused on the different patterns of development especially comparing Europe, North America, USA, South Africa and South East Asia. The literature review explicitly draws attention to a range of literature strands related to peri-urban agricultural development around various parts of the world. It aims to explore the key questions related to various trajectories of development paths with respect to peri-urban agriculture in various parts of the world. Along with that the review attempts to 
explore various theories and concepts proposed in literature related to urbanization, periurban agriculture development in particular and agricultural development in general. Moreover the review has extensively focused on various studies concerned to the aims and objectives of this dissertation.

\subsubsection{Chapter 2: Dynamics of peri-urban agricultural development and farmers' adaptive behavior in the emerging megacity of Hyderabad, India (Published in Journal of Environmental Planning and Management)}

This chapter describes the adaptation of agricultural management practices due to structural change in the urban periphery of Hyderabad, India. The research investigates structural change drivers along with most common types of adaptations realized by periurban farmers and the corresponding environmental impacts. In this paper, Professor Markus Hanisch and I contributed to answer the following sub- research questions.

1) How does the growth of the cities affect structural changes of agricultural production in terms of choosing crops, scale of production or technologies in use?

2) What are the causes and effects of the most common types of adaptation behavior of farmers in the GHA?

3) Can we draw a link between agricultural development and sustainability in this context?

We hypothesize that "around the city of Hyderabad, structural change is not on a sustainable trajectory, because existing small-scale farm structures together with current land price developments have not been following the conventional scenario in which farms grow in size.

The chapter concludes that increasing cost of agricultural inputs ${ }^{7}$ such as labour and land has motivated farmers to intensify water, machine and chemical use, thereby creating problematic environmental impacts. In addition farmers also resort to part-time farming and organize efforts to share family labour. The problematic connection between the deterioration

\footnotetext{
${ }^{7}$ For more details see Chapter 2
} 
of the economics of the agricultural production in the GHA and the increase of agricultural externalities has thus, far, not resulted in a well suited strategy for coordinating and accompanying structural change in Hyderabad peri-urban area.

\subsubsection{Chapter 3: Farmers' discernment about sustainability in the peri-urban farming using Multi-Criteria Decision Analysis with AHP}

This chapter presents a comprehensive interpretation of farmers' perceptions related to different dimensions of sustainability in Greater Hyderabad Area (GHA). Drawing reflections from the social construction theory we further investigate to understand the verbalized discourses in connection with farming as well as farmers that translates into perceptions on sustainability dimension. In this paper I address the sub-research questions

- How do the farmers in the urban agglomerations themselves know and think about relative sustainability of what they do in agriculture?

- How do the farmers themselves differentiate production systems with respect to different dimensions of sustainability?

- What are the key motivational factors motivating/impeding sustainable reorganization of peri-urban agriculture?

Based on the above research question we hypothesize that "Farmers adopting different production systems have different perceptions about sustainability in general" and "they give different weights to different attributes of sustainability" in particular". To answer this question we used Analytical Hierarchy Process a tool in Multi-Criteria Decision Analysis (MCDA). We have drawn various criteria from the literature particularly used in sustainability assessments covering broad economic, environmental and social dimensions. We asked the farmers to rank their preferences on one to nine scale based on pair-wise comparisons.

The data is fed into the "expert choice" software and the sensitivity results are presented in the paper. The results ${ }^{8}$ clearly demonstrate that sustainability dimensions in this

\footnotetext{
${ }^{8}$ For more details see paper 3
} 
context are contradictory instead of complementing each other. The closer observation reveal the existence of a considerable trade-offs between three dimensions of sustainability. This analysis provides us a practical insight on the value assigned by different farmers adopting various production systems about the sustainability dimension. This is highly useful for the policy makers and urban planner to construct the sustainability in the peri-urban farming.

\subsubsection{Chapter 4: Fostering Sustainability in peri-urban farming through societal innovations and community participation: A case about the entire village adoption of organic farming in peri-urban Hyderabad, India}

This paper accentuates the feasible competence of farmers near the cities towards sustainable development through extensive participation and collective action by recasting their social ties with other actors in the society. This case is an evident example for societal innovations where the communities prompted to innovate novel ways of farming through effective participation. The demographic imbalances coupled with farming distress have relatively provoked the need for change in order move forward for certain societal innovation in farming. This paper explores an eccentric case where the farmers in the entire village turned out for blanket adoption of organic farming through single case study approach using in-depth interviews, household survey and focus group discussions in the urban fringe of Hyderabad. In this paper I attempt to answer the broad research questions with the help of a case study, the research questions include

- How far the demographic disturbances and structural change drivers do motivate farmers towards grass root collective action trough enhanced participation?

- How the farmers' participation and collective action do relates to social innovations and enhancement of social capital through adoption of sustainable strategies in farming?

- What are the components of social capital that could relatively influence the emergence of social innovations?

- What are key motivational incentives/other factors motivating/impeding the sustainable reorganization of peri-urban agriculture?

To answer this research questions I have selected an eccentric, outliner case in the suburb of Hyderabad where the entire farmers in the village gave up using chemicals. I have 
organized focus group discussions, key informants interviews and individual household interviews. The cause and effects for this kind of transformation has been explored at group level and individual level. To explore the core element highly responsible for the change in the village, among all the participation and social capital variables, I relied on "principal factor analysis through strata 10.2 ".

In the end I attempt to pursue how to integrate peri-urban agriculture in the existing agricultural policies in India. Similarly how to position agriculture in the urban fringe in various government schemes commissioned at national and state level. The policy recommendation discusses the core problems with respect to peri-urban farming in GHA and how to build a possible nexus with the existing policy frame works. It also throws some light on the various alternatives in relation to technology as well as community based approaches to address the current issues within the background of sustainable peri-urban agricultural development. Furthermore this policy paper explored various implementation gaps in promoting peri-urban agriculture and suggests few alternatives drawing few successful examples implemented by the government as well as NGOs. This policy paper is compiled based on various reports, policy documents related to agriculture policies in India and also various studies explicitly done on political economy of different policies in India and Andhra Pradesh. Finally a stakeholder map has suggested to successfully implementing the sustainable peri-urban agricultural development. This approach emphasizes a need for high priority in coordinating between different stakeholders, organizations and policies. This coordination role should be facilitated by urban development in order to achieve or think about sustainability in farming in the urban fringe areas.

\subsection{References}

Aleamoni, L. M. (1976) "The relation of sample size to the number of variables in using factor analysis techniques". Educational and Psychological Measurement, 36:879883.

Annapurna, Shaw. (2005) "Peri-urban Interface of Indian Cities: Growth, Governance and Local Initiatives”. Economic and Political Weekly, January 8th, 2005, 129-136.

Ann Forsyth. (2012) “Defining Suburbs”. Journal of Planning Literature, 27 (3): 270-281. 
Barrett, P.T and Kline, P. (1981) "The observation to variable ratio in factor analysis". Personality Study and Group Behaviour, (1): 22-33.

Bennet, J.W. (1968) "Reciprocal economic exchanges among North American agricultural operators" .Southwestern Journal of Anthropology, 24: 276-309.

Berger, P.L and T. Luckmann.(1967) „The social construction of reality: A treatise in the sociology of knowledge". London: Penguin.

Bryant, Christopher R. (1986) "Farmland conservation and farming landscapes in urbancentred regions: the case of the Ile-de-France region". Landscape and Urban Planning, 13: 251-276.

Bryant, C.R.; Chahine, G and Delusca; K. Daouda. (2010) "Adapting to Environmental and Urbanisation Stressors: Farmer and Local Actor Innovation in Urban and Peri-urban Areas in Canada" .ISDA. Montpeller, France (Innovations and Sustainable Development).http://hal.archivesouvertes.fr/docs/00/52/19/83/PDF/Bryant_Adapting _ to_environment.pdf

Bryant, C.R and Johnston, T.R.R. (1992)"Agriculture in the city's countryside" .University of Toronto Press.

City of Hyderabad Population Census (CHPC). (2011) "Hyderabad (Greater Hyderabad) City Census 2011 data. Available at http://www.census2011.co.in/census/city/392hyderabad.html (Access date: 25th September, 2011)

Coughlin, Robert E. (1979) "Agricultural land conversion on the urban fringe". Farmland, Food and the Future, In. Max Schnepf, 29-47. Ankeny, IA (Eds.). Soil Conversion Society of America.

Directorate of Economics and Statistics. (2010). Hand Book Ranga Reddy District, 2010, Hyderabad, Andhra Pradesh.India

Dupont, V. (2011) “The Dream of Delhi as a Global City". International Journal of Urban and Regional Research, 35(3): 533-54.

Furuseth, Owen. J and John, T. Pierce. (1982) "Agricultural Land in an Urban Society". Washington, DC: Association of American Geographers.

FAO. (2007) "Profitability and Sustainability of Urban and Peri-urban Agriculture". Occasional Paper 19: Agricultural Management, Marketing and Finance Division, UNFAO, Rome, Italy.

Goldman, M. (2011) "Speculative Urbanism and the Making of the Next World City" .International Journal of Urban and Regional Research, 35(3): 555-81. 
FAO. (2011) "The Place of Urban and Peri-urban Agriculture (UPA) In: National Food Security Programmes. Integrated Food Security Support Services (TCSF)". Policy and Program Development Support Division, UNFAO, Rome, Italy.

Folke, C; Carpenter, S; Walker, B; Scheffer, M; Elmqvist, T; Gunderson, L and Holling, C.S. (2004)"Regime Shifts, Resilience, and Biodiversity in Ecosystem Management". Annuual Review of Ecology, Evolution and Syststematic, 35 (1): 557-581.

Hyami, Y and V.W. Ruttan. (1985) "Agricultural Development: An International Perspective" Baltimore: John Hopkins Press.

Hayati,D; Ranjbar, Z and Karami, E. (2010) "Measuring Agricultural Sustainability.Biodiversity, Biofuels, agroforestry and Conservation Agriculture". Sustainable Agriculture Reviews, 5:73-100.

Johnston, T. R. R and C. R. Bryant. (1987) "Agricultural Adaptation: The Prospects for Sustaining Agriculture Near Cities”. In: W.Lockeretz., (Eds.) Sustaining Agriculture Near Cities, Iowa, Soil and Water Conservation Society.

Kennedy, L. (2007) "Regional industrial policies driving peri-urban dynamics in Hyderabad" India. Cities, 24 (2), 95-109.

Kennedy, Christopher; Lawrence, Baker; Shobhakar, Dhakal and Anu Ramaswami. (2012) "Sustainable Urban Systems: An Integrated Approach". Journal of Industrial Ecology, $16(6): 775-79$.

Klostermann, J. E. M and Cramer, J. (2007) "Social construction of sustainability in water companies in the Dutch coastal zone". Journal of Cleaner Production, 15 (16):15731584.

Krischenmann, F. (2004)'Ecological Morality: A new ethic for agriculture". In: D. Rckerl \& C. Fransis (Eds.). Agro- ecosystem analysis (pp 167-176), No 43. In the series, Agronomy, American Soc, Agronomy, Crop. Sci.soc series America and Soil Sci. Soc of America, Maidson WI.

Kuehnast, K and Dudwick N. (2004) "Be Better a hundred friends than a hundred rubles? Social networks in transition". World Bank.The Kyrgyz Republic, Environmentally and Socially Sustainable Development (ESSD) Division. Wahinghton, D.C.

Lawerence, H.W. (1988) "Changes in Agricultural Production in Metropolitan Areas". Professional Geography, 40(2): 159-175.

Muwana, N; Mawapanga and David, L. D. (1996) "Choosing between Alternative Farming Systems: An Application of the Analytic Hierarchy Process" .Review of Agricultural Economics, 18(3): 385-401.

Mudroch, J.P; Lowe, N; Ward, T and Marsden. (2003) "The Differentiated Countryside". New York, Routledge. 
Munda, G; Nijkamp, P and Rietveld, P. (1994) "Qualitative multi-criteria evaluation for environmental management”. Ecological Economics, 10 (2): 97-112.

Mundfrom, D.J and Shaw, D.G. (2013) "Minimum sample size recommendations for conducting factor analysis". International Journal of Testing, 5(2):159-168.

Neumeier, S. (2012) "Why do Social Innovations in Rural Development Matter and Should They be Considered More Seriously in Rural Development Research? - Proposal for a Stronger Focus on Social Innovations in Rural Development Research". Sociologia Ruralis, 52 (1): 48-69.

Pierce, John T. (1994) "Towards the Reconstruction of Agriculture: Paths of Change and Adjustment". The Professional Geographer, 46 (2): 178-190.

Robinson, G.M. (2004) "Geography of agriculture: globalization, restructuring and sustainability". Harlow, Pearson Education.

Rollin, Bernard. (1995) “Farm Animal Welfare Ames”. Iowa State University Press.

Sadok, W ; Angevin, F ; Bergez, J ; Bockstaller, C and Colomb, Bruno ; G. Laurence et al. (2008) "Ex-ante assessment of the sustainability of alternative cropping systems: implications for using multi-criteria decision-aid methods". A review. Agron. Sustain. Dev. 28 (1):163-174.

Seto, Karen C; Sánchez-Rodríguez; Roberto and Fragkias, Michail. (2010) "The New Geography of Contemporary Urbanization and the Environment". Annu. Rev. Environ. Resourc.35 (1): 167-194.

Sharp, J.S and Smith, M.B. (2003) "Social capital and farming at the rural-urban interface: the importance of non-farmer and farmer relations". Agricultural systems, 76 (3): 913-927.

Smither, J and Jhonson, P. (2004) "The dynamics of family farming in North Huron County, Ontarion.Part 1. Development Trajectories". The Canadian Geographer, 48(2): 191208.

Strassert, G and Tony, P. (2002) "Selecting farming systems using a new multiple criteria decision model: the balancing and ranking method". Ecological Economics, 40: 267277.

Tiwari, D.N; Loof, R and Paudyal, G.N. (1999) "Environmental-economic decision-making in lowland irrigated agriculture using multi-criteria analysis techniques". Agricultural Systems, 60 (2):99-112.

Thomson, J.T and K.S.Freudenberger. (1997) "Participatory Rural Appraisal Tools that may be useful in an institutional analysis: Crafting institutional arrangements for community forestry". Food and Agriculture Organization of the United Nations. Rome. Available online at http://www.fao.org/docrep/w7483e/w7483e0a.htm. 
Tzoulas, K; Korpela, K; Venn, S; Yli-Pelkonen, V; Kaźmierczak, A; Niemela, J and James, P. (2007) "Promoting ecosystem and human health in urban areas using green infrastructure: a literature review" .Landscape and urban planning, 81 (3):167-178.

van der Falk, A; van Dijk, T; Altes, W.K and van den Brink, A.(2009) "Planning open spaces: balancing markets, state and communities". In: van der Falk, A., van Dijk T., (Eds.). Regional Planning for Open Space. Routlegde, London, pp. 301-323.

Wilson, G.A. (2013)" Community resilience: path dependency, lock-in effects and transitional ruptures". Journal of Environmental Planning and Management, Jan 21:2013.

Zasada, Ingo. (2011) "Multifunctional peri-urban agriculture-A review of societal demands and the provision of goods and services by farming". Land Use Policy, 28 (4): 639648. 


\section{Dynamics of peri-urban agricultural development- A literature review}

This chapter is based on an extensive literature review of which broadly explores the ramifications of rapid urbanization on food production in the fringe areas. Further the review accentuates the recent development trends, various concepts, theories and approaches around the world aimed at analyzing peri-urban agricultural development. The review compiles notions of agricultural development in the urban fringes and connected theories and concepts pursued by various scholars around the world to measure and compare the sustainability of peri-urban farming. In addition the survey is meant to describe and compare typical changes that farmers adapt in response to the drivers of urbanization in various parts of the world.

\subsection{Introduction}

"The distribution of population and of sustenance activities cannot be understood without reference to the influence of the individual hinterland city, just as the influence of the individual hinterland city cannot be understood without reference to the influence of the nearest metropolis (Jonthan D. Mayer 1980)"

Perhaps the major urban transitions in Europe and South America have profoundly occurred from 1950 through the 1970s. In contrast, the bulk of urban growth of the decades to come is expected to happen in developing countries with significant implications on agricultural lands, forests and other natural resources (Siciliano 2012): According to the Food and Agriculture Organization (FAO), by 2020, the developing countries of Africa, Asia, and Latin America will host 75 percent of all urban dwellers. Urbanization is not only a socioeconomic phenomenon; but it is also a process of ecological transformation by humans (Huang et al. 2010). The high concentration of people in densely populated developing countries' urban areas, has seriously prompted the ongoing discourses and questions on how to manage agro-ecosystem in urban fringe (Azadi et al. 2011). 
Morgan (2009) in his article claims that the food system represents a core element of life that has traditionally been neglected in urban planning. The author describes this issue as a "Puzzling Omission "in the literature. Urban planners fairly justify this neglect by asserting that the food system is largely an issue of rural development and therefore beyond the scope of the urban planning agenda. However, the relation between urban food safety and rural development has recently become a matter of global interest because of the foreseeable future: Rapid urbanization will continue and growing population will eventually trigger food crises in many parts of the world. The upsurge of global food prices in 2007-08, extreme weather events related to climate change effects, resulting land use shifts and conflicts, all have been described as first indicators of more problematic developments to be expected in the future. (Morgan and Sonnino, 2010).

Twenty years ago researchers described the path of global development as "great transformation" (Seto et al. 2010) considerably emphasizing the changes in environment due to population growth. Since 2008 the numbers of global urban population have surpassed those of the rural population Seto at all 2008 call this phase of development "second great transformation" (Seto et al. 2010). This dramatic increase in the global urban population is enhancing stress on the global food systems. The recent upsurge of global food prices (200708) initiated consumer protests worldwide and relatively set-off questions related to food sovereignty and appropriate places of food production (Lerner Eakin 2012). The bulk of urban growth occurs in the urban peripheries, or 'peri-urban' areas of the developing world. In this connection the main question in front of us could be to better understand how urban peripheries can be sustainably managed and what is the role of peri-urban agriculture?

It is estimated that by 2050 the global urban population could reach around 6.3 million, which reaches to a share of 3.5 billion urban dwellers worldwide in 2010 (UNHABITAT 2012). The data on urbanisation indicate different dynamics and patterns of development around the world. This literature review deals with concepts and main observations to better understand this development. It is divided into five chapters. The first chapter of this review draws major attention on various issues related to peri-urban agriculture. My aim is to identify and review important literature on various development paths with emphasis on the key drivers in various parts of the world. In the second chapter I concentrate on developments in India.The third chapter accentuates the various theories and 
concepts in relation to urbanisation in general and peri-urban agricultural development vis-àvis agricultural development theories in particular.

The fourth chapter reviews literature related to measuring sustainability and farmers perceptions, values and beliefs on peri-urban agricultural development. The fifth chapter deals with literature strand related to the importance of various community based approaches in the context of peri-urban agriculture. Finally I draw conclusions from this review for the operationalization of my own work and refine my research questions. .

\subsection{Methods used while reviewing}

This literature review is in general relies on online web browsing especially about the research publication on peri-urban agriculture development. To obtain more specific results, I essentially used the key words, namely 'peri-urban agriculture', 'peri-urban agricultural development' 'urban fringe farming', 'peri- urban areas', and the results provided us about 300 articles published in various peer-reviewed journals, reports, and on-line papers. In order to encapsulate the global trends the review has essentially explored global publications from the journal home pages of 'Science Direct', 'Wiley journals', 'Springer link', 'Oxford Journals', 'Taylor and Francis (tandoff online) websites. In order to search the publication from the Indian context I relied on various Indian research journals from India including 'Economic and Political Weekly', online reports. Key issues in peri-urban areas

This literature search has substantially resulted into various key strands of subjects related to peri-urban areas and their development patterns. These strands of literature on periurban agricultural development could be comparatively categorized into four main broad categories of research. They include topics related to land use change in urbanisation milieu, corresponding environmental impacts, various alternatives related to multifunctionality and rural-urban linkages and finally farmers and consumers. Studies cover a wider range of disciplines, for example urban planning (Cadieux 2008; Hummeler 1998), geography (Smithers and Jhonston 2004; Antrop 2004; Bourne 1996), Sociology (Bryant and Jhonston 1992), Ecology (Buciga et al.2012), Political Economy (Goldman 2011) and Hydrology (Perry and Nawaz 2008). 
Auch et al. (2012) categorized the major drivers of urbanisation that facilitates or constrain land use change, he describes that the most basic human induced driving forces in these areas includes political, economic, cultural and social attributes that changes over time. For example 'expanding a highway system around the city accentuates both economic and cultural driver, through changing employment structure and location (Economic).Similarly the growing desire for rural exurban lifestyle describes cultural driver, changing housing supply relates to demographic, cultural and economic factors. In addition intrinsic government policies' contributes both political as well as economic drivers, while the decline in agricultural competitiveness and profitability sufficiently relates to economic factors and finally the growing impermanence syndrome indicates both economic and cultural drivers. The studies on peri-urban smallholders in developing countries reveal that the land shortages in these areas stipulate distress diversification into agricultural wage work (Brigsten and Tengstam 2011). While the market access, endowments and finance access drives farmers into higher degree of diversification with higher incomes.Although a high rate of urbanization and a high incidence of rural poverty are two distinct features of many developing countries, there is little understanding on the effects of the former on the latter (Cali and Menon 2012).

Huang et al. (2010) examined two aspects of resource use as a result of urbanization which includes (1) consumption of natural resources such as water and land (2) transformation and use of land for urban activities. The review on current trends in peri-urban farming articulates the issues related to inappropriate linkages between rural and urban areas (McGee 2008). Narain (2009) foresees the necessity to revisit the current top down policies related to land acquisition in developing countries like India and claim that such policies should be more participatory involving landowners and peri-urban residents in India. The trends in urbanisation fall short of more inclusive and participatory approaches in planning, (Narain 2009). Generally transportation and connectivity are major issues in the peri-urban areas in the developing countries. In addition the common property resources are getting diverted to other uses and affecting the livelihood of the people depending on these resources (Narain and Nischal 2007). Furthermore literature indicates the growing trade-offs between pro-growth and anti-growth discourses and related interests in peri-urban development (Pacione 1990). Very few studies highlight the lack of equitable access to water in both urban 
and peri-urban areas for farmers (Packialakshmi et al. 2011). There is considerable gap in addressing the structural issues related to water and sanitation which are dramatically neglected in policy regimes (Allen et al. 2006). In other words the natural resources in periurban areas are more prone to practices of increasing contamination of ground water resources, unsustainable waste-water management, and unhealthy practices in urban and periurban food production. All these issues questions the sustainability of peri-urban agriculture (Binns et al 2003). The urbanisation has prompted various trade-offs amongst environmental, economic and socio-cultural issues and raises concerns about the costs associated with them (Simon 2003). In similar vein, Temple et al. (2011) conclude that production systems observed in the peri-urban areas are beyond socially acceptable limits and there is increased need for innovation imperatively towards the ecological intensification of production systems. Allen (2003) criticizes the inadequacy of planning system for dealing with processes of environmental and developmental change in the peri-urban context. He emphasizes that the environmental planning and management cannot be simply based on extrapolation of planning approaches and tools used in rural and urban areas. Instead it is claimed that these areas need planning approaches that respond to the specific environmental, social, economic and institutional aspects of the peri-urban interface.

Bon et al. (2011) elucidate that the major challenge for the peri-urban farmers is producing high quality products amongst highly populated areas under conditions of an often disproportionately polluted environment. Connected to this discussion another argument by ;Bryant (2010) in which it is argued that developing producers' adaptive capacity could be one of the key contributing factors to alleviating urban food insecurity. He suggests that the introduction and consideration of multifunctional attributes of agriculture could help strengthen peri-urban communities and local organizations and to design more appropriate and integrative policies and therewith substantially strengthen the quality of life and food production in peri-urban areas. The urban fringe areas have received little attention in this regard (Bryant 1995).

Crop production in peri-urban areas is extensively market driven and often constrained by tenure insecurity and non-agricultural land demands (Drechsel and Dongus 2010). Moreover the common phenomenon that distinguishes peri-urban areas is that the agriculture is affected by the cost of urban expansion For example in a case study from India 
it has been was argued that about 77 percent of available land in the peri-urban areas cannot be managed sustainably because of the unclear planning of land use (Dutta 2013). In addition untreated waste disposal into peri-urban water bodies in most developing countries has been identified as a major problem for food production. This is especially true for in the case of Hyderabad where the city is known to discharge unlimited wastes into the Musi River (Ensink et al. 2010).At the same time there is dramatic increase in the use of city waste water forperi-urban agriculture around Hyderabad from 1989 to 2002 along the downstream of Musi River from 5213 to 42813 ha indicating shifts in land use especially related to waste water irrigated agriculture (van Rooijen et al. 2011).Another challenge for peri-urban agricultural sustainability is the growing conflict about access to water resources between urban residents and peri-urban residents where it has been observed that the priority is generally given to urban residents that eventually excludes the peri-urban farmers from access to water (Burgin et al. 2013; Huang et al. 2012). A similar conflict emerges with regard to access to energy. In the state of Andhra Pradesh in India energy subsidies to farmers have dramatic negative impacts on energy efficiency with farmers suffering from unreliable energy supplies and city dweller suffering from power cuts. (Dreschel and Zimmerman (2005) reports that the market access in the urban areas influence farmers to intensify the farming operations throughout the year leading to new externalities. Additionally land speculations make peri-urban farming unsustainable when farm owners actively seek investors or developers for their land or even cease farming in search of a suitable buyer (Berry 1978). Dunk et al 2011 describe six considerable peri-urban land use conflicts namely "noise-pollution, visual-blight, health hazards, nature conservation, preservation and changes to the neighbourhood" (Dunk et al. 2011).

In contrast Bryant (1985) states that urbanisation may have positive influence to periurban farming. For example access to major urban centres may provide farmers with income alternatives outside agriculture. Those may complement farming activities and stabilize semiprofessional peri-urban agriculture (Deichmann et al. 2009). However Atkinson (2004) notes that in southern countries only $10 \%$ of the population entering into the city find employment. Furthermore other scholars have argued that peri-urban residents including farmers may have a more advantageous geographical position for selling their labour and agricultural products which in turn may help to so sustain their agricultural livelihoods (Buciga et al. 2012). 
Allen (2001) indicates that the peri-urban interface represents a socially heterogeneous place where urban and rural activities meet representing a mosaic of agricultural and urban ecosystems, affected by material and energy flows demanded by urban and rural areas. In these places- we can see the coexistence of a mix of people including small farmers, informal settlers, industrial entrepreneurs and urban middle class with often competing interests, practices and perceptions. Literature indicates that the peri-urban areas are the regions where there is more dynamic interaction between the urban and the rural (Tacoli 2006; Diaz Caravantes 2012). The urban fringe land supports the urban areas through supply of natural resources such as land and produce food to feed the cities. In addition a substantial number of studies indicate the natural resource transfer from peri-urban to urban in terms of land annexation, housing construction and water (Diaz Caravantes 2012).Studies indicates that globally there is substantial neglect to address the specific needs and challenges of peri-urban populations especially agriculture dependent populations and they face huge risks due to overlapping trends of development in terms of socio-economic changes together with biophysical degradation (e.g. pesticide residues in water bodies) and climate change impacts (Garscahngen et al. 2012).

\subsection{Studies on peri-urban agricultural development}

\subsubsection{Global studies}

The literature on peri-urban agriculture development considerably polarise into four discriminate strands of literature on peri-urban agricultural development. To geographically categorize the development pattern 4 regions can be distinguished: Europe, and the USArepresenting developed economies, Sub-Saharan Africa, representing the developing countries. China and Australia represent the Asian Pacific region and finally we focus on literature about South Asia and arrive at India. The literature review on the developed world shows that key drivers (Figure 2-1) of peri-urban agricultural development are the reform measures after instigation of Common Agricultural Policy (CAP) in Europe and a massive emphasis towards supporting peri-urban agriculture in USA where in some cities development of peri-urban agriculture went hand in hand with the application of concepts of multifunctionality, social farming and community development. Alternative Food Networks 
and Amenity led development in North America, along with a movement to hobby farming in America give examples of these trends (Daniels 1986; Renting 2009; Zasada 2011; Paul 2013; Olson 2012) In contrast, food security, growing population and huge in-migration into the peri-urban areas has prompted international donors to integrate respective projects, into development programs (Lanjouw 2001; Lynch 2013; Makita 2010, Rogerson 2011). At the same time, in rapidly urbanizing regions inAsia where sustainable peri-urban development has not become a top priority of the development agendas. This is particularly true for the socalled mega cities of Asia (Ooi 2009)

The recent developments in China reveal the adoption of massive tourism development approaches in the peri-urban areas (Qian et al. 2012) by the Chinese government. This kind of development is highly motivated to improve the quality of agricultural products and services, while actively developing multiple functions of agrotourism which have wider economic, environmental and social benefits (Yang 2010).

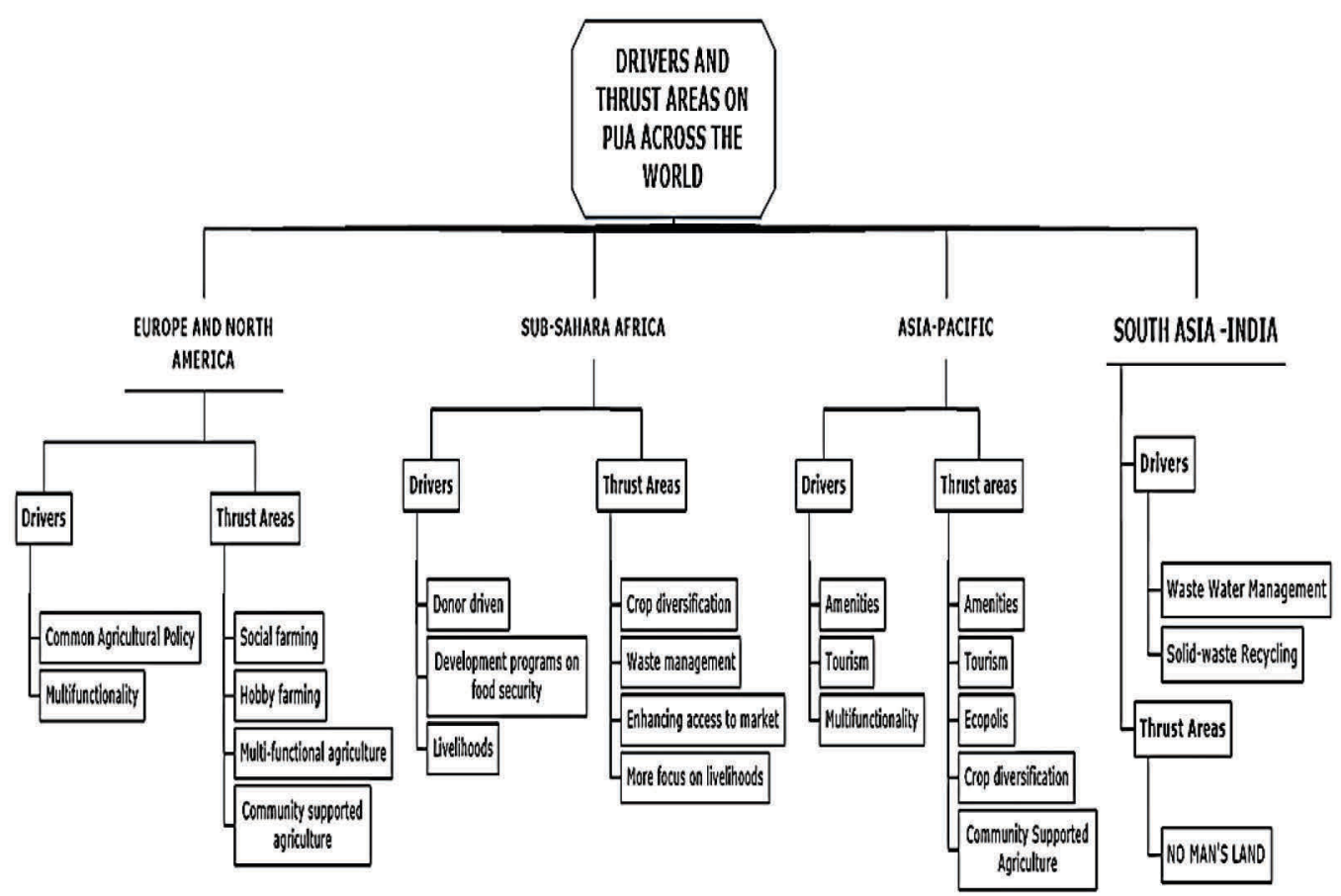

Figure 2-1: Key drivers and thrust areas on PUA across the world

Source: Author's compilation from literature 
Similar development approaches have been identified in Australia with exclusive emphasis on strengthening the multifunctionality of agriculture in peri-urban spaces.(Henderson 2005). However, in Asia, sustainability claims can be easily become disappointed in close proximity to megacity market opportunities and facing competition with other sectors on the land market, In India, central governments major emphasis on periurban planning seems to be pretty much focus on making "world class cities through market liberalization" (Goldman 2011). Indian cities with their peri-urban spaces highly rely on new forms of industrialization as part of peri-urban development that indeed represents an “infrastructure led development model” (Kennedy 2007) through information technology revolution and urban agglomeration. Goldman describes this approach as "Liberalization through urbanisation". There are only few studies on the resulting land use changes and the impacts on farming from Delhi, Bangalore and Chennai (Marshall et al. 2001). The following chapter provides a summary of research with respect to various issues in the peri-urban areas in India.

\subsubsection{Urban and peri-urban agriculture in India}

The issue of peri-urban agriculture in India is sensibly under represented both in the research as well as in the policy dialogue. Table 1describes various thematic issues related to urban and peri-urban areas in India. A considerable number of publications focus on issues related to wastewater among various international journals. This could be mainly due to the "Hyderabad wastewater declaration" signed at Hyderabad during 2002 by various international agencies and facilitated by UNFAO. The majority of publications at national and international level clearly emphasize much more on “urbanisation' governance, metropolitan reconstruction, environmental planning and management, pollution, urban waste management. The farming issues and farm crisis and farmers adaptations due to the large scale structural change is not a priority of research. 
Table 2-1: Studies related to peri-urban areas on various themes in India

\begin{tabular}{l} 
Thematic issues \\
\hline \hline Pollution effect on agriculture \\
Peri-urban Farmers selling ground water, \\
Urban Commons \\
Regional industrial policies and governance \\
issues \\
Urban livelihoods and spatial conflicts \\
Land alienation studies; Landscape \\
Urbanism \\
Metropolitan Restructuring, Urban Planning
\end{tabular}

Environmental planning and management

Urban organic waste and urban compost

Peri-urban environment\& community driven development

Agroforestry and bio-diversity

Heavy metals and pollution

Wastewater

Water supply and Urban governance

Landscape policies

Rural-urban linkages

Wastewater and Health implications

Land use dynamics

\section{Authors}

Agarwal et al.(2003)

Joel Ruet et al. (2007); Packialakshmi et al. (2011); Amita and Vinay (2011)

Kennedy 2007; Dupont 2007; Isa Bad and

Marie Halen Zerah (2007)

Reddy and Reddy (2007); Leon (2012)

Annapurna Shaw and Satish (2007); Maansi (2012)

Allen (2003); Narain (2007); Sridharan and Surendra Kumar (2013)

Nuna (2000)

Dhaniya Bharat (2003)

Arun Chaturvedi et al.(2013); Reddy and Praveena (2011).

Rai (2012); Kaur Ravinder and Rani Rupa (2006)

Buchler (2004); Buchler and Devi (2003, 2005); Buchler et al. (2002); Gayatri Devi (2006); Kurian et al. (2013); Ensink et al. (2010); Raghavendra (2006)

Basu and Main (1997); Ramachandraiah (2006); Ramachandraiah and Sheela Prasad (2008); Ramachandraiah and Vedakumar (2007); Agenes and Guillaume (2008); Suresh Kumar (2012); Milind Sohoni (2012)

Narain (2009)

Narain and Nischal (2007)

Rai (2012)

Dutta (2013); Neha Goel (2011) 
Structural change and urban expansion

Metropolitan restructuring

Peri-urban dynamics
Fazal (2011)

Shaw and Satish (2007), Ashima (2013)

Dupont (2005, 2006); Dupont and Sridharan (2006); Annapurna Shaw (2005)

Table 2-2: Studies related to peri-urban areas on various themes in India-2

\begin{tabular}{|c|c|}
\hline Thematic issues & Authors \\
\hline Subaltern urbanisation & Denis et al. (2012); Pushpa et al. (2005) \\
\hline Power and Injustice, political economy & $\begin{array}{l}\text { Banerjee et al.(2011); Mahadev and } \\
\text { Darshini (2011); Goldman (2011); Kennedy } \\
\text { (2007) }\end{array}$ \\
\hline $\begin{array}{l}\text { Labour exclusion, Migration and } \\
\text { urbanisation, Poverty }\end{array}$ & $\begin{array}{l}\text { Bhattacharya et al.(2011); Kundu and } \\
\text { Saraswathi (2012); Vamsi and Sripad } \\
\text { (2012); Karen and Anant (2012) }\end{array}$ \\
\hline Pesticide residues in urban water bodies & $\begin{array}{l}\text { Sukesh Narain Sinha (2012); Shukla et al. } \\
\text { (2006) }\end{array}$ \\
\hline Agriculture and water transfers & Celio and Giardono (2007) \\
\hline Agriculture diversification & Parthasarathy Rao et al.(2008) \\
\hline Peri-urban agriculture, Urban farming & $\begin{array}{l}\text { Marshal et al.(2001); Yasmeen (2001); } \\
\text { Ramalingegowda et al. (2012); Rahul and } \\
\text { Sunita (2006); Firdous and Ahamed (2012); } \\
\text { Krishna Gopal and Simmons (2006); Satya } \\
\text { (2012); Henrik and Ashinder Kaur (2012) }\end{array}$ \\
\hline
\end{tabular}

Source: Own compilation by author

A closer examination of Indian urbanisation strategies reveals that the focus of development seems to be on "infrastructure led development" (Kennedy 2007). This kind of development approach where the disregard for peri-urban farming in research and policy has to do with the view that the mass of "peasants' have become the final obstacle, preventing India from attaining globally integrated economic prosperity (Goldman 2011). Analysing how to address the issue of sustainable peri-urban agricultural development in the presence of a rather negative image of farming provides a challenging area of research (Kennedy et al 2012). Apparently the urban planners' evident emphasis in India on the development of 
"world-class" infrastructure for "model enclaves" in the metropolitan peripheries is considerably represents a case for "degenerated peripheralisation". This approach provides an example of how powerful language and the social discourse on urbanisation and the urban peripheries can play a leading role in bringing or not bringing peri-urban farmers on the agenda of developers (Kennedy 2007). In order to meaningfully inform decision makers, research on the sustainability of peri-urban farming will have to consider this role.

The following chapter briefly describes the prominent discourses about the relationship between cities and their peripheries. Related to this a renowned book on urbanization "The New Landscape" applies a historical perspective to the existing understanding of urban centres and peripheries. In this book the authors describe peri-urban areas as 'hermaphrodite landscapes'- because - they neither have traditional cores nor recognizable peripheries (Chatopadhyay 2010). Scholars working on developing countries often use the term-peri-urban development (Forsyth 2012). A significant number of papers on place based conceptualization of peri-urban areas and related topics starts from a "nearby city" perspective to explain related influences of cities on development. Pryor (1968) first used the term "rural-urban fringe "in the context of the analysis of "urban invasion". Since then the rural-urban fringe has received great attention from various academic disciplines mainly from planners and geographers. Finally Daniels 1999; Davis 1993; Nelson and Sanchez 1997 have come up with the terms "exurbia" and "semi-urban". Later on terms like the urban-rural divide, the fringe, sprawl, and the semi-urban landscape add to the long list of expressions for the particularities of the peri urban spaces (Gonzalez-Abraham et al. 2007)

The notion of "Cities as engines of growth" refers to effects and financial power of urban agglomerations. In the year 2006 cities contributed up to $53 \%$ of gross national product in low income countries, $73 \%$ in middle income countries and $83 \%$ in high income countries (UN-HABITAT 2006). Victor and Hope (2011) argue that the recent resurgence of "urban bias" and "city centric development" discourses are increasingly guiding theoretical arguments about the role of cities for rural development :(1) the financial dominance of the city as the "epicentre of investment or engine of development has lead de-investment and widespread neglect of rural demands. In addition this rural neglect has triggered the deficit of capital and infrastructure in combination with evasion of rural labour. (2) The "urban bias "discourse (Lipton 2005) refers to the impact of neoliberal policies on rural-urban relations 
and the agriculture for development (Kay 2009). Lipton (2005) claims that there has been a bias in the allocation of resources to cities which has led to inefficient and inequitable resource allocation in favour of the cities. He advocates "a development strategy which creates and enhances the synergies between agriculture and industry and goes beyond the rural-urban divide".

O'Neill et al. (2011) advocates the idea of integrated urban and peri-urban development with the concept of cultural landscapes. Related to this is the idea of impure settlements (Metropolitan village). This concept is driven by the empirical observation that people may have "citizen identities" and still live in the periphery. At the same time people may have rural identities but still have to settle in the cities. (Pahl 1966). Another theory of peri-urban development has its roots in the literature based on the "Corridor Theory "where the term corridor implies to a linear system of urban places together with the linking surface transport media. Urban corridors are very persistent historically, and they form one of the major types of urban systems in the New World. Corridors have been widely studied in the USA and Australia. The development of a corridor-centered economic landscape can be described in five cumulative historical stages: initial occupancies, commercial agriculture, railway transport, motor transport, and metropolitanism. In each stage, the innovations diagnostic of changes in the economic system appear first in corridors, and diffuse outwards in a sequential pattern termed a culture gradient (Whebell 1969).

Concept like the eco-city (Waggoner 2006 and planning concepts like "conjugate ecological planning" reflect the need to balance the relationship between environmental and economic development in the pace of urban planning (Wang 2004). A "New option price theory" describes the impact of urban development on farm land pricing and concludes that both the land use conversion probability and urban influences are important factors affecting the option value of state farmland (Isgin and Foster 2006). Kellerman (1978) examined the determinants of rent from agricultural land around metropolitan. Using von Thünen's rent theory, which concludes that the primary force determining the land price pattern is transport cost to the market. Von Thünen's theory is believed to still widely and applies to situation of weak infrastructures in underdeveloped parts of the world, but has been called "outdated" for explaining land rents in the more developed part of the world (Sinclair 1967). 


\subsection{Theorizing agriculture change and adaptation in the urban fringe}

Heimlich and Anderson (2001) state that that there are still a lot of inconsistencies and overlaps in the ways that different researchers conceptualize farmer adaptive behaviour in structural change The literature on farming landscapes in the urban fringe has many dimensions and diversities. Bryant (1985) categorized different trajectories of change of which first he called agricultural development, second agricultural adaptation and finally agricultural de Similarly in response to confronting pressures of urbanisation, Smither and Jhonson (2004) described four possible farm level trajectories - especially "growth and decline", "intensification", "persistence" and "de-intensification" as a consequence of changing pattern of land, labour and capital use. "Growth and decline" describes a scenario in which aggregate increase or decrease in scale of production occurs, without a fundamental restructuring of the relationship between the main agricultural inputs and the intensity of production process. 'Intensification' defines a scenario in which the main agricultural inputs, such as labour and capital are increased. 'Persistence' refers to a status quo -preserving condition. Finally, 'de-intensification' characterizes a situation in which agriculture is no longer competitive with other sector uses, and farmers react by reducing their main agricultural inputs, eventually leading to farm closures.

Bryant and Johnston (1992) classified the related agricultural diversification scenarios as 'off-farm diversification', which generally involves increased reliance on non-farm employment to support a household, and "on-farm diversification", characterized by 'changes in production practices or management approaches' aimed at minimizing potential nuisance from neighbours. Butt (2013) suggests that the process of peri-urbanisation emerge from a range of drivers that differ from the socio-economic and geographic settings. He indicates that additional factors hecalled ex-urbanization, hidden urbanisation, retiree mobility and displaced suburbia all have significant implications on the features of agricultural systems along with kind and scale of farm adaptation. Studying near city farming in Athens, Moissidis and Duquenne (1997) proposed two types of peri-urban farms. They are "purely traditional farm which adopts extensive production systems and in long-term decline". Another category represents "the farm adapted to peri-urban area" and the third category represents "the intensive farm, corresponding to a protectionist system of production (mainly greenhouse 
cultivation)". They reveal that, in the case of Athens, the traditional farms have gradually disappeared due to urban sprawl and high demand for non-agricultural uses of land.

Heimlich and Brook (1989) describe the relationship between farm types and persistence. Their model anticipates three different types of farms in the rural-urban interface, (1) alternative enterprises (small in size with high value output), (2) recreational enterprises (very small scale, operated by hobby farmers), and (3) traditional enterprises, (large operations engaged in conventional commodity production). The alternative enterprises can include consumer-oriented entrepreneurial agriculture with emphasis on direct marketing and value additions. Between these categories 'mixed' types that combine the characteristics of one another exist (Inwood and Sharp 2012). Jhonston and Bryant (1987) proposed three divergent types of farm changes in the urban-rural interface considering the internal and external farm conditions. These changes include "positive adaptations that enhance farm production" (e.g. adding non-traditional business activities, urban oriented direct marketing, or intensifying traditional production), another farm change include "normal or managerial adjustments" (farm changes consistent with changes occurring across the agricultural sector including the adoption of new agricultural technologies to increase efficiency) and finally " negative adaptations" (such as reducing production intensity or farm investments, perhaps in anticipation of a future sale to developers). The adaption models developed by Johnston and Bryant (1987) and Smithers and Jhonson (2004) observes the farm adaptation strategies that emerge from complex interplay between farm household and farm business in rural-urban interface. In addition Smithers and Jhonson (2004) distinguishes the role of 'farmer agency' in managing change and impart credence to the farm family acting and contributing to farm decision making. Sharp and Smith (2003) argued that farmer adaptation varies, relatively based on constraints and limitations created by alternative local social setting. For example, depending on social capital, farmers can try to develop a relationship with non-farm neighbours to build trust and understanding about potentially offensive farm practices. Finally, Bowler (1992) following earlier research of Whatmore et al. (1987) identifies six paths of development in response to farm crisis which are pursued individually or in combination. 
Table 2-3: Various paths of peri-urban agricultural development

\section{PATHS OF DEVELOPMENT}

Extension of the industrial model of farm business development based on traditional products and services

Redeployment of farm resources (including human capital) into new agricultural products or services

Redeployment of farm resources (including human capital) into new non-farm products and services

Redeployment of human capital into off-farm occupation

Maintenance of traditional farm production and services with either reduced inputs and/ or reduced income

Hobby or part-time (semi-retired) farming

Source: Bowler (1992)

\subsection{Agricultural development theories and associated discourses}

In Asia and the developing world, technological innovation was long described as the main driver of structural change in agriculture (Hayami and Ruttan 1985) that indicates the choice of technology and production strategy is a product of resource endowments and economic forces. In order to understand the development with close association to technical change, afterwards this model has been revised and the role of institutional change and innovation in affecting agricultural development (Ruttan 1989) has been incorporated. Buttel extends the technological perspective on agricultural change speaking of a "technological treadmill" in which a globalizing food system marginalizes small producers (Buttel 1989). Another approach closely related to this interpretation is the process of "subsumption and uneven development" (Whatmore et al. 1987). More recently, the influence of concentration and internationalization of processors and retailers and the subsequent vertical integration of agro-food systems have also been described as important drivers of structural change in developing countries (Goodman and Watts1997, Reardon et al. 2004).

The nature of forces influencing the speed of change in agriculture and corresponding effect on resource management in a given location may vary. The causes and effects of intensification could vary in spatial and temporal scales. Kates et al. (1993) have categorized 
the theories of intensification that seeks to explain agricultural intensification into two broad categories.

“....those that relates production to household needs and wants (usually population driven) under conditions of subsistence" and those that relates production to demands from the markets" (Kates et al. 1993)

The intensification may occur over a long period of time in response to increasing population pressure through experimentation, adaptation and assimilation, which is described as "autonomous intensification" (Swift 1979). In contrast the intensification may happen more or less overnight as result of or a response to global events and changes in national policies and such phenomena can be described as " policy-led intensification" (Birch and Bjarne 1996).

The broader economic theories that were extensively described in the literature basically the Productionist/capital-penetration/subsumption, appropriatism, Substitution, uneven development would throw light on understanding larger scale contexts of agricultural change but underestimated the importance of internal environments, life cycles of farms, human agency problems and institutions in shaping opportunity sets for farmers (John, T. Pierce 1994). Related to this argument, Ilbery (1992) argues that these economic approaches "relegate farmers to the role of non-decision makers and constraints are emphasized at the expense of choice".

Bryant and Jhonston (1992) claim that to understand the post-industrial agricultural landscape in the urban fringe, the system of exchange in which farms operate needs to be considered together with lifecycles of the farm family, proximities to the market, and policy related factors, in short they content that the complexity of changes in the agricultural landscape (.e.g. degeneration, adaptation and development) is the product of different modes of production (industrial and post-industrial), each inclined to respond differently to the same external stimuli at a variety of spatial scales.

To support Bryant and Jhonston's arguments, Marsden et al. (1989) proposes to consider the importance of family development cycles in determining the choice of what they term "survival" or "accumulation" strategies. Finally, a broad range of researchers have 
argued that there is no "unified pattern of agricultural development" and no unified theory of it.

\subsubsection{Studies related to farmers' perceptions, attitudes and beliefs}

Studies analysing the motivations and perceptions of change among farmers are still relatively rare. (Handerson 2005). A study on perceptions related to the use of pesticides in peri-urban area indicates a significant difference in the perceptions on pesticide use among the farmers and their neighbours (Ahamed et al. 2011). While the neighbours perceive that pesticide use is more harmful to environment and contributes to reduction in the food quality, farmers did not see a problem with using chemicals. Similar forms of conflicts were analysed by Hammond (2002); Lapping et al. 1989).

Research on attitudes related to chemical use in peri-urban farming (Lagerkvist et al. 2012) indicates that often the urban consumers' demand for clean and spotlessness vegetables encourage the excessive use of pesticides. Additionally, the desire to reduce losses and waste can cause farmers to violate the recommended intervals between pesticide application and harvest. The study reveals that farmers respond to consumers' needs by applying pesticides indiscriminately for the purpose of improving aesthetic quality attributes resulting in higher prices and profit margins.

A study from Cameroon examined the effect of property rights and socio-economic factors for the likelihood of using pesticides and fertilizers in peri-urban agricultural system. Farmers with impermanent land rights and those whose fields are more distant from the homestead are likely to use more chemical fertilizer. In addition the frequency of contacts with extension agents was found to positively influence to the use of chemicals (Nkamleu and Adesina 2000). Feola and Binder (2010) applied an Integrative agent cantered (IAC) framework, that has its roots from the 'behavioural theory' and suggested that this kind of frameworks generally aims at understanding the farmers behaviour in the agricultural systems. This approach is highly useful to understand the general dynamics of farmers' behaviour and corresponding feedback processes in the agricultural system which forms a basic part of complex social-ecological systems. 
Recent developments in the literature indicate a growing concern among the scholars to focus on discourses, perceptions and the social construction of agricultural change. Nasongkhla and Sintusingha (2012) explore the social construction of city beautification involving local participatory approaches at the municipal level of Mae Hong Son Town. Other scholars have argued that with regard to land degradation issues in peri-urban areas a more critical evaluation of how the knowledge, understanding and perceptions of local actors drive behavior and affect land-use decisions at the micro-level is crucial for sustainable environmental policies in the future (Maconachie and Bins 2006).

Capek (2010) emphasizes that socio-ecological approaches would meaningfully benefit the urban sociology perspectives and enhances our understanding of interactions between nature and the city. These understanding facilitate people to participate fully in discussions related to sustainability with expectable changes in their behaviour.

\subsubsection{Community approaches, innovations}

The concept of Multifunctionality with its significance, while imparting value to both the commodity and non-commodity outputs of agriculture has been well recognized in Europe. Various studies have shown the positive aspects of Multifunctionality in agriculture. It is suggested that the notion of a 'multifunctional agricultural regime' better encapsulates the diversity, non-linearity and spatial heterogeneity that can currently be observed in modern agriculture and rural society (Wilson 2001). The studies related to multifunctional nature of agriculture includes various community based approaches and innovation in the European context.

At the same time literature indicates a growing phenomenon related to urban farming associations around the world. These kinds of developments fuelled to examine the upsurge of cooperative activities, knowledge and perceptions of the actors involved in urban farming associations due to growing demand for urban and peri-urban agriculture in Freetown (Maconachie 2012). This study highlights how urban and peri-urban agriculture (UPA) activities are currently driving revival of community-based cooperation, which could be a development approach that could play an important role in safeguarding urban and peri-urban farmer's livelihoods. 
In addition Cazaux et al. (2007) characterize urban outskirts as multidimensional production and consumption areas (Potter and Tilzey 2005) that has to fulfil different functions in particular. The infusion of the Multifunctionality concept with better implication on societal transformation processes has significantly influenced research and policy approaches in different ways amongst countries and disciplines (Renting et al. 2009). Many studies have considered diversification, recreational and environmental farming, landscape management and specialization together with direct marketing (Zasada 2011).

Van Dijk (2011) indicates that the city should be understood as a combination of various social processes facilitated by various networks and a sociology of structural and cultural wholes. He states that the process of managing urbanisation through network relations and thus service provision between inhabitants and local state differ in means and modes across different socio-economic collectivises and urbanized spaces. He concludes that this process is often overlooked in Indian cities among discussions about governance, citizen participation and urban development.

Moreover the literature has pretty much emphasized on studies related to community practice, community discourses and communitarian reference points influencing food system dynamics in peri-urban areas based on community development theories (Dixon 2010). In his perspective the influence of corporate dominated food systems in the nearby cities has been discussed. An important concept in this regard is provided by "community supported agriculture in the urban fringes". A study on "community supported agriculture" (CSA) indicates that CSA offers better opportunities for small-scale and part-time farmers as well as scope for the farmers to diversify their opportunities and livelihoods (Wells et al. 1999). CSA can play a prominent role in bringing people together that enhances social relationship with affinity towards place, farming, nature, providing a sensible and viable counter-balance to the large scale global industrial food systems (Wells et al. 1999).

The opportunities for smallholders in peri-urban areas to raise their incomes increasingly depend on their ability to compete in the urban market. These abilities could be better enhanced with community negotiations and producer organizations. Related to this, Markelova (2009) indicates that the institutional arrangements and producer organizations could effectively tackle the market issues in developing countries. McGregor et al. 2011 
highlight the importance of community based approaches to tackle agricultural crises in periurban areas. Moffat and Tina (2005) argue that the urban and peri-urban political ecology needs to explicitly recognize and analyze the relationships between communities and their peri-urban areas and those of material, natural, and social resources.

An emerging body of literature related to alternative food networks (AFS) pursues the reconfiguration of structures related to production system, distribution and consumption of food. The essential part of this literature confers the local sale and the emerging idea of proximity to urban centres. AFN at a local scale can be easily developed by linking periurban farmlands and cities (Paul and Mckenzie 2013). Many authors conclude that 'periurban farmland preservation could be better possible if the farm land preservation is guaranteed. In this connection, Glowacki-Dudka et al. (2013) describes the role of social capital playing vital role in enhancing sustainable local food networks and community development where the emergence of strong social capital in a community as a consequence of the connections and reciprocity that emerge with the development of locally grown food system. Jarosz (2008) and her work on alternative food networks (AFNs) indicates that AFN is an umbrella term that represents efforts on the spatial and social reorganization of food production, distribution and consumption that mainly represents two processes: urbanisation and rural restructuring. An Shi et al. (2011) reveal that China's middle class is driven by a growing interest in promoting 'green' and sustainable food, which is perceived to be healthy, safe and environmentally friendly. Their work explores the relationship between the Chinese middle class, an overwhelmingly urban group, and Chinese sustainable agriculture from the perspective of Community Supported Agriculture (CSA). They studied the CSA farm's environmental and institutional sustainability, in order to better integrate its development within the larger context of contemporary Chinese agriculture. Finally they conclude that CSA farms are successful in facilitating the nexus between producers and consumers through knowledge and trust. Voleria and Noelia 2012 describe in a similar vein as the role of emerging "Vegetable Tourism" in Spain. They conclude that this type of consumer producer relationship is replicable model for promoting innovations in peri-urban farming. 


\subsection{Research agenda}

Farm adaptation and structural change in the urban fringe areas cannot be captured by one general theory. This literature review has displayed a multitude of concepts and approaches which help to better understand and explain how cities influence change in periurban agriculture. In this discussion, finding answers to questions about the future role of agriculture in a more and more urbanizing world is equally important than finding answers to the questions about sustainable agricultural development. In my dissertation I attempt to contribute to this discussion with empirical work on my hometown Hyderabad. In what follows I will take up what I consider to be important strands from literature and apply them to the context of megacity development in the Greater Hyderabad Area. In the next chapter I will build on hypotheses from the literature about important trajectories of farm development in peri urban areas and apply them to my empirical observations from farms in the GHA. In paper 3 I will have a deeper look into how farmers of different farming systems of the GHA participate in the different social discourses about sustainability of peri-urban agriculture. In paper 4 I will discuss determinants of farmers' adoption of more sustainable agricultural practices and compare what is known with what I find for in a particular case. My last paper is a policy paper. I discuss main literature arguments of how to stimulate sustainable peri urban development and review current policies in India.

\subsection{References}

Adell, G. (1999) "Theories and Models of peri-urban interface: a changing concept landscape". London Development Planning Unit: University College, London.

Agnes, H and Guillaume, T. (2008) "Between Citizens and Institutions: The Dynamics of the Integration of Water supply and Sanitation services in Hyderabad". CSH Occasional Paper, New Delhi, ISSN. 0972-3579

Ahmed, N; Englund, Jan-Eric; Åhman, I; Lieberg, M and Johansson, Eva. (2011) "Perception of pesticide use by farmers and neighbors in two peri-urban areas". Environment, (412-413):77-86.

Allen, S. (2001) “Mat Urbanism: The Thick 2-D”. CASE: Le Corbusier's Venice Hospital and the Mat Building Revival". In: Sarkis, H., Allard, P., Hyde, T., (Eds.). CASE Series, pp. 118-126, Munich, New York (Harvard Design School / Prestel). 
Allen, A. (2003) "Environmental planning and management of the peri-urban interface: perspectives on an emerging field". Environment and Urbanization, 15 (1):135-148.

Allen, A; Davila, J. D and Hofmann, P. (2006) "The peri-urban water poor: citizens or consumers?" Environment and Urbanization, 18 (2): 333-351.

American Planning Association, (2007) "Policy Guide on Community and Regional Food Planning". Chicago, APA.

Amita, B andVinay, G. (2011) "Urban Commons". .Economic and Political Weekly, XLVI (50): 7-10

Anne G; Busck. Soren, P; Kristensen, S. P; Anette R. and T. Primdhal. (2006) "Land system changes in the context of urbanization: Examples from the peri-urban area of Greater Copenhagen". Danish Journal of Geography, 106 (2): 21-34.

Ann Forsyth. (2012) “Defining Suburbs”. Journal of Planning Literature, 27(3): 270-281.

Annapurna, Shaw. (2005) "Peri-urban Interface of Indian Cities". Economic and Political Weekly, XL (02): 18-20.

Antrop, M. (2004) "Landscape Change and the Urbanization Process in Europe". .Landscape and Urban Planning, 67(1-4): 9-26.

Aravind, N.A.M; Subjadra Devi and Savitha Swamy. (2009) "Reshaping Urban Green Spaces". Economic and Political Weekly, XLIV (46): 22-24.

Arun Chaturvedi; Rahul, L and Alka Chaturvedi. (2013) "City- forest relationship in Nagpur: One of the Greenest Cities in India". Urban Forestry and Urban Greening, 12(1): 7987.

Ashima, S. (2013) “Urban Municipalities, Governing India's Megacities" .Economic and Political Weekly, XLVIII (13): 95-101.

Atkinson, G and Oleson, T. (1996) "Urban Sprawl as a Path Dependent Process". Journal of Economic Issues, 30(2): 609-615.

Auch, Roger F; Napton, D. E; Kambly, S.M and Thomasand Sayer, K. L. (2012) "The driving forces of land changes in the Northren Piedmont of the United States". Geographical Review, 102 (1): 53-75.

Azadi, Hossein; van Acker; Veronique. Zarafshani, K and Witlox F. (2012) "Food systems: New-Ruralism versus New-Urbanism”. J. Sci. Food Agric. 92 (11): 2224-2226.

Banerjee-Guha and Swapna. (2009) "Neoliberalising the 'Urban': New Geographies of Power and Injustice in Indian Cities". Economic \& Political Weekly, 44 (22):95-107. 
Bedore, Melanie. (2012) "Geographies of capital formation and rescaling: A historicalgeographical approach to the food desert problem". The Canadian Geographer / Le Géographe canadien, pp. N/A.

Berry, D. (1978) "Effects of Urbanization on Agricultural Activities". Growth and Change, 9 (3): 2-8.

Bhattacharya; Rajesh and Kalyan Sanyal. (2011) "Bypassing the Squalor: New Towns, Immaterial Labour and Exclusion in Post-colonial Urbanisation".Economic \& Political Weekly, XVII: 33-34.

Bigsten, A and Tengstam, S. (2011) "Smallholder Diversification and Income Growth in Zambia". Journal of African Economies, 20 (5):781-822.

Birch, Torben and Bjarne, F. (1996) "Changes in Small-scale Agriculture: A case study from Southwestern Tanzania". Danish Journal of Geography, 96: 60-69

Birley, M. H and Lock, K. (1998) "Health and peri-urban natural resource production". Environment and Urbanization, 10 (1): 89-106.

Binns, J. A; Maconachie, R. A. and Tanko, A. I. (2003) "Water, land and health in urban and peri-urban food production: the case of Kano, Nigeria". Land Degrad. Dev. 14 (5): $431-444$.

Bon, H. P; Laurent and M. Paule. (2010) "Sustainable urban agriculture in developing countries". A review.Agron. Sustain. Dev. 30 (1):21-32.

Bourne, L.S. (1996) "Reinventing the Suburbs: Old Myths and New Realities". Progress in Planning, 46(3): 163-184.

Bowler, I.R. (1992) "Sustainable agriculture' as an alternative path of farm business development.In: "Contemporary Rural Systems in Transition". (Eds.). I.R. Bowler, C.R. Bryant, and M.D. Nellis, 237-53. Wallingford: C.A.B. International

Bryant, Christopher R. (1984) "The recent evolution of farming landscapes in urban-centred regions". Landscape Planning, 11 (4): 307-326.

Bryant, Christopher R. (1986) "Farmland conservation and farming landscapes in urbancentred regions: the case of the Ile-de-France region". Landscape and Urban Planning, 13: 251-276.

Bryant, Christopher R. (1989) "Entrepreneurs in the rural environment". Journal of Rural Studies, 5 (4): 337-348.

Bryant, C.R and Johnston, T.R.R. (1992) “Agriculture in the city's countryside”. University of Toronto Press. 
Bryant, Christopher R. (1995) "The role of local actors in transforming the urban fringe" .Journal of Rural Studies, 11 (3): 255-267.

Bryant, C.R; Chahine, G.and Delusca K. Daouda. (2010) "Adapting to Environmental and Urbanisation Stressors: Farmer and Local Actor Innovation in Urban and Periurban Areas in Canada" .ISDA. Montpeller, France (Innovations and Sustainable Development).http://hal.archivesouvertes.fr/docs/00/52/19/83/PDF/Bryant_Adapting_ to_environment.pdf

Bryld., E. (2003) "Potentials, problems, and policy implications for urban agriculture in developing countries". Agriculture and Human Values, 20 (1): 79-86.

Buciega, A; Pitarch, M.D and Esparcia, J. (2009) "The context of rural-urban relationships in Finland, France, Hungary, the Netherlands and Spain" .Journal of environmental policy and planning, 111: 9-27.

Buechler, S. J and Devi, G. (2003) "Household food security and wastewater-dependent livelihood activities along the Musi River in Andhra Pradesh, India". World Health Organisation, Geneva, Switzerland

Buechler, S. J. (2004) "A sustainable livelihoods approach for action research on wastewater reuse in agriculture. In: Scott, C., Faruqui, N. I., and Raschid, L. (Eds.). Wastewater Use in irrigated agriculture -confronting the livelihoods and environmental realities". $\mathrm{CABI} / \mathrm{IWMI} / \mathrm{IDRC}$ publishers

Buechler, S.J; Devi, G and L. Raschid. (2002) "Livelihoods and wastewater irrigated agriculture along the Musi river in Hyderabad city, Andhra Pradesh, India". Urban Agriculture: 14-17.

Buechler, S and M. Gayathri Devi. (2003) "Wastewater as a source of multiple livelihoods?A study of a rural area near Hyderabad City, Andhra Pradesh, India”. In: Rema Devi and Naved Ahsan (Eds.). "Water and Wastewater: Developing Country Perspectives". International Water Association, London, U.K: 939-948

Buechler, S and M. Gayathri Devi. (2005) "Local Responses to Water Resource Degradation: Farmer Innovations in a Rapidly Urbanising Area in India". The Journal of Environment and Development, 14(4):410-438.

Budsara, L and G. Phrek. (2010) "Transforming agri-food systems in peri-urban area of Northern Thailand: A case study of vegetable farming of Ban Ping Noi farmers". Paper presented in 9th European IFSA symposium, 4-7th July, 2010, Vienna (Austria)

Burgin, Shelley; Webb, Tony and Rae, Debbie. (2013) "Stakeholder engagement in water policy: Lessons from peri-urban irrigation". Land Use Policy, 31: 650-659.

Buttel, F.H. (1989) "The US farm crisis and the restructuring of American agriculture: Domestic and International Dimensions. In: D. Goodman and M. Redclift., (Eds.). The International Farm Crisis", 46-83. New York: St. Martin's Press. 
Butt, A. (2013) "Exploring Peri-urbanisation and Agricultural Systems in the Melbourne Region”. Geographical Research, pp. N/A.

Čapek, Stella M. (2010) "Foregrounding Nature: An Invitation to Think about Shifting Nature-City Boundaries". City \& Community, 9 (2): 208-224.

Cazaux, G; Carels, K and D. Van Gijseghem. (2007) "Prospects and challenges for Agricultural diversification in a peri-urban region (Flanders - Belgium)". Beleidsdomein Landbouw en Visserij, AfdelingMonitoring en Studie, Brussel.

Celio, M and Giordano, M. (2007) "Agriculture-urban water transfers: a case study of Hyderabad, India”. Paddy and water Environ, 5 (4): 229-237.

Chattopadhyay, S. (2010) "Cities and peripheries" .Historical Research, 83 (222): 649-671.

Chen, Xiangming; Wang, Lan and Kundu, Ratoola (2009) "Localizing the Production of Global Cities: A Comparison of New Town Developments Around Shanghai and Kolkata". City \& Community, 8 (4): 433-465.

Crush, J; Hovorka, A and D.Tevera. (2011 "Food security in Southern African cities: The place of urban agriculture". Progress in Development Studies, 11 (4): 285-305.

Daniels, L. Thomas. (1986) "Hobby farming in America: Rural development or threat to commercial agriculture?" Journal of Rural Studies, 2(1): 31-40.

Daniels, L. Thomas. (1999) "When City and Country Collide": Managing Growth in the Metropolitan Fringe. Washington, DC: Island Press.

Davis, J. S. (1993) "The Commuting of Exurban Home buyers" .Urban Geography, 14(1): 729.

Davis, C and T. Schaub. (2005) "A Transboundary Study of Urban Sprawl in the Pacific Coast Regionof North America: The Benefits of Multiple Measurement Methods". International Journal of Applied Earth Observation and Geoinformation, 7(4): 268283.

Deichmann, U; Shilpi, F and R. Vakis. (2009) "Urban Proximity, Agricultural Potential and Rural Non-farm Employment: Evidence from Bangladesh". World Development, 37(3): 645-660.

Denis, E; Partha Mukhopadhyay and Marie-Hélène Zérah. (2012) "Subaltern Urbanisation in India". Economic \& Political Weekly, 47 (30): 89.

Dahiya, Bharat. (2003) "Peri-urban environments and community driven development: Chennai, India”. Cities, 20 (5): 341-352. 
Dhingra, Chhavi; Gandhi, Shikha; Chaurey; Akanksha and P.K. Agarwal. (2008) "Access to clean energy services for the urban and peri-urban poor: a case-study of Delhi, India". Energy for Sustainable Development, 12 (4): 49-55.

Diaz-Caravantes, R. (2012) "Balancing urban and peri-urban exchange: water geography of rural livelihoods in Mexico". The Geographical Journal, 178 (1): 42-53.

Dinham, B. (2003) "Growing vegetables in developing countries for local urban populations and export markets: problems confronting small-scale producers". Pest.Manag. Sci, 59 (5): 575-582.

Dixon, J. (2010) "Diverse food economies, multivariant capitalism, and the community dynamic shaping contemporary food systems". Community Development Journal, 46 (Supplement 1): i20-i35.

Dossa, Luc H; Abdulkadir; Aisha, Amadou; Hamadoun, Sangare; Sheick and E. Schlecht. (2011) "Exploring the diversity of urban and peri-urban agricultural systems in Sudano-Sahelian West Africa: An attempt towards a regional typology". Landscape and Urban Planning, 102 (3):197-206.

Drechsel, P and Dongus, S. (2010). Dynamics and sustainability of urban agriculture: examples from sub-Saharan Africa. Sustain Sci, 5 (1): 69-78.

Drechsel, P and Zimmermann, U. (2005) "Factors influencing the intensification of farming systems and soil-nutrient management in the rural-urban continuum of SW Ghana". $J$. Plant Nutr. Soil Sci. 168, (5): 694-702.

D'Souza, R. and Nagendra, H. (2011) "Changes in Public Commons as a Consequence of Urbanization: The Agara Lake in Bangalore, India”. Environmental Management, 47 (5): 840-850.

Dunk, A; von der Grêt-Regamey; Adrienne, D; Thomas, H and Anna, M. (2011) "Defining a typology of peri-urban land-use conflicts - A case study from Switzerland" .Landscape and Urban Planning, 101 (2): 149-156.

Dupont, V and Sridharan, N. (2006) "Peri-Urban Dynamics: Case Studies in Chennai, Hyderabad and Mumbai". CSH Occational Paper, New Delhi, ISSN 0972-3579

Dupont, V. (2007) "Conflicting stakes and governance in the peripheries of large Indian metropolises - An introduction”. Cities, 24 (2): 89-94.

Dupont, Véronique. (2005) "Peri-Urban Dynamics: Population, Habitat and Environment on the Peripheries of Large Indian Metropolises: A Review of Concepts and General Issues". CSH Occasional Paper (New Delhi: CSH).

Dutta, V. (2013) "Land Use Dynamics and Peri-urban Growth Characteristics: Reflections on Master Plan and Urban Suitability from a Sprawling North Indian City". Environment and Urbanization Asia, 3 (2): 277-301. 
Ensink, J.H; J. Scott; Christopher, A; Brooker, Simon and Cairncross, Sandy. (2010) "Sewage disposal in the Musi-River, India: water quality remediation through irrigation infrastructure". Irrig Drainage Syst, 24 (1-2):65-77.

Fazal, Shahab (2010) “Actors and Their Role in PUI Land Transformation”, New Delhi: 6980 .

Feola, Giuseppe and Binder, Claudia R. (2010) "Towards an improved understanding of farmers' behaviour: The integrative agent-centred (IAC) framework". Ecological Economics, 69 (12): 2323-2333.

Firdaus, Ghuncha and Ahmad, Ateeque (2011) "Impact analysis of urbanization on rural livelihood - an empirical study of an urban centre of Delhi, India". International Journal of Urban Sciences, 15 (3): 147-160.

Francisco, Sergio R and Ali, M. (2006) "Resource allocation tradeoffs in Manila's peri-urban vegetable production systems: An application of multiple objective programming". Agricultural Systems, 87 (2): 147-168.

Ganesh, K. (2007) "Urban wastewater for irrigation: A case study of farmers along Musi River in Hyderabad”.Karnata Journal of Agricultural Science, 22(1), 235-237.

Garschagen, Matthias; Renaud Fabrice, G and Birkmann, Jörn. (2011) "Dynamic Resilience of Peri-Urban Agriculturalists in the Mekong Delta under Pressures of SocioEconomic Transformation". In: Environmental change and Agriculture in Mekong Delta, Advances in Global Change Research, 45:141-163.

Gayathri Devi, M. (2006) "Multi-stakeholder Processes for safe use of wastewater and sustainable urban agricul-ture: A case study of Hyderabad, India". Paper presented at the Third World Urban Forum in Vancouver, Canada (19-23 June, 2006)

Glowacki-Dudka, M; Murray, J and Isaacs, K. P. (2013) "Examining social capital within a local food system". Community Development Journal, 48 (1): 75-88.

Goldman, M. (2011) "Speculative Urbanism and the Making of the Next World City" .International Journal of Urban and Regional Research, 35(3): 555-81.

Gonzalez-Abraham, C.E; Radeloff, V.C; Hammer, R.B; Hawbaker, T.J; Stewart, S.I and Clayton, M.K. (2007) "Building Patterns and Landscape Fragmentation in Northern Wisconsin, USA”. Landscape Ecology, 22(2): 217-230.

Goodman, D and J. Watts. (1987) "From Farming to Biotechnology: A Theory of Agroindustrial Development", New York. St. Martin's Press.

Gregory, P and M. Mattingly. (2009) "Goodbye to natural resource-based livelihoods? Crossing the rural/urban divide" .Local Environment, 14 (9): 879-890. 
Hyami, Y and V.W. Ruttan. (1985) "Agricultural Development: An International Perspective”. Baltimore: John Hopkins Press.

Heikkila, E.J and Lathrop, R.G. (2003) "Land Resource Impact Indicators of Urban Sprawl" .Applied Geography, 23(2-3), 159-175.

Heimlich, R. E and D. H. Brooks. (1989) "Metropolitan Growth and Agriculture: Farming in the City's Shadow”, AER-619, U.S. Dept. of Agriculture, Economic Research Service.

Heimlich, R.and Anderson, W. (2001) "Development of the urban fringe and beyond: impacts on agriculture and rural land.Economic Research Service”. U.S. Department of Agriculture. Agricultural Economic Report No. 803.

Henrich, V and Ashinder Kaur. (2012) "Grow your own food! The Potential for Small-scale Urban Farming in India”.Economic and Political Weekly, XLVII (24)

Henderson, V. (2003) "The Urbanisation Processand Economic Growth: The So-What Question". Journal of Economic Growth, 8 (1): 47-71.

Henderson, Steven R. (2005) "Managing land-use conflict around urban centres: Australian poultry farmer attitudes towards relocation". Applied Geography, 25 (2): 97-119.

Hayes, Joseph; Roth, Michael and Zepeda, Lydia (1997) “Tenure Security, Investment and Productivity in Gambian Agriculture: A Generalized Probit Analysis". American Journal of Agricultural Economics, 79 (2): 369.

Huang, Shu-Li; Yeh, Chia-Tsung and Chang, Li-Fang. (2010) "The transition to an urbanizing world and the demand for natural resources". Current Opinion in Environmental Sustainability, 2 (3): 136-143.

Huang, Shu-Li; Chen, Yu-Hwa; Kuo, Fei-Yu and Wang, Szu-Hua. (2011) "Emergy-based evaluation of peri-urban ecosystem services". Ecological Complexity, 8 (1): 38-50.

Hubbard, Michael and Onumah, Gideon. (2001) "Improving urban food supply and distribution in developing countries: the role of city authorities" .Habitat International, 25 (3): 431-446.

Hummeler, C. (1998) "Strategies for preventing suburbanization.Urban Ecology". In: Breuste, J; Feldmann, H; and Uhlmann, O.(Eds.). Results of the international conference held in Leipzig, Germany, June 25 - 29, 1997. 461-465, Berlin, Heidelberg (Springer).

Ilberry, B.W. (1992) "State assisted farm diversification in the United Kingdom. Contemporary Rural Systems in Transition". In: I.R.Bowler; C.R. Bryant, and M.D. Nellis, (Eds.). 100-116. Wallingford: C.A.B.International. 
Inwood, S.M and Jeff Sharp, S. (2012) "Farm persistence and adaptation at the rural-urban interface: Succession and farm adjustment” .Journal of Rural Studies, 28: 107-117.

Indrajeet, R. (2006) "Representation and Development in Urban Peripheries" .Economic and Political Weekly, XLI (41): Oct 14.

Isgin, Tamer and Forster, D. Lynn. (2006) "A Hedonic Price Analysis of Farmland Option Premiums under Urban Influences”. Canadian J Agric Econ, 54 (3): 327-340.

Ives, Christopher D and D. Kendal. (2013) "Values and attitudes of the urban public towards peri-urban agricultural land" .Land Use Policy, 34: 80-90.

Jarosz, L. (2008) "The city in the country: Growing alternative food networks in Metropolitan areas". Journal of rural studies, 24: 231-244.

Johnston, T. R. R. and C. R. Bryant. (1987) "Agricultural Adaptation: The Prospects for Sustaining Agriculture near Cities". In: W. Lockeretz Ankeny (Eds.). Iowa, Soil and Water Conservation Society.

Jonathan, D.Mayer. (1980) "Urban Ecology and Location Theory: Dominance and Territory". Geoforum, 11: 399-407.

Jussaume Jr; Raymond, A and Glenna, Leland. (2009) "Considering Structural, Individual and Social Network Explanations for Ecologically Sustainable Agriculture: An Example Drawn from Washington State Wheat Growers". Sustainability, 1 (2): 120132.

Kates, R.W. et al. (1993) "Theory, Evidence, Study Design. In: Turner, B.L. et al. (Eds.). Population Growth and Agricultural Change in Africa". University Press of Florida, Gainesville

Karen, C and Anant, M. (2012) "Urban Poverty in India, Tools, Treatment and Politics at the Neoliberal Turn," XLVII: 47-48

Kaur, Ravinder and Rani, Rupa. (2006) "Spatial Characterization and Prioritization of Heavy Metal Contaminated Soil-Water Resources in Peri-Urban Areas of National Capital Territory (NCT), Delhi”. Environ Monit Assess, 123 (1-3): 233-247.

Kellerman, A. (1978) "Determinants of Rent from Agricultural Land Around Metropolitan Areas". Geographical Analysis, 10 (1):1-12.

Kennedy, L. (2007) "Regional industrial policies driving peri-urban dynamics in Hyderabad, India".Cities, 24 (2): 95-109.

Kennedy, Christopher; Lawrence, Baker; Shobhakar, Dhakal and Anu Ramaswami. (2012) "Sustainable Urban Systems: An Integrated Approach". Journal of Industrial Ecology, $16(6): 775-79$. 
Kundu, A and Saraswathi, L.R. (2012) "Migration and Exclusionary Urbanisation in India". Economic and Political Weekly, XLVII: 26-29.

Kurian, Mathew; Ratna Reddy, V; Dietz, Ton and Brdjanovic, Damir (2013) "Wastewater reuse for peri-urban agriculture: a viable option for adaptive water management?" Sustain. Sci, 8 (1): 47-59.

Lagerkvist, Carl Johan; Ngigi, Marther; Okello, Julius. J and Karanja, N. (2012) "Means-End Chain approach to understanding farmers' motivations for pesticide use in leafy vegetables: The case of kale in peri-urban Nairobi, Kenya". Crop Protection, 39: 7280 .

Lapping, M. B and Fitz Simons, J. F. (1982) "Beyond the land issue: farm viability strategies".Geo. Journal, 6 (6): 519-524.

Lanjouw, Peter; Quizon, Jaime and Sparrow, Robert. (2001) "Non-agricultural earnings in peri-urban areas of Tanzania: evidence from household survey data". Food Policy, 26(4):385-403.

Lannoo, Steven; Verhaeghe, Pieter-Paul; Vandeputte, Bart and Devos, Carl (2012) "Differences in social capital between urban and rural environments". Journal of Urban Affairs, 34 (4): 373-394.

Lerner, A.M.M.Y and Eakin, Hallie. (2011) "An obsolete dichotomy? Rethinking the ruralurban interface in terms of food security and production in the global south". The Geographical Journal, 177 (4): 311-320.

León, Carmelo J; González, Matías, Araña, J.E and León, Javier de. (2012) “An Evaluation of Endogenous Sustainable Development Planning for the Rural-Urban Environment in Gran Canaria". European Planning Studies: 1-17.

Leon, A.M. (2012) "Critiquing Landscape Urbanism" .Economic and Political Weekly, XLVII (7):22-24.

Lipton, M. (2005) "Urban bias". In: T. Forsyth (Eds.). Encyclopedia of international development. London: Routledge: 724-26.

Lynch, Kenneth; Maconachie, Roy; Binns, Tony; Tengbe, Paul and Bangura, Kabba. (2013) "Meeting the urban challenge? Urban agriculture and food security in post-conflict Freetown, Sierra Leone" .Applied Geography, 36: 31-39.

Maansi, P. (2012) "Urban Planning in Bombay (1898-1928)". Economic and Political Weekly, XLVII (28).

Maconachie, R. A and Binns, T. (2006) "Sustainability under threat? The dynamics of environmental change and food production in peri-urban Kano, northern Nigeria" .Land Degrad. Dev, 17 (2):159-171. 
Mahadevia, Darshini (2011) "Branded and Renewed? Policies, Politics and Processes of Urban Development in the Reform Era". Economic \& Political Weekly, 46 (31): 5664.

Makita, K; Fèvre, E.M; Waiswa, C; Bronsvoort, M.D.C; Eisler, M.C and Welburn, S.C. (2010) "Population-dynamics focussed rapid rural mapping and characterisation of the peri-urban interface of Kampala, Uganda". Land Use Policy, 27 (3): 888-897.

Markelova, Helen; Meinzen-Dick; Ruth. Hellin, Jon. and Dohrn, Stephan. (2009) "Collective action for smallholder market access" .Food Policy, 34 (1): 1-7.

Marsden, T.K; R.J.C. Munton; S.J. Whatmore and J.K.Little.(1989) "Strategies for coping in capitalist agriculture; an examination of the response of farm families in British Agriculture". Geoforum, 20(1):1-14

Marshall, F; Lintelo, D.TE and D.S. Bhupal. (2001) "Peri-urban agriculture in Delhi, India. Food Nutrition and Agriculture, UNFAO". Available online: http://www.fao.org/DOCREP/004/Y1931M/Y1931M00.HTM.

McGee, T. G. (2008) "Managing the rural-urban transformation in East Asia in the 21st century”. Sustain. Sci, 3 (1):155-167.

McGregor; Duncan F.M; Adam-Bradford, Andrew Thompson; Donald, A and Simon, David. (2011) "Resource management and agriculture in the peri-urban interface of Kumasi, Ghana: Problems and prospects". Singapore Journal of Tropical Geography, 32 (3): 382-398.

Mettepenningen, Evy; Vandermeulen, V; van Huylenbroeck.Guido; Schuermans, N; van Hecke; Etienne and Messely, Lies et al. (2012) "Exploring Synergies between Place Branding and Agricultural Landscape Management as a Rural Development Practice". Sociologia Ruralis, 52 (4): 432-452.

Moffat, T and Finnis, Elizabeth. (2005) "Considering social and material resources: the political ecology of a peri-urban squatter community in Nepal". Habitat International, 29 (3): 453-468.

Mojid, M.A; Wyseure, G.C.L; Biswas, S.K and Hossain, A.B.M.Z. (2010) "Farmers' perceptions and knowledge in using wastewater for irrigation at twelve peri-urban areas and two sugar mill areas in Bangladesh" .Agricultural Water Management,98 (1):79-86.

Moissidis, Antonis and Duquenne, Marie-Noelle. (1997) "Peri-Urban Rural Areas in Greece: The Case of Attica". Sociologia Ruralis, 37 (2): 228-239.

Morgon, K. (2009) "Feeding the city: The Challenge of Urban Food Planning" .International Planning Studies, 14(4): 341-348 
Morgan, K and Sonnino, R. (2010) "The urban foodscape: World cities and the new food equation, Cambridge". Journal of Regions, Economy and Society (forthcoming).

Midmore, D.J and Jansen, H.G.P. (2003). Supplying vegetables to Asian cities: is there a case for peri-urban production? Food Policy, 28 (1): 13-27.

Myres, G.A. (2010) "Social construction of peri-urban places and alternative planning in Zanzibar". .African Affairs, 109(437):575-595

Narain, V and Nischal, S. (2007) "The peri-urban interface in Shahpur Khurd and Karnera, India”. Environment and Urbanization, 19 (1):261-273.

Narain, V. (2009) "Growing city, shrinking hinterland: land acquisition, transition and conflict in peri-urban Gurgaon, India". Environment and Urbanization, 21 (2):501512.

Nasogkhla, S.T and Sintusingha, S. (2012) "Conflicting Green Landscape Ideologies in a Tai Rural Town in Thailand" .International Journal of Urban and Regional Research, 36(6): 1146-1165.

Neha, Goel. (2011) "Dynamic Planning and Development of Peri-Urban areas, A case of Faridabad City. Institute for Town Planners". Indian Journal, 8 (2-3):15-20.

Nelson, A.C and Sanchez, T.W. (1999) "Debunking the Exurban Myth: A Comparison of Suburban Households" .Housing Policy Debate, 10(3): 689-709.

Nkamleu, G.B and Adesina, A.A. (2000) "Determinants of chemical input use in peri-urban lowland systems: bivariate probit analysis in Cameroon". Agricultural Systems, 63 (2): 111-121.

Nunan, Fiona (2000) "Urban organic waste markets: responding to change in HubliDharwad, India". Habitat International, 24 (3): 347-360.

Olson, Jeffrey L and Munroe, Darla K. (2012) "Natural amenities and rural development in new urban-rural spaces”. Regional Science Policy \& Practice, 4 (4): 355-371.

O’Neill, Karen M; Rudel, Thomas K; McDermott and Melanie, H. (2011) "Why Environmentally Constrained Towns Choose Growth Controls". City \& Community, 10 (2):111-130.

Ooi, Giok Ling. (2009) "Challenges of sustainability for Asian urbanization Current Opinion”. Environmental Sustainability, 1 (2): 187-191.

Pacione, Michael. (1990) "Development pressure in the metropolitan fringe". Land Development Studies, 7 (2): 69-82. 
Packialakshmi, S. K; Ambujam, N and Nelliyat, Prakash. (2011) "Groundwater market and its implications on water resources and agriculture in the southern peri-urban interface, Chennai, India". Environ Dev Sustain, 13 (2):423-438.

Pahl, R. E. (1966) “The Rural-Urban Continuum1”.Sociologia Ruralis, 6 (3):299-329.

Parthasarathy, D. (2013) "Rural, Urban, and Regional: Re-spatializing Capital and Politics in India”. In: Tim Bunnell, D Parthasarathy, and Eric C. (Eds.). London, Blackwell

Paül, V; McKenzie and Fiona H. (2013) "Peri-urban farmland conservation and development of alternative food networks: Insights from a case-study area in metropolitan Barcelona (Catalonia, Spain)". Land Use Policy, 30 (1): 94-105.

Perry, T and Nawaz, R. (2008) "An investigation into the extent and impacts of hard surfacing ofdomestic gardens in an area of Leeds, United Kingdom". Landscape and Urban Planning, 86(1):1-13.

Potter, C and Tilzey, M. (2005) "Agricultural policy discourses in the European post-Fordist transition: neoliberalism, neomercantilism and multifunctionality". Progress in Human Geography, 29 (5): 581-600.

Pierce, John T. (1994) "Towards the Reconstruction of Agriculture: Paths of Change and Adjustment". The Professional Geographer, 46 (2): 178-190.

Pryor, R. J. (1968) “Defining the Rural-Urban Fringe”. Social Forces, 47: 202-215.

Pushpa, A; Phillippe C; Paul A.J; Suresh Kumar R and Hans Schenk. (2005) "Peri-urban Dynamics, Population, Habitat and Environment on the Peripheries of large Indian Metropolise: A review of concepts and General issues". In: Veronique Dupont (Eds.). CSH Occational Paper No.14/2005, de Centre Sciences Humanies, Fresh Research Institute. Rajdhani Art Press, New Delhi, 2005.

Qian, Junxi; Feng, Dan and Zhu, Hong. (2012) "Tourism-driven urbanization in China's small town development: A case study of Zhapo Town, 1986-2003". Habitat International, 36 (1): 152-160.

Raghavendra, Seshagiri. (2006) 'Re-examining the 'low water tariff' hypothesis: lessons from Hyderabad, India". Urban Water Journal, 3:4:235-247.

Rai, Prabhat Kumar (2012) "An eco-sustainable green approach for heavy metals management: two case studies of developing industrial region". Environ Monit Assess 184 (1): 421-448.

Rahul, G and Sunita, G. (2006) "Peri-urban Agriculture and Aquaculture". Economic and Political Weekly, XLI (18); 28-29 
Ramalingegowda, U.C; Srikanthamurthy, P.S; Nagaraj, N and Chandrakanth, M.G. et al. (2012) "Economics of Peri-urban Agriculture: case of Magadi off Bangalore". Economic and Political Weekly, XLVII (2); 20-25

Ramachandraiah, C. (2006) "Inequities in Urban Water Supply in India: Municipalities in Andhra Pradesh". In: Coopey, R. and T. Tvedt. (Eds.). A History of Water, Vol. II-The Political Economy of Water, I. B. Tauris: London, 2006.

Ramachandraiah, C and Sheela Prasad. (2008) "The Makeover of Hyderabad: Is it the 'Model' IT City? In: Ramachandraiah, C; Van Westen, A.C.M and Sheela Prasad. (Eds.). Hi-Tech Urban Spaces: Asian and European Perspectives: 293-318.

Reardon, T. Timmer, P and Berdegue, J. (2004) "The rapid rise of supermarkets in developing countries: induced organizational, institutional, and technological change in agri-food systems". Electronic journal of agricultural and development economics (eJADE), 1 (2):168-183.

Reddy, B and Praveena.T. (2011) "Development versus Livelihoods in peri-urban Hyderabad”. LEISA; India (December): 24-25.

Reddy, R.V and Reddy, S.B. (2007) "Land Alienation and Local Communities: Case Studies in Hyderabad and Secunderabad". Economic and Political Weekly, 42(31): 32333240 .

Renting, H; Rossing, W.A.H; Groot and J.C.van der Pleog. (2009) "Exploring multifunctional agriculture. A review of conceptual approaches and prospects for an integrative transitional framework". Journal of Environmental Management, 90(1): 112-113.

Roberts, R. (1992) "Nature uneven development and the agricultural landscape" In: I.R. Bowler, C.R. Bryant, and M.D. Nelli. (Eds.). "Contemporary Rural Systems in Transition": 119-30. Wallingford: C.A.B. International.

Ruttan, U. (1989) "Institutional innovation and agricultural development". World Development, 17: 1375-87.

Satya, P.M. (2012) "Peri-urban Agriculture in India". Seronica Journal, 3(2):19-27

Schnaiberg, A. (1980) “The Environment: From Surplus to Scarcity”. New York: Oxford University Press.

Seto, Karen C; Sánchez-Rodríguez, Roberto and Fragkias, Michail. (2010) "The New Geography of Contemporary Urbanization and the Environment". Annu. Rev. Environ. Resource, 35 (1): 167-194.

Sharp, J. S and M. B. Smith. (2003) "Social Capital and Farming at the Rural-Urban Interface: the Importance of Nonfarmer and Farmer Relations". Agricultural Systems, 76: 913-927. 
Shaw, Annapurna and Satish, M.K (2007) "Metropolitan restructuring in post-liberalized India: Separating the global and the local". Cities, 24 (2):148-163.

Shukla, G., et al., (2006) "Organochlorine pesticide contamination of ground water in the city of Hyderabad" .Environment international, 32 (2), 244-247.

Siciliano, G. (2012) "Urbanization strategies, rural development and land use changes in China: A multiple-level integrated assessment" .Land Use Policy, 29 (1):165-178.

Simon, David. (2003) "Dilemmas of development and the environment in a globalizing world: theory, policy and praxis". Progress in Development Studies, 3 (1): 5-41.

Sinclair, R. (1967) "Von Thunen and Urban Sprawl". Annals of the Association of American Geographers, 57 (1): 72-87.

Smither, J and Jhonson, P. (2004) "The dynamics of family farming in North Huron County, Ontarion.Part 1. Development Trajectories". The Canadian Geographer, 48(2): 191208.

Sohoni, Milind. (2012) "World Bank's Urban Water Report on India: Thinking Backwards" .Economic\& Political Weekly, 47 (47): 47-48.

Sridhar, K.Sand Surendra Kumar. (2013) "India's Urban Environment; Air/water Pollution Abatment" .Economic and Political Weekly. XLVII (06): 28-32.

Sukesh Narain Sinha, et al. (2012) "Quantification of organophosphate insecticides and herbicides in vegetable samples using the liquid chromatography techniques" .Food chemistry, 132: 1574-1584.

Suresh Kumar, R. (2012) "Water City and Urban Planning: Assessing the role of Groundwater in Urban Development Planning”. CSH Occasional Paper No: 31.

Swathi Chattopadhyay. (2010) “Cities and peripheries".Historical Research, 83(222): 1-23

Swift, J. (1979) "Notes on Traditional Knowledge, Modern Knowledge and Rural Development". IDS Bulletin, 10(2) 41-43

Tacoli, C. (2003) "The links between urban and rural development". Environment and Urbanization, 15 (1), pp. 3-12.

Tacoli, C. (2006) “The Earthscan reader in rural-urban linkages”. London: Earthscan.

Tang, Bo-sin; Wong, Siu-wai and Lee, Anton K.W. (2005) "Green Belt, Countryside Conservation and Local Politics: A Hong Kong Case Study". Rev Urban \& Reg Dev Stud, 17(3): 230-247 
Temple, L. K; Moise, Tetang, J and Bikoi, A. (2011) "Organizational determinant of technological innovation in food agriculture and impacts on sustainable development". Agron. Sustain. Dev, 31 (4): 745-755.

Trauger, A. (2009) "Social agency and networked spatial relations in sustainable agriculture". Area, 41 (2): 117-128.

The New York Times, (2008) "India Grapples with how to convert its farmland into factories". 17 September, A6.

UN-Habitat. (2012) "Urban Patterns for a Green Economy: working with Nature". Online at www.unhabitat.org/pmss/ listItemDetails.aspx? Publication ID=334.

van Dijk, T. (2011) "Networks of Urbanization in Two Indian Cities" .Environment and Urbanization Asia,2 (2): 303-319.

Von Rooijen, D.J and Hung Turrial. (2009) "Urban and industrial water use in the Krishna Basin, India". Irrigation and Drainage, 58(4): 406-428.

Valeria, P.C and Noelia, A.V. (2012) "Agritourism in peri-urban areas: Lessons from a Vegetable Tourism Initiative in the BAIX LLOBEREGAT Agrarian Park (Catlonia)". Cuadernos de Tuisma, 29: 283-288.

Wang, R.S. (2004) “Ecopolis planning of Yongzhou, Chaina” Science and Technology Press, Beijing

Wells, B; Gradwell, S and Yoder, R. (1999) "Growing food, growing community: Community Supported Agriculture in rural Iowa”. Community Development Journal, 34(1): 38-46

Whatmore, S; Munton, R.; Little, J and Marsden, T. (1987). Towards a typology of farm business development in advanced capitalist agriculture. Sociologia Ruralis, 27: 2137

Whebell, C. F. J. (1969) "Corridors: A Theory of Urban Systems". Annals of the Association of American Geographers, 59 (1): 1-26.

Wilson, Geoff A. (2001) "From productivism to post-productivism ... and back again? Exploring the (un)changed natural and mental landscapes of European agriculture". Trans Inst Br Geog, 26 (1):77-102.

Wood, Jolie. (2013) "Protest, Politics, and the Middle Class in Varanasi". Economic \& Political Weekly, forthcoming.

Xie, Y; Batty, M and Zhao, K. (2005)"Stimulating Emergent Urban Form: Desakota in China" CASA working paper, 95, London (Centre for Advance Spatial Analysis, University College, London. 
Yang, Jun and Jinxing, Zhou (2007) "The failure and success of greenbelt program in Beijing”. Urban Forestry \& Urban Greening, 6 (4): 287-296.

Yang, Zhenshan Cai; Jianming and Sliuzas, Richard. (2010) "Agro-tourism enterprises as a form of multi-functional urban agriculture for peri-urban development in China". Habitat International, 34 (4): 374-385.

Yan Shi; Cunwang cheng; Peng Lei; Tijun wen and Caroline, Merrifield. (2011) "Safe food, green food, good food: Chinese Community Supported Agriculture and The Rising Middle Class". International Journal of Agricultural Sustainability, 9(4): 551-558.

Yardley, Jim. (2011) "In India, Dynamism Wrestles with Dysfunction" .New York Times, 8 June.

Yasmeen, G. (2001) "Urban Agriculture in India: A survey of expertise, capacities and recent experience". International Development Research Center (IDRC), South Asia Regional Office, New Delhi, India

Zasada, Ingo. (2011) "Multifunctional peri-urban agriculture - a review of societal demands and the provision of goods and services by farming" .Land Use Policy, 28 (4): 639648. 


\title{
3. Dynamics of peri-urban agricultural development and farmers' adaptive behaviour in the emerging megacity of Hyderabad, India
}

\author{
${ }^{1}$ Zakir Hussain \\ Humboldt University, Berlin \\ Division of cooperative sciences \\ ${ }^{2}$ Markus Hanisch \\ Division of cooperative sciences \\ Humboldt Universität zu, Berlin
}

Published in: Journal of Environmental Planning and Management, 2013

DOI: $10.1080 / 09640568.2012 .751018$

Avalable Online: http://www.tandfonline.com/doi/abs/10.1080/09640568.2012.751018

\begin{abstract}
This paper describes adaptation of agricultural management practices due to structural changes in the urban periphery of Hyderabad, India. We investigate structural-change drivers along with the most common types of adaptation realized by peri-urban farmers and the corresponding environmental impacts. From 120 farmer interviews, in which qualitative and quantitative data was collected, we found that increasing costs for agricultural inputs like labour and land have motivated farmers to intensify water, machine and chemical use, thereby creating problematic environmental impacts. In addition, farmers also resort to parttime farming and organize efforts to share family labour. Based on these findings, we discuss agricultural policies and strategies within the framework of environmental planning and management for the Greater Hyderabad Area (GHA), drawing policy-design conclusions that may enable better integration of farming into the on-going process of megacity development.
\end{abstract}

Keywords: peri-urban agriculture development; farmers' adaptive behaviour; resource use trends, Hyderabad, India 


\subsection{Introdution}

The Urban population across the world is supposed to double from 3.3 billion in 2007 to 6.4 billion by 2050, with concomitant growth of peri-urban areas sharing elements of 'urban' and 'rural' characteristics (Tacoli 2006). The United Nation's Food and Agricultural Organization claims that, in the near future, development of adequate agricultural policies and strategies within the framework of environmental planning and management will become the key challenge for sustainable management of peri-urban agricultural systems (FAO 2007). In the process of megacity expansion, rapidly growing populations are expected to face problems of environmental management and food security. In the periphery, different types of agricultural land users have been needing to adapt farming systems while competing with an increasing number of non-agriculture land users (Robinson 2004). The ways in which agricultural users adapt may have significant implications, not only for the livelihoods but also for the sustainability of people living in both the countryside and cities (Allen 2003).

Levels of unsustainable resource use and environmental degradation in peri-urban areas have raised concerns about their general sustainability (Walker and Salt 2006). It has been argued that peri-urban areas are typically confronted with problems such as resource exploitation and the increase of human-induced greenhouse gas emissions, along with a general loss of resilience and degradation of social capital (Folke et al. 2004). Agricultural producers have to adapt to changing conditions and are important stakeholders in the process of peri-urban development. In combination with urbanisation, the main forces of structural change in agriculture vary. In developed economies agricultural policies are gaining importance as drivers of change (Critchley et al. 2007, Potter and Tilzey 2005), while technological innovation remains another important factor (Cochrane 1993). In Asia and the developing world, technological innovation was long described as the main driver of structural change in agriculture (Hayami and Ruttan 1971). More recently, however, increasing internationalization of processors and retailers and subsequent vertical integration of globalizing agro-food systems have also been described as important drivers of structural change in developing countries. (Reardon Timman and Berdegue 2004; Goodman and Watts 1997). Reddy and Reddy (2007) as well as Zasada et al. (2011), however, show that on the 
fringes ability to adapt also depends on culture, traditions and economic necessities, with migratory movement of displaced low-income fringe-dwellers

Other studies have analysed the impacts of urbanisation, aiming at drawing links between particular peri-urban mitigation strategies and patterns of public and ecosystem health in urban fringe areas. For example, Tzoulas et al. (2007) find that urban peripheries may positively contribute to the urban environment by providing "green lungs" to absorb emissions and help urban residents recuperate from physical and psychological stress. Some authors even draw an optimistic scenario for the interaction between urban centres and their peri-urban environments. For example, in a study of rural-urban relationships in Europe, Buciega et al. (2009) take a closer look at the various meanings of 'rural' and 'rurality' in different European contexts. They find that urban pressure is not necessarily perceived as a negative process by residents of fringe areas and go on to show that, in various European contexts, rather the opposite seems to hold true. In a similar vein, Sharp and Smith (2003) describe a situation in which the development of new types of neighbourly relations and social capital, for example when land-owning agriculturists develop relations with their nonfarm neighbours, may serve as mitigation strategies for otherwise marginalized peri-urban farmers.

\subsection{Urbanisation in Hyderabad}

The Greater Hyderabad Area (GHA) is among South India's fastest growing urban conglomerations. With a population of 6.8 million people (CHPC 2011), the GHA has adopted an "infrastructure-led growth model" (Kennedy 2007). During the last ten years, the state has set in motion a number of infrastructure-based development projects, including a new international airport; "Fab-City", a planned hub for advanced semiconductor and electronics manufacturing, for which the government has dedicated some 1,050 acres of land; as well as an eight-lane outer-ring road of $162 \mathrm{~km}$ in length. Meanwhile, the real estate sector in Greater Hyderabad Area has been experiencing a boom (Reddy and Reddy 2007). Official statistics on land use data pinpoint that, over the last two decades, huge amounts of agricultural land in the Greater Hyderabad Area (GHA) have been reallocated to other sectoral uses (Directorate of Economics and Statistics 2010). This has resulted in the 
emergence of "mixed-spaces" in which agricultural land users directly neighbour land users from other sectors (Dupont et al. 2000). In addition, high land prices are increasingly motivating farmers to sell their land (Krishna Gopal and Simmons 2006; Reddy and Praveena 2010). Despite these challenges, farming remains an important economic activity. In the presence of pressures from urbanisation, many farmers have been changing their farming systems: continuing or even extending agricultural activity and delivering substantial amounts of produce to the urban markets. Before looking at the situation in the Greater Hyderabad Area in more detail, the following section compares concepts explaining how farmers in peri-urban areas generally adapt to urban development.

\subsection{Adaptation behaviour of peri-urban farmers}

As we have suggested, urbanisation can create both threats and opportunities for periurban farms. The literature distinguishes between different concepts seeking to explain scenarios of farm adaptation to factors characteristic of urbanisation. Heimlich and Anderson (2001) distinguish three types of farms according to their relative sensitivity to pressures caused by urbanisation. The "traditional farm types" are characterized by limited factor mobility and slow adaptation to changing environments. "Sensitive farms" are characterized as being most affected by increasing land-use constraints and improved opportunities to sell land, in addition to general fragmentation of production and the threat of government expropriation. "Dynamic" farms are known for their flexibility in changing production patterns and integrating multifunctional elements, including recreation, environmental preservation and landscape conservation functions.

In confronting pressures caused by urbanisation, Smithers and Johnson (2004) describe four likely farm-level trajectories - "growth and decline", "intensification", "persistence" and "de-intensification" - as consequences of changing patterns of land, labour and capital use. Growth and decline describes a scenario in which aggregate increases or decreases in the scale of operation occur, without a fundamental restructuring of the relationship between the main agricultural inputs and the intensity of the production process. Intensification defines a scenario in which the main agricultural inputs, such as labour and capital, are increased. Persistence refers to a status quo-preserving condition. Finally, de- 
intensification characterizes a situationin which agriculture is no longer competitive with other sector uses, and farmers react by reducing their main agricultural inputs, eventually leading to farm closures Bryant and Johnston (1992) classify diversification scenarios as "off-farm diversification", which generally involves increased reliance on non-farm employment to support a household, and "on-farm diversification", characterized by "changes in production practices or management approaches" aimed at minimizing potential nuisance from neighbours. Sharp and Smith (2003) argue that farmer adaptation varies, based on constraints and limitations created by alternative local social settings. For example, based on social capital, farmers can try to develop a relationship with non-farm neighbours to build trust and understanding about potentially offensive farm practices. Another scenario has farmers integrating activities by increasingly cooperating with each other in areas like input use and marketing (Singh 2008).

In what follows, we briefly discuss our main research questions and the way we approached them methodologically, after which we make use of Smithers and Johnson's (2004) scenario description to categorize different scenarios in conjunction with Bryant and Johnston's (1992) observations about farm diversification, in order to better understand developments around the Greater Hyderabad Area. Finally, we draw conclusions and offer suggestions for planning and management of the peri-urban spaces in the GHA.

\subsection{Research questions}

A key issue in current discussions on peri-urban development in Europe and America is the multifunctional nature of peri-urban landscapes, with their market and non-market aspects (Bryant et al. 2007), and adaptation of farms to rapid structural changes. Meanwhile, in India, where our case is situated, discussion of development in the fringe areas is rather dominated by infrastructure and transportation issues, while debate on agricultural policy focuses mainly on food security and self-sufficiency in predominantly rural areas.

The structural change taking place in Indian agriculture has been comparatively slow. For example, the proportion of workers employed in agriculture has fallen by $13 \%$ - from $70 \%$ in 1980 to $57 \%$ in 2005 (Bino et al. 2009) - while, at the same time, the proportion in, 
for example, the UK has fallen by almost $60 \%$, with less than $2 \%$ of the labour force now working in agriculture (Defra 2011). More than $70 \%$ of the agricultural producers in India fall under the category of capital-constrained "marginal farmers" owning less than one hectare of land (Lerche 2011). While peri-urban farmers may be privileged by good infrastructure and market access in regions such as Europe and the USA, in the peri-urban areas of India, higher costs for labour, land rent, and irrigation are known to cause relatively smaller profit margins (Whatmore 2002).

Thus, the structural change process in agriculture in general and the structure of the peri-urban farms in the Greater Hyderabad Area (GHA) in particular widely differ from the examples analysed in studies on peri-urban agricultural development in the developed world. In addition, necessary modernisation in agriculture puts the livelihoods of peri-urban farmers at risk, because they are often credit constrained; seasonal cost structures often result in debts at high interest rates and, consequently, an overall decrease in net profits (Lerche 2011).

Our hypothesis is that, around the city of Hyderabad, structural change in agriculture is not on a sustainable trajectory, because existing small-scale farm structures together with current land price developments have not been following the conventional scenario in which farms grow in size. This discrepancy has raised several research questions for us, to be addressed in the following sections:

- How does the growth of cities affect structural changes of agricultural production in terms of choosing crops, scale of production or technologies in use?

- What are the causes and effects of the most common types of adaptation behaviour of farmers in Greater Hyderabad Area?

- Can we draw a link between agricultural development and sustainability in this context?

\subsection{Research method}

Our study aims to identify farmer adaptations as well as changes in land use practices with respect to urbanisation. The official data on land use changes in the GHA indicates that urbanisation and related infrastructure projects reached their maximum between 2004 and 
2006, accompanied by a particularly steep hike in land prices (Department of Stamps and Registration, Government of Andhra Pradesh, 2008). Our aim has been to further explore this general hypothesis and specify some of the causalities and changes in farm management practices that took place both during and after this period

For this purpose, during two field visits in 2011, we collected qualitative and quantitative data through semi-structured surveys with the main aim being to better understand adaptation of farm structures within the GHA. Our sample is a purposive one, including both farmers and experts and exploring administrative areas within the GHA in which the consequences of urbanisation clearly have impacts on agriculture. Quantitative data targeted measurable components of these changes, such as the cost of production and use of major agricultural inputs. Qualitative data targeted the farmers' main perceptions on drivers of change.

Altogether, we interviewed 120 farmers from eight administrative areas (mandals) in Andhra Pradesh - the Indian federal state of which Hyderabad is the capital - by randomly selecting 15 candidates from a list of farmers registered in each mandal. In addition, we consulted local agricultural extension officers, input agencies, and other key informants in the villages to check the validity of data obtained from farmers on input use, cropping patterns and overall village trends. To sample the peri-urban mandals in GHA, we defined four criteria: agricultural activity, distance to the city centre, land prices, and medium to high intensity of paddy- or vegetable-based cropping patterns. The sampling relied on the village list of the Hyderabad Municipal Development Authority (HMDA), which lists 55 mandals in GHA, including four peripheral surrounding districts: Ranga Reddy (22 mandals), Nalgonda (five mandals), Medak (10mandals) and Mahaboobnagar (two mandals). We selected five mandals from Ranga Reddy, two mandals from Nalgonda and one from Medak. In Mahaboobnagar, however, the intensity of cultivation and level of urbanisation are relatively low, making it a candidate in which the problems mentioned in the introduction appear to be less imminent, so we excluded it from our study.

Selected administrative areas in the GHA exhibit intense agricultural activity combined with a vegetable- or paddy-based cropping pattern, within a radius of $50 \mathrm{~km}$ to the city centre. Following the advice of regional agricultural officers, we also incorporated two 
mandals with particular characteristics to understand how favourable marketing infrastructure (Mulugu) or full availability of (waste-) water (Pochampalli) affected farmer perceptions about the profitability of agriculture. Thus, our sample seeks to provide a window on the current problems of urbanisation on agricultural activities in the GHA, rather than representing the 22 administrative areas themselves.

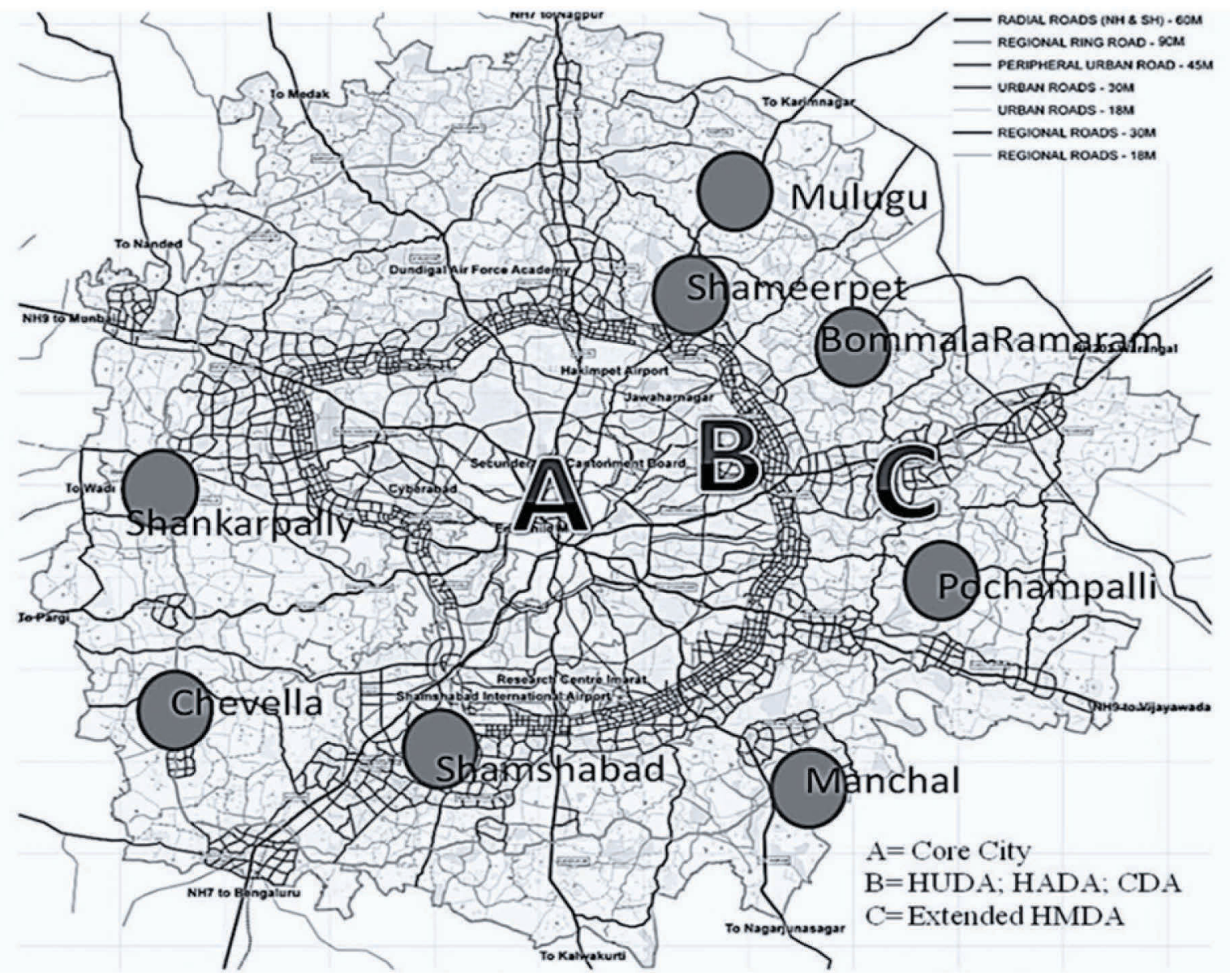

Figure 3-1: Map indicating mandals selected for study in GHA

Source: Draft metropolitan development plan, 2031, Hyderabad Metropolitan Region 
Table 3-1: Characteristics of selected administrative areas in GHA

\begin{tabular}{|c|c|c|c|c|c|c|c|c|}
\hline & \multicolumn{5}{|c|}{ Ranga Reddy } & \multirow{2}{*}{$\begin{array}{l}\text { Medak } \\
\text { Mulugu }\end{array}$} & \multicolumn{2}{|l|}{ Nalgonda } \\
\hline & Shameerpet & Shamshabad & Shankarpally & Chevella & Manchal & & B.Ramaram & Pochampalli \\
\hline $\begin{array}{l}\text { Dist. from } \\
\text { the city }(\mathrm{km})\end{array}$ & 28 & 23 & 30 & 45 & 42 & 48 & 42 & 42 \\
\hline Households & 18348 & 14118 & 11409 & 10765 & 8620 & 8178 & 7167 & 9446 \\
\hline Population & 42179 & 55784 & 85291 & 72292 & 55483 & 39827 & 44379 & 34114 \\
\hline $\begin{array}{l}\text { Decadal } \\
\text { population } \\
\text { growth* }\end{array}$ & 54.14 & 21.24 & 10.78 & 11.69 & 13.69 & 11.24 & 13.88 & 12.33 \\
\hline Cultivators & 4519 & 17661 & 5600 & 7259 & 12230 & 8335 & 6010 & 10371 \\
\hline $\begin{array}{l}\text { Geographical } \\
\text { area (ha) }\end{array}$ & 25495 & 19290 & 20482 & 27374 & 27705 & 19479 & 17083 & 19369 \\
\hline $\begin{array}{l}\text { Agricultural } \\
\text { area (ha) }\end{array}$ & 4610 & 2844 & 8445 & 7215 & 4986 & 6559 & 2773 & 3486 \\
\hline $\begin{array}{l}\text { Production } \\
\text { intensity }\end{array}$ & $\begin{array}{l}\text { Intensive } \\
\text { veg. } \\
\text { production } \\
\text { area }\end{array}$ & $\begin{array}{l}\text { Intensive } \\
\text { veg. } \\
\text { production } \\
\text { area }\end{array}$ & $\begin{array}{l}\text { Intensive } \\
\text { veg. } \\
\text { production } \\
\text { area }\end{array}$ & $\begin{array}{l}\text { Medium } \\
\text { to high } \\
\text { intensive } \\
\text { veg. and } \\
\text { paddy } \\
\text { growing } \\
\text { area }\end{array}$ & $\begin{array}{l}\text { Low to } \\
\text { medium } \\
\text { intensive } \\
\text { veg. } \\
\text { growing } \\
\text { area }\end{array}$ & $\begin{array}{l}\text { High } \\
\text { intensive } \\
\text { veg } \\
\text { growing } \\
\text { area }\end{array}$ & $\begin{array}{l}\text { Medium } \\
\text { intensity veg } \\
\text { +paddy } \\
\text { growing } \\
\text { area }\end{array}$ & $\begin{array}{l}\text { High intensity } \\
\text { paddy+ veg. } \\
\text { growing area } \\
\text { with waste water } \\
\text { use }\end{array}$ \\
\hline
\end{tabular}

Source: District Handbooks of Statistics, Ranga Reddy, Nalgonda and Medak, 2007. 
Table 3-1 indicates approximate distances from Hyderabad city to the selected study locations, along with corresponding factors causing pressure on their agricultural land users. We asked farmers to assess and rank the importance of variables such as the development of land prices, land rents, farm profits, input costs, labour costs and other problems related to on-going structural changes in the agricultural sector. In addition, based on a list of adaptation scenarios related to the literature discussed above, we asked farmers about their perceptions regarding the continuity and profitability of agriculture within urban fringe areas, their main adaptation strategies, and related consequences that they saw for the sustainability of periurban farming.

The next sections of this paper describe the main drivers of change, observable adaptation scenarios and relevant examples of the impacts of urbanisation on agriculture in the GHA. As primary drivers of change, we first describe the actual rates and scales of urbanisation, effective demographic changes and population pressures, land and labour prices and lease rates, as well as the profitability of important crops over time. Then, we analyse adaptation scenarios, specifically addressing farmers' willingness to continue agriculture as their main activity, increase of cooperation among farmers in terms of exchange of family labour, and upcoming mechanization trends. Finally, we exemplify the effects of production system adaptation with regard to the sustainability of resource use and draw conclusions for agricultural policy and urban planning.

\subsection{Causes and effects of urbanization on agriculture}

\subsubsection{Main drivers of change}

Our socio-economic data allows us to characterize the respondents, peri-urban farmers of the GHA, as follows: Agriculture is the main source of income for $84 \%$ of the interviewees and $8.3 \%$ of them work as both farmers and as hired agricultural labourers. Education levels among the farmers in the selected mandals range from primary to high school. The average age of the respondents is between 35 and 50 years, with an average farming experience of 20 years. Farmers own an average of 2.4 ha of arable land, of which 1.56 ha is cultivated. The remaining land ( 0.84 ha on average) is left as fallow or dry land, where farmers eventually 
grow crops depending on water availability and rainfall. Overall, the 120 farmers interviewed can be characterized as middle-aged, experienced, small-plot agriculturalists that derive their main income from agriculture. The following subsections describe the main drivers of change to which these peri-urban farmers have to respond.

\subsubsection{Population pressure}

Hyderabad city ranks as the sixth largest urban agglomeration in India. Between 1981 and 2001, it had decadal growth rates of 50 and 27\%, respectively. Over the past decade, Hyderabad kept growing at a rate of almost $2 \%$ per year, reaching a total of 6.8 million inhabitants at the end of 2011 (CHPC 2011). The Hyderabad Master Plan, which is the main planning concept of the GHA, indicates that "most of the previous decade's population growth has taken place away from the city core" (JNNURM 2010). Thus, urbanisation within the fringe areas is one important driver triggering the kinds of changes in peri-urban agriculture described in the following subsections.

\subsubsection{High land prices}

Land prices are important drivers of agricultural change. The main factors behind increasing prices are city development-linked land acquisitions. Together with speculation by real estate agents, this has led to a steep increase in land prices in the GHA.For example, farmers in the village of Jaganguda (in Shameerpet mandal, $20 \mathrm{~km}$ north of the city) report that, until the year 2000, agricultural land prices were about USD 550/ha, but when use changed to building land, its value increased to more than USD 20,000 USD/ha during 2003. Similarly, farmers claim that land prices in Shamshabad (a mandal $23 \mathrm{~km}$ from the city centre) were about USD 220/ha during 2004, but due to inception of the new international airport, land prices reached some USD 70,000 per ha during 2006. A closer look at the official statistics on land sales and achieved market values shows that land prices in all of the sampled mandals have increased dramatically since 2003. 
Table 3-2: Agricultural land value (USD/Ha) in selected administrative units

\begin{tabular}{lllll}
\hline & \multicolumn{3}{l}{ June 2004 } & \multicolumn{3}{l}{ September 2009 } \\
\cline { 2 - 5 } Administrative Unit & Min & Max & Min & Max \\
\hline Shamshabad & 970.55 & $1,294.97$ & $172,543.95$ & $280,383.92$ \\
Shameerpet & 647.03 & $6,49.01$ & $237,249.93$ & $258,815.92$ \\
Chevella & $970: 55$ & $1,401: 91$ & $10,783.99$ & $53,919.98$ \\
Shankarpally & 829.21 & $1,294.07$ & $43,135.90$ & $64,703.98$ \\
Manchal & 647.03 & $1,078.39$ & $32,352.10$ & $43,136.10$ \\
Mulugu & $1,078.39$ & $1,105.43$ & $53,919.90$ & $75,487.97$ \\
B.Ramaram & 647.03 & $1,294.07$ & $25,881.59$ & $43,135.98$ \\
Pochampalli & 970.55 & $1,401.91$ & $53,919.98$ & $64,703.98$ \\
\hline
\end{tabular}

Source: Dept. Stamps and Registrations, Government of AP, www.igrs.ap.gov.in

\subsubsection{Agricultural land consumption}

In the period between 2002 and 2007, across the 20 mandals of the peripheral district of Ranga Reddy, urbanisation has absorbed about 90,000 ha of land. The official data on Land put to Non-agriculture use (LNA) in Ranga Reddy, reveals that over the last two decades there has been considerable increase in LNA, from 77,942 ha in the 1990s to about 100,000 ha in 2008 (Directorate of Economics and Statistics, Hyderabad 2010). In 2010, only $10 \%$ of the total area of Ranga Reddy (230,000 ha) remained under cultivation. Similar developments are ongoing in the other districts. Official data indicates that, until 2007, in the district of Nalgonda 109,964 ha had been put to Non-Agricultural Use (NAU), and in the Medak district 66,055 ha had been put to NAU, with 30 to $40 \%$ of the land converted to realestate in the peripheral mandals of the city (Hand Book of District Statistics Nalgonda and Medak 2007).

\subsubsection{Land tenancy rates and in-migration}

Land prices have not only affected land sales. Along with pushing up land prices, urbanisation has also increased the rates of agricultural land tenancy in the GHA. Our data 
(Table 3-3) reveals that urban growth and the land market have not been the only factors affecting tenancy rates.

Table 3-3: Tenancy rates/ha in different administrative units of GHA

\begin{tabular}{|c|c|c|c|c|c|}
\hline \multirow[b]{3}{*}{$\begin{array}{l}\text { Administrative } \\
\text { unit }\end{array}$} & \multirow[b]{3}{*}{$\mathrm{N}$} & \multicolumn{4}{|c|}{ Tenancy rates (USD/ha) } \\
\hline & & \multicolumn{2}{|c|}{ June 2004} & \multicolumn{2}{|c|}{ September 2009} \\
\hline & & Mean & SD & Mean & SD \\
\hline B. Ramaram & 15 & 44.40 & 7.953 & 126 & 33.67 \\
\hline Chevella & 15 & 40.80 & 7.504 & 137.07 & 39.347 \\
\hline Manchal & 15 & 33.00 & 14.298 & 99.67 & 33.410 \\
\hline Mulugu’ & 15 & 54.75 & 14.079 & 122.14 & 17.549 \\
\hline Pochampalli & 15 & 43.20 & 9.741 & 130.40 & 36.795 \\
\hline Shameerpet & 15 & 48.20 & 31.474 & 119.60 & 61.966 \\
\hline Shamshabad & 15 & 47.08 & 10.492 & 149.97 & 42.816 \\
\hline Shankarpally & 15 & 54.00 & 16.016 & 131.62 & 19.132 \\
\hline Total $(\mathrm{N}=120)$ & 120 & 45.27 & 16.689 & 126.63 & 39.330 \\
\hline
\end{tabular}

Source: Survey data, 2011

Increasing demand for fresh food and vegetables in the ever-growing city is also attracting tenants from coastal districts of Andhra Pradesh, and more and more land is being rented for commercial farming. New tenants have in-migrated from places like East and West Godavari in Andhra Pradesh. One out of five vegetable growers in the GHA is a tenant farmer who pays land rent to the land- owner . Contract types for tenants range from fixed payments for agricultural labour to sharecropping and last usually 1-2 seasons. These shorttermed arrangements are known to carry problems like "land shirking", depletion of land fertility and unsustainable water use (Barzel 1989), with lasting consequences for the environment, the sustainability of farm incomes and profitability. 


\subsubsection{Decreasing farm incomes}

Not only competition for land has been driving structural changes in peri-urban agriculture. In addition, costs for other agricultural inputs like fertilizers, seeds and labour have increased, thus reducing farmer incomes. This observation not only holds true for paddy production, in which a minimum price system aims at stabilizing producer prices; also, over the last decade the farmers of our sample have experienced dramatic increases of input prices in vegetable production. In addition, other sectors are competing with agriculture on the local labour market. Many formerly agricultural labourers are now working in the construction industry, where they can realize higher incomes.

Table 3-4 provides examples of shrinking profitability in eggplant and cabbage production, Table 3-5 exemplifies cost structures for paddy cultivation. In our sample, the total costs for cabbage and paddy production almost doubled during the period 2003-2009, while the cost of eggplant production went up by about $30 \%$. Although the demand for fresh vegetables is increasing along with Hyderabad consumer prices, the development of prices cannot compensate the rise of input cost for farmers. Our data on production cost for paddy imply that increases in labour costs combined with rising input prices have been the main factors reducing agricultural profitability. 


\begin{tabular}{llll}
\hline Crop & Particulars & June 2004 & September 2009 \\
\hline Eggplant & Total cost (USD) & 148.85 & 178.82 \\
$\mathrm{~N}=20$ & Yield (Mt/ha) & 0.80 & 1.00 \\
& Price/Mt (USD) & 36.80 & 46.00 \\
& Gross income (USD) & 294.40 & 460.00 \\
& Net income (USD) & 115.55 & 127.18 \\
& Benefit cost ratio & 1.54 & 1.17 \\
Cabbage & Total cost (USD) & 139.10 & 282.62 \\
$\mathrm{~N}=20$ & Yield (Mt/ha) & 0.70 & 0.70 \\
& Price/Mt (USD) & 128.80 & 147.20 \\
& Gross income(USD) & 360.64 & 412.16 \\
& Net income (USD) & 221.54 & 129.54 \\
& Benefit cost ratio & 2.59 & 1.45 \\
\hline
\end{tabular}

Table 3-4: Economics of production for peri-urban vegetables

Source: Survey data, 2011

Table 3-5: Average costs for inputs in Paddy production and revenues (USD/Ha)

\begin{tabular}{lll}
\hline $\mathbf{N = 1 2 0}$ & June 2004 & September 2009 \\
\hline Land preparation & 40.97 & 86.27 \\
Sowing/trans & 18.97 & 53.91 \\
Seeds & 7.98 & 21.56 \\
Fertilizers & 49.82 & 53.91 \\
Fertilizer application & 2.15 & 10.78 \\
Pesticides & 15.31 & 32.35 \\
Spraying cost & 5.17 & 10.78 \\
Weedicides & 0.00 & 12.94 \\
Weeding & 12.94 & 64.37 \\
Harvesting (machines) & 0.00 & 32.18 \\
Harvesting (labour) & 41.84 & 0.00 \\
Transport & 8.15 & 10.72 \\
Other & 9.87 & 42.91
\end{tabular}




\begin{tabular}{lll}
\hline $\mathbf{N = 1 2 0}$ & June 2004 & September 2009 \\
\hline Total Expenditure & 213.7 & 432.68 \\
Yield (tons) & 2.3 & 2.4 \\
Price/ton & 139.4 & 214.59 \\
Gross income & 320.62 & 515.01 \\
Net income & 106.92 & 82.33 \\
Cost benefit ratio & 1.5 & 1.19 \\
\hline
\end{tabular}

Source: Survey data, 2011

\subsection{Farmer perceptions on profitability and sustainability in peri-urban farming}

Asking farmers about their perceptions concerning developments in farm profitability over the last decade, we received mixed results: For $54.2 \%$ of our respondents, agriculture has been profitable, though with narrowing margins, while the rest feel that it has not $(45.8 \%)$. Answers of farmers did not differ in mandals in which the marketing infrastructure is particularly good or in which there is full water availability for irrigation from the Musi River (Mulugu and Pochampalli, respectively).

With a simple ranking exercise, we asked the farmers in our sample about their perceptions regarding typical problems of agriculture in the GHA with respect to farm profitability and the main factors reducing it. More than $90 \%$ of the farmers ranked scarcity of farm labour followed by increased production costs as the two most important factors reducing farm incomes. Water scarcity and restricted access to finance take third and fourth positions among the most relevant problems. Over $78.3 \%$ stated that agriculture is the main livelihood option for them. Surprisingly, although farming in the GHA has become increasingly difficult, a great majority $(94.1 \%)$ of respondents still wishes to continue with agriculture. The main reasons given for justifying their commitment to agricultural production were: lack of stable income opportunities in other areas, contribution of agriculture to household subsistence, household immobility, traditional value of agriculture in their families and specific knowledge accumulated over generations in their families. 
Decreasing availability of agricultural land and lack of livestock in the fringe areas has resulted in a production system which is increasingly disintegrated from the local agricultural area. For example the average farm yard manure applied in the entire study area is 11.4 metric tons per hectare annually, of which farmers have to buy the major share $(11.32$ metric tons) from the rural areas.

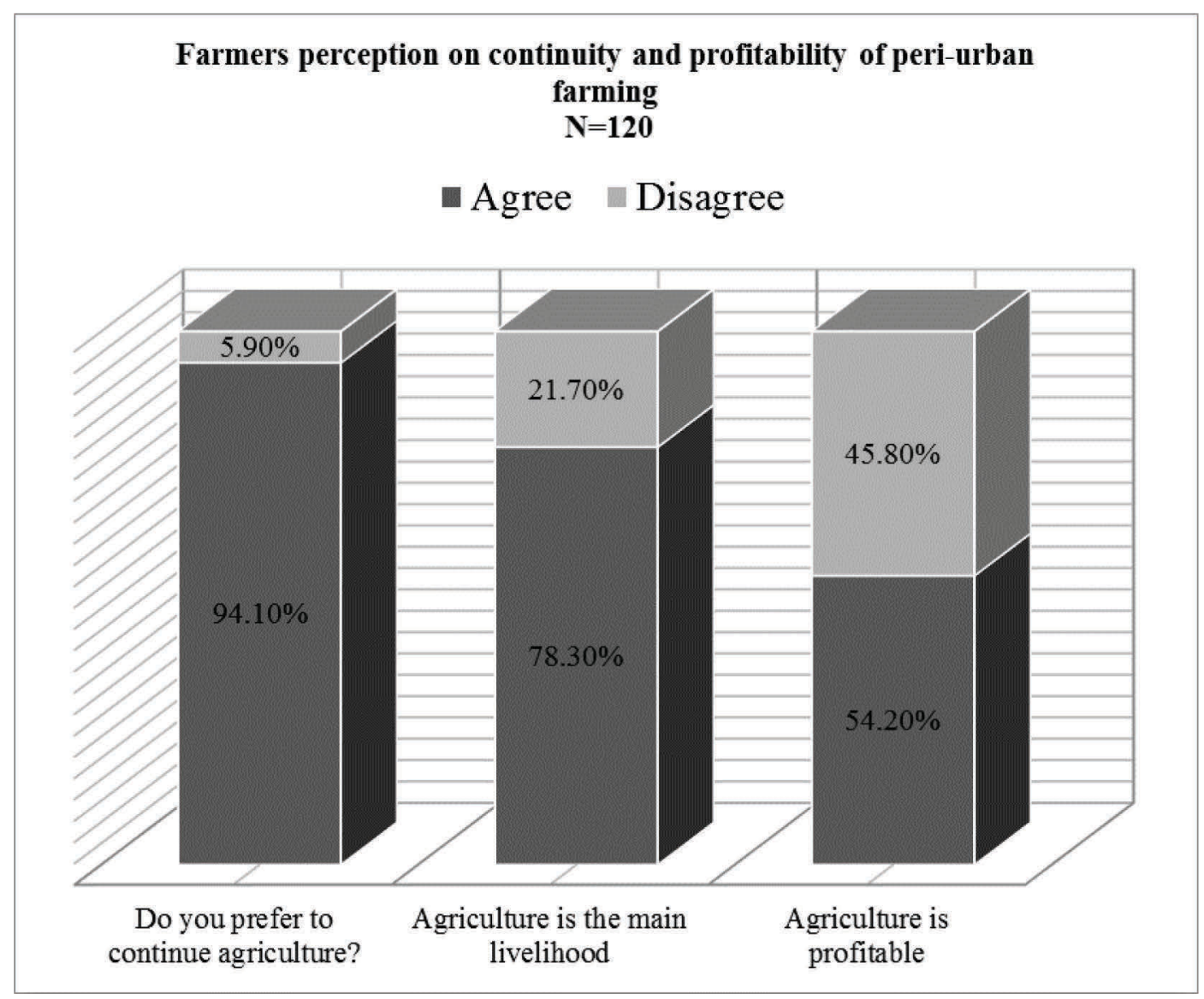

Figure 3-2: Farmers' perception on continuity and profitability of PUA

\subsection{Farm adaptations}

In the situation described, farmer adaptation strategies have not followed a generalizable pattern. Farmers in the GHA have been reacting to urbanisation with a mix of diverse strategies, including changes in cropping patterns, intensification of input use, parttime farming and participation in government schemes, selling land, increased mechanization and cooperation on the market for farm and family-farm labour. However, in the urban fringe 
areas, typical strategies of structural change in agriculture, such as further intensification of production and realizing scale economies by increasing farm size, are clearly limited. Over the last decade, farm size has remained pretty stable in most of the selected mandals, in some areas they have even decreased.

\subsubsection{Sharing family labour}

Our sample shows that, on average, only half of family members are working onfarm, while the others have often migrated to the city or are too young to work. For example, the village head of Cheededu, in the Ranga Reddy district, reports that nearly 100 families from that village and neighbouring areas have migrated to the city and have found work in the construction industry. Land has often been sold to real estate agents and speculators. For those remaining in agriculture, intensification and switching towards vegetable production are direct consequences of the increasing cost for agricultural labour. Sharing family labour during the crop season is a long-standing tradition among villagers of homogeneous ethnicity and origin in rural India (Narain, 2003). In the presence of labour scarcity, farmers in the GHA, though increasingly belonging to different ethnicities and origins, are beginning to share family labour in organized ways.

Focus group discussion with farmers in Cheededu and Rangapur, two villages within a radius of $35 \mathrm{~km}$ from the city, exemplify how cooperation came into being. These farmers mainly grow crops like paddy, vegetables, castor and jowar (sorghum). Over the last decade, the rates for hired labour have gone up, from USD 2/day to around USD 4.55 /day, in this area.

Farmers collectively plan their two growing seasons by means of a sowing calendar. In a cropping season of 120 days, for example, participating farmers in Cheededu allocate 60 days for work on their own farms, 30 days for working in other farmers' fields and 30 days for agricultural contract work. However, this kind of s haring is not uniformly applied in all the GHA villages. 


\subsubsection{Changing cropping patterns}

The reasons for changes in cropping patterns are diverse. Increasing urban demand for vegetables is often referred to as a major economic factor causing changes (Parthasarathy et al. 2008). Data from official statistics (Directorate of Economics and Statistics, Hyderabad 2010) confirm that, for example, paddy cultivation has witnessed a steep fall during the period 2001 to 2008, in particular in Ranga Reddy, where paddy production has declined by $50 \%$ (District Hand Book of Statistics, Ranga Reddy 2009). On one hand, increasing input costs and falling groundwater levels related to heavy extraction are often mentioned as primary factors for this decline. On the other hand, we have also observed increases in paddy production as an adaptation strategy in areas in which farmers are resuming subsistence production after having sold parts of their land (Shamshabad). In fact, a steep rise in paddy has occurred in the mandal of Pochampalli, because Musi River waste-water irrigation has become

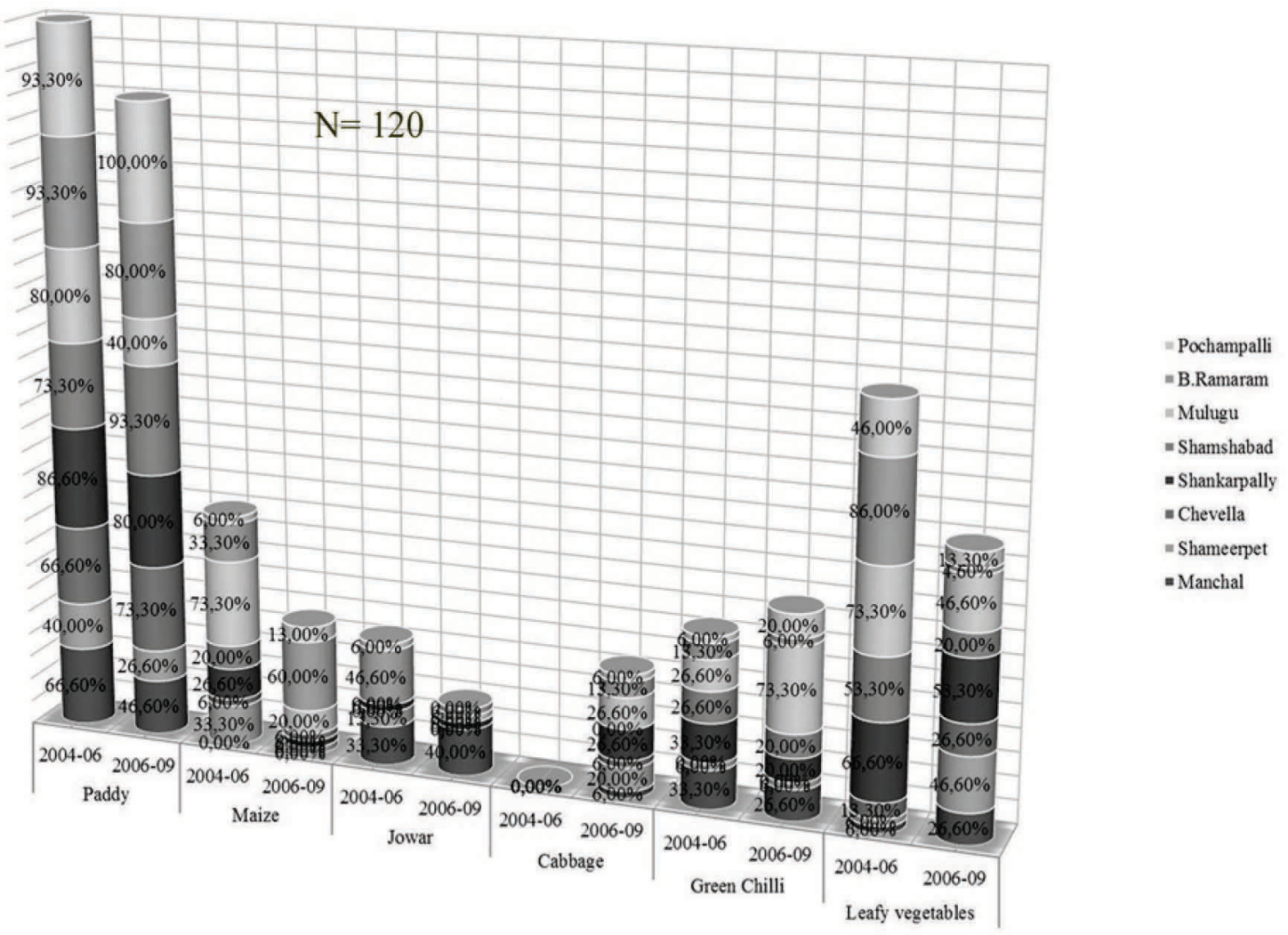

Figure 3-3: Cropping pattern changes in PUA 
available for farming. Urbanisation has adversely affected grape cultivation in the GHA. Until 2005, the Greater Hyderabad Area used to be the hub of grape cultivation in the region, with a total of 12,000 ha planted. But the land speculation and production constraints already outlined have prompted the farmers to sell most of their grape gardens, so that today only 5,000 hectares are being used for grape production.

\subsubsection{Intensification}

A general trend towards intensification of labour and input use can also be observed. Along with a change in cropping patterns our own observations document a growing trend in the number of pesticide applications to crops: from three to five sprays on food crops to a maximum of 45 sprays on vegetables, per season. For reasons explained below, farmers apply more on vegetables, often spraying indiscriminately on alternate days.

Table 3-1: Pesticide use in GHA (Number of sprays/Ha)

\begin{tabular}{|c|c|c|c|c|c|c|c|c|c|c|c|c|}
\hline \multirow[t]{3}{*}{ Mandals } & \multicolumn{4}{|c|}{ Food crops } & \multicolumn{4}{|c|}{ Commercial crops } & \multicolumn{4}{|c|}{ Vegetables } \\
\hline & \multicolumn{2}{|c|}{ June 2004} & \multicolumn{2}{|c|}{ Sept. 2009} & \multicolumn{2}{|c|}{ June 2004} & \multicolumn{2}{|c|}{ Sept. 2009} & \multicolumn{2}{|c|}{ June 2004} & \multicolumn{2}{|c|}{ Sept. 2009} \\
\hline & $\begin{array}{l}\text { Mea } \\
\mathrm{n}\end{array}$ & $\mathrm{SD}$ & $\begin{array}{l}\text { Mea } \\
\mathrm{n}\end{array}$ & $\mathrm{SD}$ & $\begin{array}{l}\text { Mea } \\
\mathrm{n}\end{array}$ & $\mathrm{SD}$ & $\begin{array}{l}\text { Mea } \\
\mathrm{n}\end{array}$ & $\mathrm{SD}$ & $\begin{array}{l}\text { Mea } \\
\mathrm{n}\end{array}$ & $\mathrm{SD}$ & $\begin{array}{l}\text { Mea } \\
n\end{array}$ & SD \\
\hline $\begin{array}{l}\text { B. } \\
\text { Ramaram }\end{array}$ & 1.07 & $\begin{array}{l}0.2 \\
6\end{array}$ & 2.21 & $\begin{array}{l}0.5 \\
8\end{array}$ & 3.40 & $\begin{array}{l}0.9 \\
1\end{array}$ & 6.25 & $\begin{array}{l}1.2 \\
5\end{array}$ & $\begin{array}{l}10.4 \\
7\end{array}$ & $\begin{array}{l}5.7 \\
4\end{array}$ & $\begin{array}{l}20.4 \\
9\end{array}$ & $\begin{array}{l}9.8 \\
9\end{array}$ \\
\hline Chevella & 2.20 & $\begin{array}{l}0.4 \\
1\end{array}$ & 4.73 & $\begin{array}{l}0.4 \\
6\end{array}$ & 3.80 & $\begin{array}{l}0.6 \\
8\end{array}$ & 9.20 & $\begin{array}{l}1.2 \\
7\end{array}$ & 5.00 & $\begin{array}{l}1.2 \\
5\end{array}$ & $\begin{array}{l}10.4 \\
0\end{array}$ & $\begin{array}{l}6.0 \\
0\end{array}$ \\
\hline Manchal & 2.07 & $\begin{array}{l}0.8 \\
8\end{array}$ & 3.47 & $\begin{array}{l}0.9 \\
2\end{array}$ & 4.00 & $\begin{array}{l}2.2 \\
7\end{array}$ & 6.20 & $\begin{array}{l}2.2 \\
1\end{array}$ & 6.00 & $\begin{array}{l}3.3 \\
8\end{array}$ & $\begin{array}{l}12.9 \\
3\end{array}$ & $\begin{array}{l}6.9 \\
1\end{array}$ \\
\hline Mulugu & 1.80 & $\begin{array}{l}0.5 \\
6\end{array}$ & 2.80 & $\begin{array}{l}0.5 \\
6\end{array}$ & 3.18 & $\begin{array}{l}0.9 \\
8\end{array}$ & 5.36 & $\begin{array}{l}1.2 \\
9\end{array}$ & 6.40 & $\begin{array}{l}2.7 \\
2\end{array}$ & $\begin{array}{l}19.1 \\
3\end{array}$ & $\begin{array}{l}6.9 \\
0\end{array}$ \\
\hline $\begin{array}{l}\text { Pochampal } \\
\text { li }\end{array}$ & 1.47 & $\begin{array}{l}0.5 \\
2\end{array}$ & 2.60 & $\begin{array}{l}0.6 \\
3\end{array}$ & 3.80 & $\begin{array}{l}1.3 \\
2\end{array}$ & 6.60 & $\begin{array}{l}1.5 \\
5\end{array}$ & 9.60 & $\begin{array}{l}7.1 \\
4\end{array}$ & $\begin{array}{l}14.2 \\
7\end{array}$ & $\begin{array}{l}7.8 \\
5\end{array}$ \\
\hline $\begin{array}{l}\text { Shameerpe } \\
\mathrm{t}\end{array}$ & 2.60 & $\begin{array}{l}0.9 \\
9\end{array}$ & 3.60 & $\begin{array}{l}0.5 \\
1\end{array}$ & 4.67 & $\begin{array}{l}2.2 \\
6\end{array}$ & 7.47 & $\begin{array}{l}2.3 \\
6\end{array}$ & 6.47 & $\begin{array}{l}2.9 \\
5\end{array}$ & $\begin{array}{l}17.4 \\
7\end{array}$ & $\begin{array}{l}5.2 \\
5\end{array}$ \\
\hline $\begin{array}{l}\text { Shamshab } \\
\text { ad }\end{array}$ & 1.40 & $\begin{array}{l}0.5 \\
2\end{array}$ & 2.60 & $\begin{array}{l}0.5 \\
2\end{array}$ & 4.30 & $\begin{array}{l}1.1 \\
6\end{array}$ & 7.20 & $\begin{array}{l}1.6 \\
2\end{array}$ & 9.20 & $\begin{array}{l}3.4 \\
6\end{array}$ & $\begin{array}{l}24.2 \\
0\end{array}$ & $\begin{array}{l}8.7 \\
4\end{array}$ \\
\hline $\begin{array}{l}\text { Shankarpal } \\
\text { ly }\end{array}$ & 1.86 & $\begin{array}{l}0.6 \\
6\end{array}$ & 3.00 & $\begin{array}{l}0.7 \\
8\end{array}$ & 3.30 & $\begin{array}{l}0.9 \\
5\end{array}$ & 6.10 & $\begin{array}{l}2.3 \\
3\end{array}$ & 7.47 & $\begin{array}{l}4.4 \\
5\end{array}$ & $\begin{array}{l}22.1 \\
3\end{array}$ & $\begin{array}{l}7.0 \\
5\end{array}$ \\
\hline $\begin{array}{l}\text { Total } \\
(\mathrm{N}=120)\end{array}$ & 1.82 & $\begin{array}{l}0.8 \\
0\end{array}$ & 3.18 & $\begin{array}{l}1.0 \\
0\end{array}$ & 3.89 & $\begin{array}{l}1.5 \\
5\end{array}$ & 6.95 & $\begin{array}{l}2.0 \\
3\end{array}$ & 7.51 & $\begin{array}{l}4.5 \\
8\end{array}$ & $\begin{array}{l}17.8 \\
2\end{array}$ & $\begin{array}{l}7.9 \\
9\end{array}$ \\
\hline
\end{tabular}

Source: Survey data 
To support our observations, an interview with an input dealer in Vantimamidi (Mulugu) underlines that, during the last five years, annual sales of pesticides have increased at least by $30 \%$ in this region. The increasing use of pesticides is a major concern in the GHA. Spraying herbicides and pesticides has become a panacea among farmers, due to lack of proper guidance from extension services. The application of pesticides often exceeds recommended doses, because farmers cannot afford to lose their crops. Our interview partner - an agriculture officer in Shameerpet - gave examples from his region. For example, she found that farmers use on average $1.8 \mathrm{lit} / \mathrm{ha}$ of the insecticide Endosulfan, although the recommended dose is only 1 lit/ha; similarly, they often spray Monocrotophos - an insecticide known for its toxic impact on birds and humans - at a dose of 2 lit/ha, when the recommended dose is only $0.75 \mathrm{lit} / \mathrm{ha}$.

Table 3-7: Fertilizer use in GHA peri-urban farming (Number of Bags/Ha; 1 bag=50Kg)

\begin{tabular}{lllllll}
\hline $\mathbf{N = 1 2 0}$ & \multicolumn{2}{l}{ Food crops } & \multicolumn{2}{l}{ Commercial crops } & \multicolumn{2}{l}{ Vegetables } \\
\hline \multirow{2}{*}{ Mean } & June & Sept. & June & Sept. & June & Sept. \\
Range & 2004 & 2009 & 2004 & 2009 & 2004 & 2009 \\
\cline { 2 - 7 } SD & 1.658 & 2.267 & 2.304 & 3.529 & 3.475 & 6.263 \\
\hline
\end{tabular}

Source: Survey data, 2011

The data on fertilizer use changes by farmers indicate that fertilizer use has dramatically increased for all crops within the GHA and is replacing the use of farm yard manure. In Table 3-7 our data show that the usage of fertilizer in, for example, vegetable production has almost doubled, though it has increased to a lesser extend in commercial and food crops.

Notably, the farmers' dominant perspective is that, "if they do not use fertilizers they won't harvest a better yield", even though most of them know that "indiscriminate use" is harmful to soil health and groundwater. As mentioned above, Farm Yard Manure (FYM) has become a scarce resource in the Greater Hyderabad Area. Our data from farmer interviews document an increasing trend of herbicide use for almost all crops from 2004-2009. Prior to 
2000, farmers of the region were rather reluctant to apply herbicides on food crops, but due to increasing labour shortages they have started to apply herbicides to save labour.

Herbicide use goes hand in hand with mechanization. A majority of farmers (53.2\%) from our sample felt that the cost for machinery is lower when compared to the cost of human labour, due to abrupt increases in wages. Our own data on mechanization levels in farming practices in the GHA reveal that land preparation with tractors is most common $(>98 \%)$. In contrast, pesticide application is hardly mechanized yet $(12 \%)$, whereas weeding is half way towards mechanization within the GHA, and paddy harvesting is almost totally mechanized (>90\%).

\subsection{Environmental Impacts}

The main impact urbanisation has been having on agricultural developments in the GHA is that it reduces the amount of land available for agricultural uses. Pressure factors like increasing land prices, absorption of rural labour and increasing input prices affect the speed of structural change in peri-urban agriculture and the intensity of farming. High intensities of resource use are a direct impact here. In our sample, this observation holds true with regard to the use of fertilizers, herbicides and insecticides, the use of irrigation water and mechanization. At the same time, farming is partly being replaced by other incomegenerating activities for family members who find jobs either in the city of Hyderabad or in one of the government schemes that guarantee income from rural labour. Changes in land use patterns and in the traditional food production system and relative unsustainability of land and input use are consequences of this. In the next section, we will describe impacts with particular relevance for environmental management and planning.

\subsubsection{Depletion of water}

Water shortage in the urban fringes has been a recurrent theme since the mid-1980s. The decline of groundwater tables has resulted in deep bore wells now being dug of up to over 800 feet, as most of the bore wells dug in the 1990s are no longer useable (Ramachandraiah and Vedakumar 2007). Similarly, low rainfall and limited ground water recharge are seen as being responsible for the observed shrinking of about $70 \%$ of the surface 
of natural lakes and tanks. A report by the Ground Water Board categorized only 15 out of 37 mandals as safe in terms of groundwater availability and use; 8 mandals are categorized as semi-critical, indicating the loss of the groundwater source; and 12 are categorized as overexploited (CGWB 2007: 22 and 23).

By 2008, urbanisation in the GHA had intruded upon 18 water bodies over 10 ha in size and 80 water tanks of less than 10 ha (Ramachandraiah and Prasad 2004). Within the last 12 years, the surface area covered by water bodies shrank from $2.5 \%$ of the Hyderabad geographical area to $1.5 \%$ (The Hindu, July 26, 2012). Our own study reveals that farmers have invested heavily in the extraction of ground water (on average, three bore wells/farmer).

We also found that, on average, only $50 \%$ of bore-wells in our sample were fully functional. Furthermore, to better meet the rapidly expanding needs of the GHA, the city has been drawing water from different agricultural reservoirs, such as Singur and Himayat sagar, Usman sagar, and Manjira, which puts even more pressure on agriculture users in the GHA (Hyderabad Metropolitan Water and Sewage Board, 2005), consequently increasing heavy ground water extraction by peri-urban farmers as a response (Celio and Giardano 2007).

Recent data by the District Ground Water Department on depletion of ground water in the GHA indicates an alarming process of depletion, where the ground water level in Shankarpalli has gone down from 12.83 meters below ground level in 2011 to 16.52 meters in 2012. Similarly, in Shamshabad it has gone down from 10.86 meters to 14.18 meters, whereas the ground water availability in Chevella has reached the deepest level ever: falling from 19.14 to 31.54 meters from the surface. Meanwhile, in Shameerpet the available ground water level has gone down from 3.10 to 6.45 meters and in Manchal from 13.20 to 16.05 meters. Correspondingly, the water table in the city has gone down from 6.82 meters to 7.38 meters due to lack of recharge pits there (Ground Water Department 2012).

\subsubsection{Nitrogen leaking and chemical residues}

Indiscriminate use of chemical inputs in peri-urban farming is responsible for the accumulation of pesticides and heavy metals in ground water as well as in the vegetables supplied to the city. Farmers are spraying highly concentrated chemicals with an increasing number of applications year after year, thereby polluting the environment. Toxic chemicals 
reach the food chain, resulting in toxic levels of chemical residues in urban-marketed vegetables. Recent studies on pesticide residues in Hyderabad report high residual levels in ground water (Shukla et al. 2006). Similarly, a study carried out by the National Institute of Nutrition (NIN) has found that pesticide residues in some of the vegetables and fruits sold at Rythu Bazaars or by street vendors are above the internationally stipulated maximum residual levels. Green grapes and okra (lady's finger) were found to be most contaminated. The NIN study further analyzed fruits and vegetables sold by Rythu Bazars and street vendors in five zones in the GHA: Erragadda, Kukatpally, Mehdipatnam, Falaknuma and Lal BahadurNagar. It found unhealthy pesticide levels in vegetables like eggplant (brinjal), cauliflower, okra, tomato and chilli and in fruits like grapes and apples (Sukesh Narain Sinha et al. 2012)

\subsection{Discussion and conclusions}

\subsubsection{Discussion}

The megacity development of Hyderabad has been affecting crop choice, intensity of production and technologies in use in peri-urban farming. Based on a sample of 120 vegetable and paddy growers, we analysed common types of adaptation by primarily traditional farmers to income-reducing factors, such as increases in land prices and rents and costs for agricultural labour, fertilizer and chemicals. We found that typical scenarios of structural change in agriculture - characterized by increased farm size, collective marketing and on-farm investment in storage and quality (Reardon, Timmer and Berdegue, 2004) - do not apply to the majority of farmers from our sample in the Greater Hyderabad Area. Most of the farms can be categorized as "traditional farm types" (Heimlich and Anderson 2001), characterized by limited factor mobility and slow adaptation capacity to changing environments. Over the last decade, the more "sensitive" farms have closed down and obviously sold their land.

Apart from "persistence and decline", Smithers and Johnson (2004) describe "growth" and "intensification" as typical farm-level trajectories scenarios. But very high land prices inhibit structural change towards larger and more efficient farm structures in the GHA. "Intensification", "diversification" and experimenting with more valuable crops thus remain 
the only feasible strategies for farmers who are increasingly threatened by income reduction. The adaptation processes we have observed fit into diversification scenarios described by Bryant and Johnston (1992), where farmers often rely on what has been called "off-farm diversification". Off-farm employment in government schemes and urban construction work compensates for income losses in agricultural production. "On-farm diversification" can also be observed, as farmers are changing their production practices towards those involving more machinery, fertilizer, water and chemical use, as well as engaging in neighbourhood organisation for farm labour sharing. As we have mentioned above, the increases in pesticide use have been dramatic.

These observations may motivate Hyderabad's urban planners and policymakers to rethink some of their strategies regarding the city's supply of healthy food and drinking water. An agricultural policy such as the present one, which promises to secure agricultural energy supply free of charge, motivates farmers to pump as much water as possible as quickly as possible, because power supply is limited to several hours a day. This policy is in conflict with the observed drawdown of water tables in the Greater Hyderabad Area and the problematic energy supply in the city of Hyderabad. The Government of India is aware of the problem of decreasing farm incomes and is now offering remedies such as The Mahatma Gandhi National Rural Employment Guarantee Scheme (MGNREGS), a program in rural areas to ensure participating farmers one hundred days of yearly employment for families below the poverty line. The program, though contributing to the stabilization of rural incomes, is nevertheless known to be having a detrimental impact on agriculture, because it reduces the availability of hired labour in agriculture and increases its cost, which in turn increases incentives to intensify herbicide and machinery use (Special Correspondent, Deccan chronicle, $20^{\text {th }}$ September 2008). The program is, however, well received by agricultural stakeholders. In the future, the inclusion of activities related to improvement of water, manure and labour availability in agriculture may benefit peri-urban agriculture and complement the present program's activity list. The recent program by the Horticulture Department on "terrace gardening" in Hyderabad has been well received by the urban residents, and strengthening such programs could be responsible for healthy vegetables and green lungs on terraces in the megacity 


\subsubsection{Conclusions}

Our findings support the thesis that current developments in agriculture in the GHA are being accompanied by unsustainable use of natural resources and problematic levels of chemical residues in drinking water, fruits and vegetables, caused by intense small-scale agricultural production. Weakly capitalized agriculturalists cannot afford necessary investments in quality, training and on-farm infrastructure. This, together with growing demand for best-quality vegetables at the city markets, makes farmers in GHA risk-averse, because they cannot afford crop losses or quality-reducing crop damage. They react by drilling more and deeper bore wells and applying excessive dosages of fertilizers and agrochemicals.

The problematic connection between the deterioration of the economics of agricultural production in the GHA and the increase of agricultural externalities has, thus far, not resulted in a well-suited strategy for coordinating and accompanying structural change in Hyderabad's peri-urban agriculture. Such a comprehensive strategy may be necessarily complex. It should include elements connecting agricultural energy delivery with water-preserving measures to be carried out by farmers, elements of a more sustainability-oriented rural extension service targeting the knowledge base and capacities of agricultural stakeholders, as well as elements in support of healthy development of agricultural land rents and the division of risks in contract-farming arrangements. An important element here is the support of agricultural investments.

Modern food systems are driven by the increasing demand of urban dwellers for healthy, high-quality products, known to induce heavy on-farm investments and a more direct and transparent system of retail. Policies in support of peri-urban farmers should not try to slow down on-going structural change at the cost of the environment. They should, instead, couple economic and environmental incentives and secure higher farm incomes for those farmers who are willing and able to prepare for a market in which a fair farm income is accompanied by sustainable resource 


\subsection{References}

Allen, A. (2003) "Environmental planning and management of the peri-urban interface: perspectives on an emerging field". Environment and urbanization, 15 (1): 135-148.

Barzel, Y. (1989) “Economic analysis of property rights”. New York: Cambridge University Press.

Bino, P.K; Bhirdikar, Shabnam, S; Mukherjee, P; Krishna, M; Bhardwaj, R; Purandaran. K and Murthy V. (2009) “India labour market report, 2008”.Adecco-TISS Labour Market Research Initiatives (ATLMRI). Mumbai: Tata Institute of Social Sciences.

Bryant, C.R; Singh B and Andre P. (2007) "The perception of risk to agriculture and climate variability in Qubec.Implications for farmer adaptation to climatic variability and change". In: Wall, E., Smit, B., Wande J. (Eds.). Farming in a changing climate. Vancover, University of British Columbia Press: 157-170.

Bryant, C.R. and Johnston T.R.R. (1992) "Agriculture in the city's country side”. Canada: University of Toronto Press.

Bryant, C.R. (1984) "The recent evolution of farming landscapes in urban-centered regions". Landscape planning, 11 (4): 307-326.

Buciega, A; Pitarch, M.D and Esparcia, J. (2009) "The context of rural-urban relationships in Finland, France, Hungary, the Netherlands and Spain". Journal of environmental policy and planning, 111: 9-27.

Celio, M. and Giardono, M. (2007) "Agriculture and urban water transfers: a case study of Hyderabad, South-India". Paddy and water environment, 5: 299-237

Central Ground Water Board (CGWB) 2007. "Government of India Southern Region"; 22-23. Available online: http://cgwb.gov.in/district Profile/AP/Ranga\%20Reddy.pdf (Access date, $20^{\text {th }}$ September, 2011)

City of Hyderabad Population Census (CHPC), 2011.'Hyderabad (Greater Hyderabad) City Census 2011 data". Available at http://www.census2011.co.in/census/city/392hyderabad.html (Access date: $25^{\text {th }}$ September, 2011)

Critchley, W; Wettasinha C. and Waters-Bayer A. (2007) "Promoting local innovation in rural agriculture - experience and lessons for urban settings". Urban agriculture magazine, 19.

Cochrane, W.W. (1993) "The development of American agriculture: a historical analysis". ( $2^{\text {nd }}$ ed): University of Minnesota. 
Defra, (2011) "The Farm Labour and Wage Statistics, 2011. Economics and Statistics Programme Survey Design and Analysis Team, May 2011”. Available online: http://www.defra.gov.uk/statistics/foodfarm/

Directorate of Economics and Statistics, 2010. "Hand Book Ranga Reddy District, 2010", Hyderabad, Andhra Pradesh

Dupont, V; Tarlo, E and Vital, D. (2000) “Urban space and human destinies". New Delhi: Manohar Publishers \& Distributors.

FAO, (2007) "Profitability and sustainability of urban and peri-urban agriculture". Agricultural Management, Marketing and Finance Occasional Paper 19. Rome: FAO.

Folke, C; Carpenter, S; Walker, B; Scheffer, M; Elmqvist, T; Gunderson, L and Holling, C.S. (2004) "Regime Shifts, Resilience, and Biodiversity in Ecosystem Management". Annual Review of Ecology, Evolution and Syststematic, 35 (1): 557-581.

Goodman, D and Watts, M. (1997) "Globalising food.Agrarian questions and global restructuring”. London; New York: Routledge.

Hayami, Y. and Ruttan, V.W. (1971) "Agricultural development: an international perspective”. Baltimore, MD: John Hopkins Press.

Heimlich, R.E. and Anderson W.D. (2001) "Development of urban fringe and beyond: impact on agriculture and rural land”. Economic Research Service, U.S.D.A. Agricultural Economic Report No. 803. Available at http://www.ers.usda.gov/publications/aer803/aer803.pdf

JNNURM. (2010) “Jawaharlal Nehru National Urban Renewal Mission”. Ministry of Urban Development, Government of India, Available at: http://jnnurm.nic.in/citywisecdp.html (Access date: $15^{\text {th }}$ August, 2012)

Kennedy, L. (2007) "Regional industrial policies driving peri-urban dynamics in Hyderabad, India". Cities, 24 (2), 95-109.

Krishna Gopal, G.V and Simmons R.W. (2006) "Urban and peri-urban agriculture: towards better understanding of low income producer organizations". City Case Study. With assistance of IWMI-ALCI.

Lerche, J. (2011) “Agrarian crisis and agrarian questions in India". Journal of agrarian change, 11 (1): 104-118.

Narain, V. (2003) "Institutions, technology and water control. Water users' associations and irrigation management reform in two large-scale systems in India". Hyderabad: Orient Longman. 
Parthasarathy Rao, P; Joshi, P.K.; Shravan K and Kaveri G. (2008) "Agricultural diversification in Andhra Pradesh, India: Patterns, determinants and implications". Published jointly with IFPRI and ICRISAT. Hyderabad, India: ICRISAT. Available at http://www.icrisat.org/what-we-do/impi/whats-new/research\%20report\%20no21090.pdf (Access date: $12^{\text {th }}$ October, 2011)

Potter, C and Tilzey, M. (2005) "Agricultural policy discourses in the European post-Fordist transition: neoliberalism, neomercantilism and multifunctionality". Progress in human Geography, 29 (5): 581-600.

Ramachandraiah, C and Vedakumar, M. (2007) "Hyderabad's water issues and the Musi River, need for integrated solutions". Draft version of the paper presented in the "International Water Conference, Berlin 12-14 ${ }^{\text {th }}$ September, 2007.

Ramachandraiah, C and Sheela P. (2004) "Impact of urban growth on water bodies: the case of Hyderabad". Working Paper No. 60, Centre for Economic and Social Studies, Hyderabad.

Reardon, T; Timmer, P and Berdegue, J. (2004) "The rapid rise of supermarkets in developing countries: induced organizational, institutional, and technological change in agri-food systems". Electronic journal of agricultural and development economics (eJADE), 1 (2): 168-183.

Reddy, R.V. and Reddy S.B. (2007) "Land alienation and local communities: case studies in Hyderabad-Secunderabad". Economic and political weekly, 42 (31): 3233-3240.

Reddy, S.B. and Praveena T. (2011) "Development versus livelihoods" .LEISA India, (2): 25.

Robinson, G.M. (2004) "Geography of agriculture: globalisation, restructuring and sustainability”. Harlow: Pearson Education.

Sharp, J.S. and Smith, M.B. (2003) "Social capital and farming at the rural-urban interface: the importance of non-farmer and farmer relations". Agricultural systems, 76 (3):913927.

Singh, S. (2008) "Producer companies as New Generation Cooperatives". Economic and political weekly, May 17, 22-24.

Shukla, G; Kumar, A; Bhanti, M; Joseph, P.E and Taneja, A. (2006) "Organochlorine pesticide contamination of ground water in the city of Hyderabad". Environment international, 32 (2): 244-247.

Smithers, J. and Johnson, P.(2004) "The dynamics of family farming in North Huron County, Ontario.Part I. Development trajectories”. The Canadian geographer / Le Geographe canadien, 48 (2): 191-208.

Special Correspondent, Deccan Chronicle, (2008) "National Rural Employment Guarantee Scheme and its impacts on rural India”. 20 ${ }^{\text {th }}$ September 2008. 
Sukesh Narain, S; Vasudev, K; Rao, M and Vishnu, V. (2012) "Quantification of organophosphate insecticides and Herbicides in vegetable samples using the liquid chromatography techniques". Food chemistry, (132):1574-1584.

Tacoli, C. (2006) “The earthscan reader in rural-urban linkages”. London: Earthscan

Tzoulas, K; Korpela, K; Venn, S; Yli-Pelkonen, V; Kaźmierczak, A; Niemela, J. and James, P. (2007) "Promoting ecosystem and human health in urban areas using green infrastructure: a literature review". Landscape and urban planning, 81 (3): 167-178.

The Hindu, (2012) "Efforts to save catchment areas in the city". Hyderabad edition. $20^{\text {th }}$ July 2012

Walker, B.H. and Salt, D. (2006) "Resilience thinking: Sustaining ecosystems and people in changing world". Washington, D.C: Island Press.

Whatmore, S. (2002) "From farming to agribusiness: global agri-food networks. Geographies of global change: remapping the world". (Eds.) M.A. Maldem, P.J.Taylor and M.J.Watts: Blackwell Publishing.

Zasada, I., (2011) "Multifunctional peri-urban agriculture - A review of societal demands and the provision of goods and services by farming". Land use policy 28 (4): 639-648. 


\title{
4. Megacity development and farmers' discernment about sustainability. A Multi-Criteria Decision Analysis in South India's Greater Hyderabad Area
}

\author{
Zakir HussainHumboldt University, Berlin \\ Division of cooperative sciences \\ Professor Dr. Markus Hanisch \\ Professor and HeadDivision of cooperative sciences \\ Humboldt University, Berlin
}

\begin{abstract}
The meaning of sustainability often varies among different social discourses. One grey area which has rarely or never pursued could be understanding sustainability discourses in situations of rapid change and adaptation in urban peripheries which substantially escalates environmental problems. It is essential to understand that how these situations impact the farmers' perceptions on sustainability. In addition it is important as well to understand the social conflicts that determine the change in these areas. This paper analyses the perceptions of sustainability amongst farmers of the four prevalent farming systems around the megacity of Hyderabad. We asked 60 farmers from farming systems which differ in terms of input use and crop intensity in the Greater Hyderabad Area (GHA) to give weights to different attributes related to sustainability. Our finding show that farmers of the different peri-urban farming systems trade of the different economic, environmental and social dimensions of sustainability differently. We also show that farmers of different farming systems prioritize different sustainability criteria when decisions influencing agricultural sustainability are made. We relate our results to those of other studies and derive conclusions for agricultural policy and extension.
\end{abstract}

Keywords: farmers' discernment; peri-urban farming; sustainability discourses; AH 


\subsection{Introduction}

Sustainability has often prone to constant discourses amongst various actors. More often actors participate in discourses depending on professional and social backgrounds and perceive the attributes of sustainability differently. The adoption of policies towards more sustainable patterns of human behavior may benefit from the understanding as to how perceptions of sustainability emerge and change. A particularly important area of research is the study of sustainability issues in situations of rapid change and adaptation. Resource scarcity, environmental problems and social conflicts provide opportunities to learn more about the factors determining and changing sustainability perceptions.

In this paper we analyse the perceptions of sustainability among farmers of the four dominant farming systems in the Greater Hyderabad Area. The Greater Hyderabad Area (GHA) is among South India's fastest growing urban conglomerations. With a population of 6.8 million people (CHPC 2011), the GHA has adopted an 'infrastructure-led growth model' (Kennedy 2007). During the last 10 years, the state has set in motion a number of infrastructure based development projects, including: a new international airport; 'Fab-City', a planned hub for advanced semiconductor and electronics manufacturing, for which the government has dedicated some 1050 acres of land; and an eight-lane outer-ring road $162 \mathrm{~km}$ in length. Meanwhile, the real estate sector in the GHA has been experiencing a boom (Reddy and Reddy 2007). Official statistics on land use data pinpoint that, during the last two decades, huge amounts of agricultural land in the GHA have been reallocated to other sectoral uses (Directorate of Economics and Statistics 2010). Despite these challenges, farming remains an important economic activity. In the process of urbanization, adaptation and change farmers benefit from new marketing opportunities in the proximities of the city. At the same time farmers become increasingly exposed to discourses questioning the sustainability of agricultural production in the peri-urban area.

In the presence of pressures from urbanization, many farmers have been changing their farming systems either towards lower intensity or towards higher intensity of input usedelivering substantial amounts of produce to the urban markets (Hussein and Hanisch 2013). The hypothesis analyzed in this paper is that "farmers' choice of a particular farming system influences how farmers interpret and perceive the meaning of sustainability". If farmers of 
different farming systems differ as to how they perceive sustainability, strategies targeting more sustainable agricultural practices would have to consider these differences in order to be successfully implemented.

\subsubsection{Sustainability, social discourse and perception}

Since the publication of "Our Common Future" by the World Commission on Environment and Development (WCED 1987) the term "sustainability" has become an overarching discourse among all strata of society. This discourse is characterized by various interpretations of sustainability. Actors from different social and professional backgrounds are known to perceive sustainability differently (Dryzek 2005; Robinson 2004): For example farmers whose livelihoods directly depend on the productivity of farmland and livestock may with regard to sustainability consider other attributes of their environment important than the city dwellers interested in healthy foods and recreation. In the same vein the problems related to unsustainable developments are considered differently and in a given situation and depending on who is involved this may provoke very different claims: Whereas scientists may perceive sustainability as a bunch of problems that could be solved by investments in more research and technical progress, environmentalists may claim the disregard of sustainability as a catastrophe demanding radical changes in society. It follows that an actor's perception emerges in the process of social interactions within the society (Williams and Roggenbuck 1989). In a given context, discourses on "sustainability" are then the result of both individual experience and social construction (David 1989; Webster 1999). Different discourses about sustainability display the variance of actors as well as the variance in their experiences. The participation in discourses shapes individual perceptions. How individuals talk and act has to do with what people know and with what people think they know. In similar vein, Rao and Narayana (1998) highlight this cognitive dimension defining perceptions as "Important cognitive factors of human behaviour" and as mechanism that enable people to understand their environment. With regard to sustainability the process of developing and changing perceptions is important because it directly influences how people select, organize, and interpret information about their environment (Rao and Narayana 1998). Without the prior analysis of the factors determining perceptions on sustainability, projects targeting more sustainable outcomes necessarily lack reference. The empirical analysis of farmers' perceptions is important because results may become important inputs for future 
discourses on sustainability. Figure 4-1 describes this relationship and provides the analytical background for analysis. A typical scenario of conflict laden development emerges in the fringe areas of megacities in developing countries where population pressure results in increasing scarcity of land and water which in turn challenges the sustainability of traditional systems of agricultural production.

In this paper we will analyze farmers' perceptions on sustainability in the emerging Greater Hyderabad Area. Our aim is to better understand how megacity development induces changes of farming systems and in turn the perception of sustainability of farming practices. Our research focus lies on the analysis of the relation between farming systems change and the importance farmers give to different attributes of sustainability. In the following section we provide a brief literature review on the outcomes of studies related to sustainability discourses in agriculture in order to elaborate our research questions. We then describe our research method and present results from the analysis of sustainability perceptions among the farmers adopting different farming systems in the Greater Hyderabad Area. We review our findings before the background of current developments and ongoing policy dialogue in the megacity and conclude with policy recommendations in relation to sustainable development of the peri-urban agriculture in Hyderabad.

\subsubsection{Literature review}

As a contemporary paradigm, sustainability is necessarily a construct subject to the influence of varying social discourses. Huge et al. (2012) describe different strands of sustainability discourses. The first strand explicitly views sustainable development as a process of integrating developmental and environmental goals. Discourses of "environmental modernization" and "sustainable development" are prominent examples. In these discourses ideas of technical, organizational or societal modernization are the means of integration and pave the way towards more sustainable outcomes. The basic assumption is that "technical fix is possible". Market governance coupled with a helping hand of the state characterizes related policy dialogues. Another strand is formed by "limitation debates". The basic concept is imbalance in the relation between humans and nature. 
The idea is that more sustainable outcomes require limitations on human activities because ecosystem development is limited. These discourses include concepts of ecocentrism, human impact analysis and limits to growth. A focus on political control and expert knowledge characterize related policy dialogues. Finally, discourses focusing on the need for change combine concepts of the

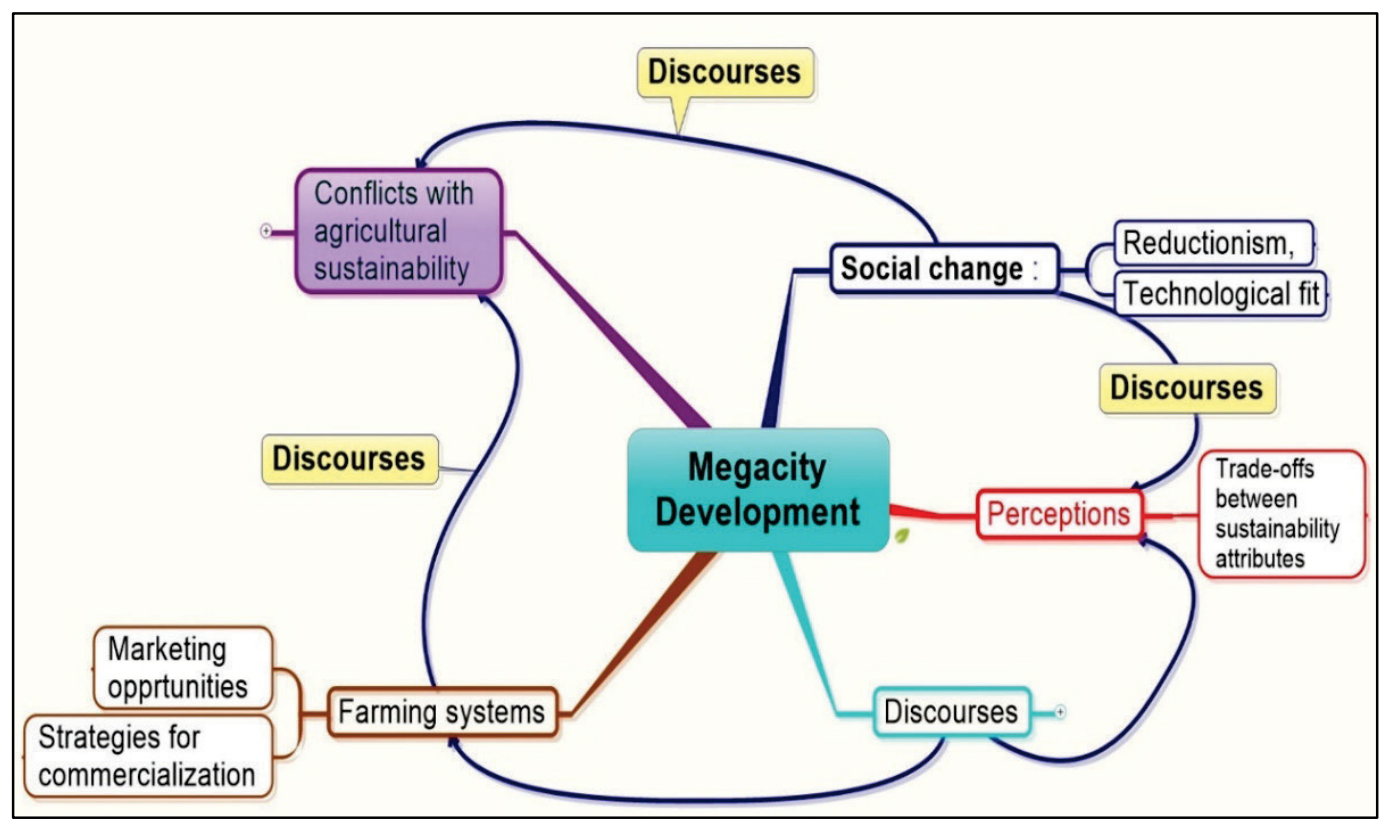

Figure 4-1: Analytical background for understanding farmers' sustainability perceptions

modernization and the limitation discourses. The idea is that "changes in values" and "changes in the social system" are the necessary elements of more sustainable outcomes. The former (values) incurs participatory governance and the effective networking of actors towards changes in the output preferences of society. The latter incurs changes towards the time horizon and perspective on sustainable development. The related policy dialogue is characterized by ideas of decentralization of environmental governance and a process oriented rather than a consequence governed perspective on decision making (WCED 1987).

Individual perceptions of sustainability are the result of experience and the participation in such discourses (Berger and Luckmann 1966; Sarbin and Kitsuse 1994). Farmers from different farming systems are known to differ in how they experience their environment, as well as to in what strands of discourses they are participating (Hindess, 1988; Heritage, 1987; Ghazouani et al, 2009). Farmers' perceptions of sustainability are known to 
be context specific and variable over localities and time. O'Tool, Wallis and Mitchell (2006) report on a survey of perceptions of sustainability conducted in rural areas of south west Victoria. Their analysis of what people perceived as socially, economically and ecologically sustainable shows that perceptions measured at the regional scale can mask local trends. In similar vein, Tathdil, Boz and Tadlidil (2009) assess farmers' perceptions of sustainable agriculture and how those are influenced by the frequency of contacts with extension officers and different socio-economic characteristics of the farmers in Turkey. The results of the study showed that the higher the contact frequency with extension services, and the greater the access to information, the greater the perceived importance of sustainable agricultural practices. Other studies have focused on measuring farmers' sustainability perceptions of the importance of different aspects of farming (International Institute for Tropical Agriculture (Annual Report 1997 ), confronted farmers' sustainability perceptions with de facto measurements of soil fertility (Mulder 2000), or analyzed farmers'perceptions on the sustainability of modern agricultural practices and inputs (Taylor et al. 1993; Drost 1998) assessed sustainability perceptions among US vegetable growers and included questions about practices of farming connected to differing farming systems like integrated pest management, nutrient management, and different types of field operations.

He found that differences in land ownership, education and crop acreage influenced growers 'perceptions and use of sustainable practices while access to information, farming experience and time constraints by and large influenced the choice of cropping patterns. He concluded that, to be effective, research and extension efforts should consider these relations. Yappa (1996) has shown how expert language can influence perceptions about poverty and agricultural development. In a study on the adoption of high yielding varieties in India, farmers were in modernization discourses categorized as "progressive" or "backwards" based on their adoption response which in turn had an influence on self-perception and attitudes towards adoption. Fleming and Vanclay (2010) have also examined the role of discourses in shaping farmer behavior towards more sustainable agricultural practices. They found that trust played an important role: Australian farmers used outsiders as informants for their discourses but only admitted insiders to directly participate in discourse shaping events and discussions. They concluded that analyzing the processes shaping these discourses is important to understand the adoption behavior of farmers. 
From this short review of literature we conclude that the way discourses are constructed fundamentally shape how human affaires are thought and spoken about, and how people perceive and act in response to sustainability problems (Foucault 1972). In the same way farmers create their own knowledge through experimentation and trial and influence discourses by inviting or repelling outside expertise (Pannel and Vanclay 2011). Understanding the ways in which farmers' perceptions of sustainability are socially constructed is then a precondition for the design of effective projects and policies. The analysis of farmers' perceptions of important elements of sustainability discourses may provide important knowledge about future scenarios of farming systems change and the adoption rates of policies targeting sustainable development. However, in sustainability studies the analysis of perceptions is relatively underrepresented (Parra-Lopez and CalatravaRequena 2006). The dominant area of research is the comparative analysis of the change of farming systems (Rigby et al. 2001; Tatlidil et al. 2009). Here the motivational aspects of farmers shifting from conventional to organic farming systems have attracted much attention (Fairweather 1999; Rigby and Caceres 2001; Mccann et al. 1997). Another area of research deals with establishing indicators of sustainability with a focus on comparing environmental indicators among farming systems (Hani et al. 2006). Prominent examples are the IDEA method developed in France using economic, social and environmental attributes for developing sustainability indicators (Diane et al. 2010) and the "Response Inducing Sustainability Evaluation (RISE) method which is an indicator based evaluation of criteria of sustainability on the farm level (Hani et al. 2003). However, Hyati (2010) recognizes three major challenges related to such comparative measurement approaches of sustainability where first, the measures fall short of pursuing trade-offs and complementarities among the three sustainability dimensions, economy, society and environment. Second, many of the indicators are too complex to communicate and not particularly practical for the work with farmers, third, different indicators do not represent the actual cause-effect relationship among important dimensions of farming and important dimensions of sustainability.

An approach of sustainability measurement on farm level which explicitly considers trade-offs and complementarities of on-farm decision making is provided by the "Analytical Hierarchy Process (AHP) -tool (Saaty 1990). AHP is a variety of what has been called "Multi criteria Decision Analysis (Mwana et al. 1996; Tiwari et al. 1999; Strassert and Tony 2002; 
Munda et al. 1994)". The main advantage of the approach is that it reveals and measures the scope of typical trade-offs between economic and social/environmental preferences and allows to better deal with farmers' decision making problems especially where conflicting economic, environmental and social objectives are involved. (Sadok et al. 2008; Mwana et al. 1997). For example, Pacini et al. (2003) compare economic aspects of sustainability in Italy among three different farming systems with AHP. They find that the representatives of different farming systems ranked different economic aspects important. Lopez and Requena (2006) compared three farming systems in Spain, using AHP. Their results show that farmers of integrated and organic farming rank environmental aspects of on farm decision making much higher than the representatives of conventional farming systems. Similarly, AHP is widely used in studies comparing farmers' values and ethical norms (Poursaeed et al. 2010) and the gender preferences in relation to sustainable agriculture (Karami and Mansoorbadi 2009). Other studies on AHP analyse important determinants of the choice of farming systems. (Bhatta and Doppler 2010; Mortazavi et al. 2009). For example Bhatta and Doppler assess the reasons for the application of different farm practices in the surroundings of Kathmandu. They find that higher yield and accessibility to markets as well as agroecological considerations are the key impacting factors of subsistence, commercial inorganic and smallholder organic farming systems in the peri-urban area of Kathmandu, respectively.

However, AHP has so far not been used to study in how far being a farmer of a particular farming system relates to how farmers rank the different attributes of sustainability. In this paper our main hypothesis is that farming in peri-urban areas exposes farmers to new market opportunities and to conflicting discourses about the sustainability of farming. Representing a particular type of farming system then gives notice about how farmers participate in such discourse and in turn how farmers think, talk and act about sustainability. We claim that "Farmers adopting different production systems have different perceptions about sustainability in general" and "they give different weights to different attributes of sustainability in particular.

Three main research questions guide the analysis

How do the farmers themselves differentiate production systems with respect to different dimensions of sustainability? 
Do farmers of different production systems perceive and trade off the main dimensions of sustainability differently?

What are the key factors motivating/impeding the sustainable reorganization of periurban agriculture?

\subsection{Data and AHP method}

Farmers in the Greater Hyderabad Area face several challenges: falling water tables, poor market infrastructure, increasing health problems due to fertilizer and chemical use, high variation in farm gate prices for conventional farm products, extreme weather events and unpredictable power supply for agricultural pumpsets (Hanisch et.al. 2010). At the same time the neighboring megacity provides new opportunities: It ensures ever increasing demand for agricultural products and a growing demand for high quality and healthy food products.

In day to day practice of farming it is, therefore, important to better understand the impacting factors involved when trade-off $s$ between typical attributes of sustainability are made. This can be done using the analytic hierarchy process (AHP) modeling. AHP is a method that assigns weights to various factors in hierarchically organized structure (Eagan and Weinberg 1999). It is a method that helps quantifying the significance of these factors by means of using pair-wise comparisons (Whitaker 2007). AHP is based on the assumption that when analyzing decision making, the quantification of a factor doesn't make sense without measuring the dominance of one attribute over another.

The Directorate of Agriculture, Andhra Pradesh and the Department of Horticulture distinguish four main types of farming systems in the Greater Hyderabad Area (Table 4-1). The typical land use pattern of the GHA includes 54.899 hectares characterized as “conventional vegetables". Paddy farmers represent a farming system classified as High Resource Use with 67.530 hectares. Integrated Crop Management is applied at 4.900 hectares (Better Management) whereas another 500 hectares of Organic Farming exist. Hansen (1996) characterizes "conventional farming" as a farming system that adopts high chemical and high energy inputs to achieve high yields. Integrated Crop Management (Better Management Farming) aims at minimal chemical and fertilizer use which is achieved through a 
combination of biological and chemical methods (Morris and Winter 1999). High Resource Use is the farming system adopted by most paddy farmers around Hyderabad because of high water and energy demand. Finally Organic Farming is adopted by farmers not using chemicals and with high concern for food safety and the protection of the natural environment (Abando and Rohenerthielen 2007).

Table 4-1: Classification of farming based on intensive input use

\begin{tabular}{|c|c|c|c|c|c|}
\hline \multirow{2}{*}{$\begin{array}{l}\text { Farming } \\
\text { systems }\end{array}$} & \multicolumn{5}{|c|}{ Intensity of Input use } \\
\hline & Seed & Fertilizers & Pesticides & Weedicides & Water \\
\hline Conventional & Market & Intensive & Intensive & Intensive & $\begin{array}{l}\text { Semi- } \\
\text { intensive }\end{array}$ \\
\hline $\begin{array}{l}\text { Better } \\
\text { Management }\end{array}$ & $\begin{array}{l}\text { Market+ } \\
\text { own }\end{array}$ & $\begin{array}{l}\text { Semi- } \\
\text { intensive }\end{array}$ & Low & Low & $\begin{array}{l}\text { Semi- } \\
\text { Intensive }\end{array}$ \\
\hline $\begin{array}{l}\text { High Resource } \\
\text { use }\end{array}$ & Market & Intensive & $\begin{array}{l}\text { Semi- } \\
\text { intensive }\end{array}$ & Intensive & Intensive \\
\hline Organic & $\begin{array}{l}\text { Own+ } \\
\text { Market }\end{array}$ & $\begin{array}{l}\text { Local } \\
\text { resources }\end{array}$ & $\begin{array}{l}\text { Local } \\
\text { resources }\end{array}$ & Nil & $\begin{array}{l}\text { Semi- } \\
\text { intensive }\end{array}$ \\
\hline
\end{tabular}

Source: Own table based on experts perception on farming systems

Comparing farmers' perceptions of sustainability affords to analyze the three dimensions of sustainability, economic development, social equity and environmental viability simultaneously. This is necessarily complex and reduces the scope of what can be done within a representative sampling procedure. Our sampling followed criteria of proximity to the city of Hyderabad (40km ring), participants' level of education (literacy), similarity of farms in terms of size and production program (main crop). Based on a list of villages and farms in the Greater Hyderabad Area sampling of 4 villages which represent production systems in the proximity of the megacity was done. In each village 15 most similar farms were chosen with the help of experts. Because the empirical method of conducting pair-wise comparisons is relatively complex, only literate farmers that are also participating in the 
surveys of the directorate were chosen. This method is similar to AHP-samplings of other studies ((Beaumariage 1990; Ethie 1989; Harker 1989). Finally a total of 60 farmers were considered for our study.

Table 4-2: Production area under different farming systems in GHA

\begin{tabular}{lll}
\hline Farming system* & $\begin{array}{l}\text { Area } \\
\text { (ha) }\end{array}$ & $\begin{array}{l}\text { No.of farmers for the } \\
\text { study }\end{array}$ \\
\hline Conventional vegetables** & 54899 & 15 \\
BMP (ICM)* & 4900 & 15 \\
$\begin{array}{l}\text { High Resource use Paddy (46 Mandals } \\
\text { HUDA)* }\end{array}$ & 67530 & 15 \\
Organic farming** & 500 & 15 \\
\hline
\end{tabular}

Source: *Directorate of agriculture, (2011), ** Department of Horticulture (2010)

\subsubsection{Criteria selection for conducting sustainability comparisons}

Based on a review of literature on criteria of sustainability measurement, we chose criteria for each dimension of sustainability (Table 4-3). Each farmer contributed with 73 pair-wise comparisons representing trade-offs in farmers' decision making towards sustainability to the study. For our study we assume that the following criteria shape a farmer's preference for enduring economic viability and represent dimensions of sustainability:

A farmer's perception of this dimension will shape important trade-offs in decision making and feed-back on the sustainability of peri-urban agriculture as a whole. The economic dimension of sustainability is covered by the analysis of priorities for profit maximization, for maximum yields, optimal crop diversification, crop specialization, marketand consumer orientation, and for input and cropping intensity are involved.To cover and compare farmers' priorities for the environmental dimension of sustainability, we compare preferences for chemical use, concerns for biodiversity, awareness of water and air pollution, food safety, for proper crop management and mechanization and preferences to employ locally produced inputs like farm manure and fodder. 
Finally, for the study of farmers preferences, the social dimension of sustainability is another important category Here preferences for individual farming, for membership in farmers' organizations, the role of family interactions, preferences towards being organized in homogeneous producer groups, preferences about information channels for example whether to get mainly informed about production methods and prices by extension officers, or preferences to receive information from input dealers, and preferences to participate in farm collectives were chosen as criteria.

Table 4-3: Different criteria selected from the literature for pair-wise comparison in economic and environmental dimensions

\begin{tabular}{|c|c|c|}
\hline Dimension & Criteria & Reference \\
\hline \multirow[t]{7}{*}{ Economic } & Profit maximization & $\begin{array}{l}\text { van Calker et al. (2005); Razei Moghaddam and } \\
\text { Karami (2008); Muwana, et al. (1996); Rigby et } \\
\text { al.(2001) }\end{array}$ \\
\hline & Yield & Muwana et al. (1996); Rigby et al.(2001) \\
\hline & Crop diversification & Elizabeth et al.( 1997) \\
\hline & Specialization & Muwana et al. (1996) \\
\hline & Market orientation & Alphonce (1997) \\
\hline & Input use & Alphonce (1997) \\
\hline & Cropping Intensity & Muwana et al. (1996); Dantsis et al (2010) \\
\hline \multirow[t]{7}{*}{ Environment } & Chemical use & van Calker et al. (2005); Muwana et al. (1996) \\
\hline & Biodiversity & $\begin{array}{l}\text { Razei Moghaddam. and Karami (2008); Lopez et al. } \\
\text { (2006) }\end{array}$ \\
\hline & $\begin{array}{l}\text { Water \& Air } \\
\text { pollution }\end{array}$ & $\begin{array}{l}\text { Lopez et al. (2006); van Calker et al. (2005); } \\
\text { Muwana et al. (1997) }\end{array}$ \\
\hline & Crop management & Rigby et al.(2001);Dantsis et al. (2010) \\
\hline & Local resources & Alphonce Christian (1997); Rodulescue et al. (2010) \\
\hline & Mechanization & Hamza and Anderson (2005) \\
\hline & Food safety & $\begin{array}{l}\text { van Calker et al. (2005); Razei Moghaddam and } \\
\text { Karami (2008) }\end{array}$ \\
\hline
\end{tabular}

Source: Authors' compilation from various studies 


\subsection{Structuring the hierarchy and pair-wise comparisons with Analytical Hierarchy Process}

We start with "disentangling" the decision problem into hierarchies. On top of the problem hierarchy is our goal to understand "sustainability perceptions among urban fringe farmers". This will be done comparing criteria of farming sustainability among four groups of farmers belonging to four types of farming systems (on the second level of the hierarchy). Finally, the three dimensions of the sustainability represent alternative choices farmers will trade off when making decisions.

Table 4-4: Different criteria selected under social dimension from the literature for pair-wise comparison

\begin{tabular}{lll}
\hline Dimension & Criteria & Reference \\
\hline Social & $\begin{array}{l}\text { Individual farming } \\
\text { Membership in }\end{array}$ & van Calker et al. (2005) \\
& Rao and Rogers (2006) \\
& $\begin{array}{l}\text { Homogenous } \\
\text { farmer groups }\end{array}$ & Rao and Rogers (2006) \\
& Family interactions & Gomez sal et al.(2005) \\
& $\begin{array}{l}\text { Neighbour } \\
\text { interactions }\end{array}$ & Chisato Maeda (2011); Van calker et al. (2005) \\
& $\begin{array}{l}\text { Techno-Advise } \\
\text { from Extn.officer }\end{array}$ & Rao and Rogers (2006), Poursaeed et al.(2010) \\
& $\begin{array}{l}\text { Techno-Advise } \\
\text { from Input } \\
\text { Agencies }\end{array}$ & Rao and Rogers (2006); Poursaeed et al. (2010) \\
& $\begin{array}{l}\text { Collective farming } \\
\text { (Participation) }\end{array}$ & $\begin{array}{l}\text { Razei Moghaddam and Karami (2008); Lopez et al } \\
\text { (2006);Chisato Maeda (2011) }\end{array}$ \\
\hline
\end{tabular}

Source: Authors' compilation from various studies

These mark the bottom level of the hierarchy and consist of 7 criteria for the trade-off between economic dimensions and environmental dimensions of sustainability respectively and they consist of eight criteria characterizing the social dimension of sustainability. To systematically study differences between the four groups of farmers in how they give priority to the 22 criteria of sustainability, pair wise comparisons have to be conducted. The results of the pair-wise comparisons are analyzed with computer software (expert choice). 
Pair-wise comparisons were based on a 1 to 9 scale developed by Wind and Saaty (1980). In this scale the mid-point, indicates "equally important" criteria, while for example the value three is moderately important, five relates to "strong importance", seven is very strong importance and finally nine indicates "Absolute importance". The numbers 2, 4, 6 and 8 are intermediary values between two adjacent judgments.

\subsubsection{Data collection and analysis}

On the basis of a questionnaire based survey we collected the responses from each group based on pair-wise comparisons. Data has been aggregated to calculate the "geometric mean" of each group of 15 farmers. With software called "Expert choice®" we generated the weights, Eigen values, Eigen vector and finally the consistency ratios which classify the quality of the comparisons: The software allows checking for the inconsistency of the input matrices obtained. If inconsistency ratios lie above $10 \%(0.1)$ this indicates that during the survey farmers had problems to make a clear judgment between the offered criteria. In the following section we present the results on the farmers' perceptions among four different farming systems in the Greater Hyderabad Area.

\subsection{Results}

\subsubsection{Farmers' perceptions on three dimensions of sustainability in GHA}

In our introduction we claim that "farmers adopting different production systems have different perceptions about sustainability in general" and "they give different weights to different attributes of sustainability in particular. The summary table of our results reveal that in our sample conventional, better management and high resource use farmers visibly prioritized the criteria of economic development over other criteria which characterize the social or environmental dimension of sustainability. This priority is most prominent among conventional farmers $(0,55)$ and high resource use farmers $(0,5)$. The result is consistent and given the entrepreneurial nature of farming in the peri-urban area of which should not be a surprise. Farmers of the better management group already show some higher concern for environmental issues $(0,327)$ than their conventional and high resource use colleagues $(0,24$, $0,25)$, Organic farmers, comparing economic and environmental criteria expectably give 
highest priority to their unique selling point which is, their concern for environment and healthy food $(0,41)$. Interestingly farmers of all farming systems ascertained lowest priority to the criteria which characterize the social dimension of sustainability.

Table 4-4: Summary of farmers' preferences related to three dimensions of sustainability

\begin{tabular}{lllll}
\hline Farmer group & Economic & Environmental & Social & Inconsistency \\
\hline Conventional & $(0.550)$ & $(0.240)$ & $(0.210)$ & 0.02 \\
Better & $(0.413)$ & $(0.327)$ & $(0.260)$ & 0.05 \\
Management & & & & \\
High Resource use & $(0.500)$ & $(0.250)$ & $(0.250)$ & 0.00 \\
Organic & $(0.327)$ & $(0.413)$ & $(0.260)$ & 0.05 \\
\hline
\end{tabular}

Figures in the parenthesis are the corresponding weights from $\mathbb{C}$ Expert choice software

The summary of sensitivity analysis Figure 4-2 describes farmers' trade-offs between the three dimensions of sustainability. The scale on the right side of the graph indicates the normalized weights (ratio of total weight to the criteria weight) of the criteria. The scale at the left side of the graph indicates the ratio of percentage weight of that criteria to the total weight of it. In addition the graph indicates that the trade-off between the three dimensions of sustainability seems to be smallest for organic farmers, somewhat reduced for farmers of the better management group and obviously largest for the remaining two groups (High Resource Use and Conventional). Within the dimensions economic criteria enjoy high priority but environmental aspects are also ranked as important among all groups of farmers. Criteria of sustainability related to fairness, collective action and social inclusion are given lowest priority by all farmers. 


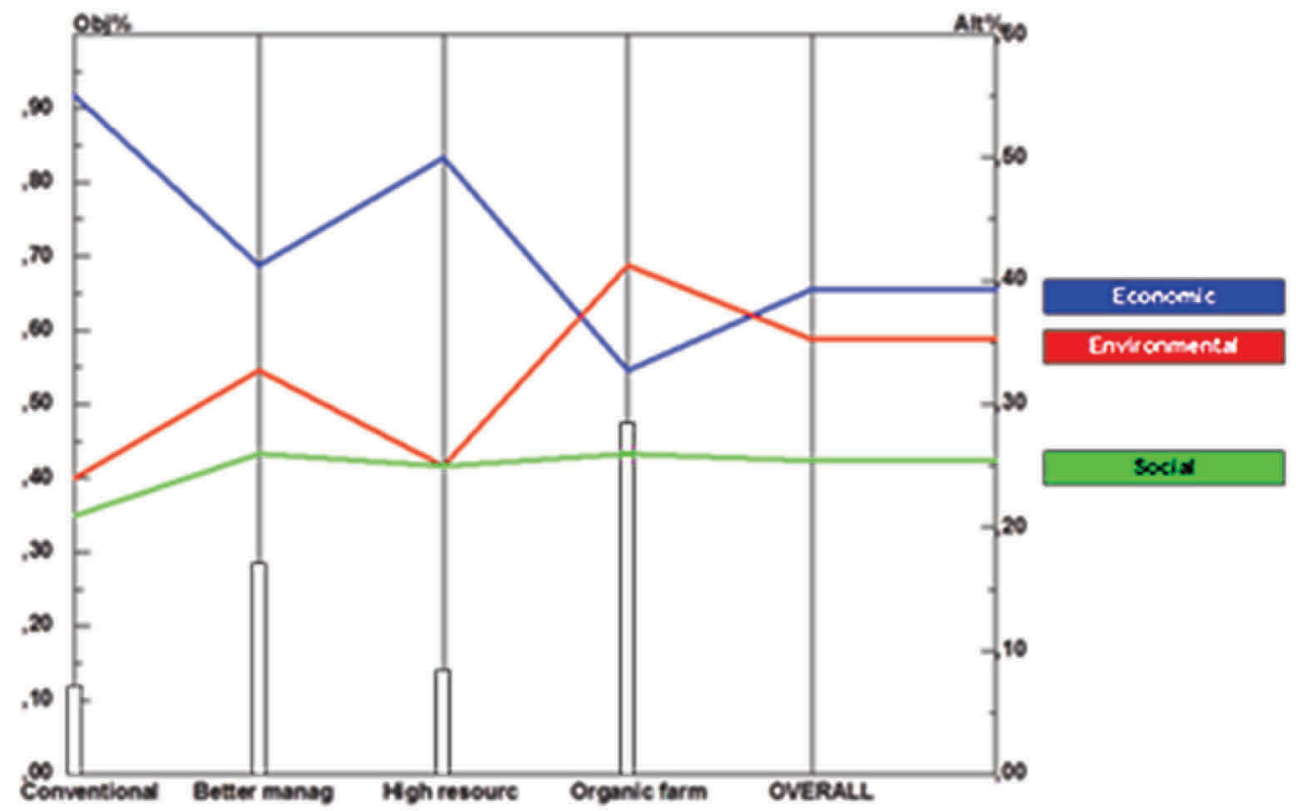

Figure 4-2: Performance sensitivity of different dimensions of sustainability

In the following sections we will analyze how farmers of the different farming systems rank the criteria in each of the three dimension of sustainability, separately. Farmers of different farming systems rank the different economic criteria of sustainability as follows (Table 4-5); Profit maximization (0.292) is a top priority for conventional farmers and enjoys similar priorities among the other three groups. High yield is a top priority for all farmers. Also in terms of market orientation and specialization the differences among farming systems are not striking. Because organic farmers are niche producers they have a tendency to rank market orientation and specialization higher than is the case with the other 3 groups. In the ranking of economic criteria of sustainability the diversification of crops and reduced input use are much more important for organic farmers and important for Better Management Farmers than with the other two groups. 
Table 4-5: Farmers' ranking related to different economic criteria of sustainability

\begin{tabular}{|c|c|c|c|c|c|c|c|c|}
\hline $\begin{array}{l}\text { Farmer } \\
\text { group }\end{array}$ & $\begin{array}{l}\text { Profit } \\
\text { maximizatio } \\
\text { n }\end{array}$ & Yield & $\begin{array}{l}\text { Input } \\
\text { use }\end{array}$ & $\begin{array}{l}\text { Market } \\
\text { Orientat } \\
\text { ion }\end{array}$ & $\begin{array}{l}\text { Cropping } \\
\text { intensity }\end{array}$ & $\begin{array}{l}\text { Speciali- } \\
\text { zation }\end{array}$ & $\begin{array}{l}\text { Crop } \\
\text { diversify- } \\
\text { cation }\end{array}$ & $\begin{array}{l}\text { Inconsist } \\
\text { ency ratio }\end{array}$ \\
\hline Conventional & $(0.292)$ & $(0.216)$ & $(0.155)$ & $(0.123)$ & $(0.091)$ & $(0.066)$ & $(0.057)$ & 0.04 \\
\hline $\begin{array}{l}\text { Better } \\
\text { management }\end{array}$ & $(0.186)$ & $(0.202)$ & $(0.178)$ & $(0.123)$ & $(0.122)$ & $(0.066)$ & $(0.122)$ & 0.08 \\
\hline $\begin{array}{l}\text { High } \\
\text { Resource use }\end{array}$ & $(0.179)$ & $(0.200)$ & $(0.214)$ & $(0.155)$ & $(0.117)$ & $(0.068)$ & $(0.066)$ & 0.05 \\
\hline Organic & $(0.194)$ & $(0.193)$ & $(0.099)$ & $(0.134)$ & $(0.137)$ & $(0.085)$ & $(0.159)$ & 0.06 \\
\hline
\end{tabular}

Figures represent criteria weights calculated with CExpert choice software

The sensitivity analysis in (Figure 4-3) illustrates the similarities and differences: among all four farmer groups, profit maximization is a top priority followed by the maximization of yield. Regarding the other criteria priorities among farmers of different farming systems differ widely. Organic farmers and Better Management Farmers clearly rank crop diversification higher than their colleagues from the other farming systems.

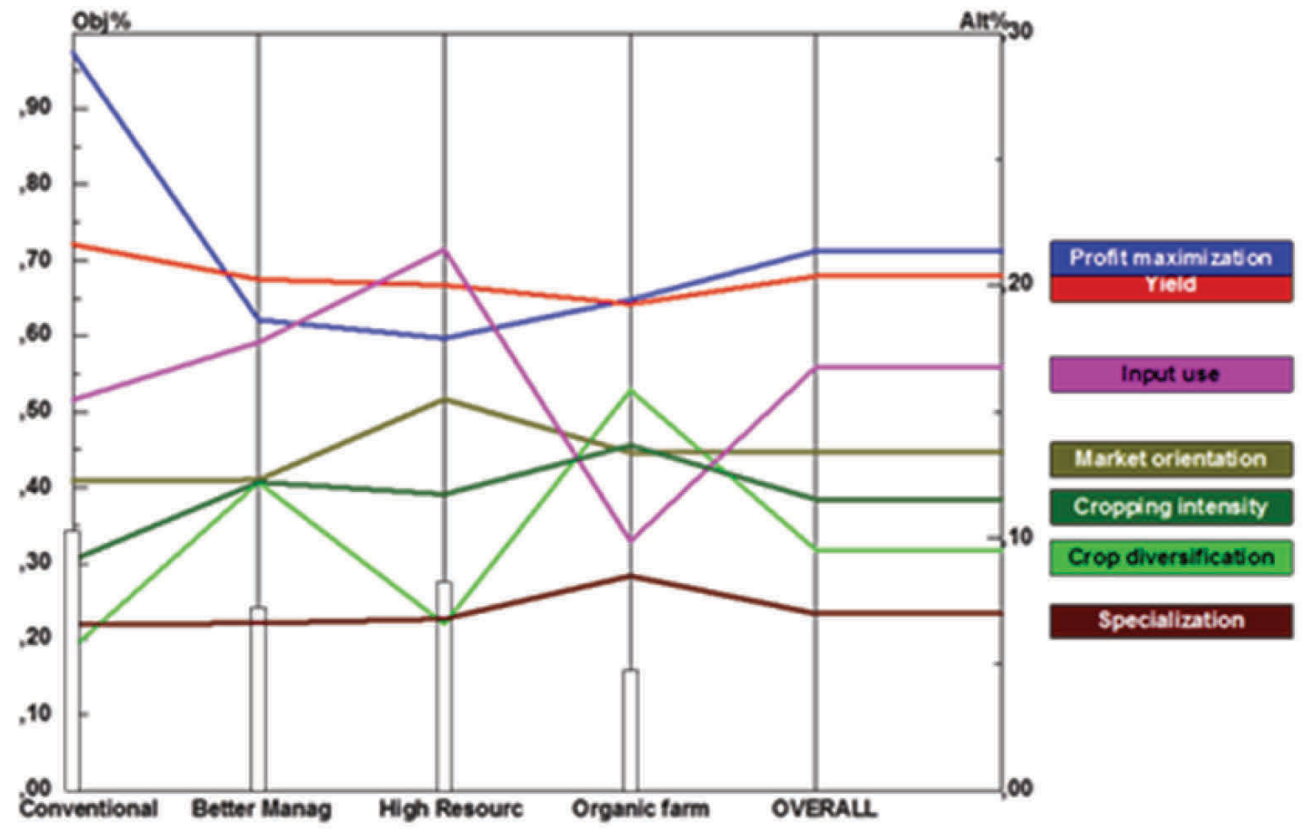

Figure 4-3: Sensitivity analysis of the criteria of economic dimension 


\subsubsection{Farmers' perceptions on the environmental criteria of sustainabilit}

Table 4-6 reveal that Conventional Farmers give highest priority to the use of agrochemicals (0.355) followed by mechanization, food safety and management. Better Management Farmers give their highest priority to crop management $(0,21)$, followed by biodiversity $(0,19)$ mechanization $(0,16)$ and chemical use $(0,15)$. High Resource Use Farmers prioritize mechanization $(0,26)$ over crop management $(0,23)$ over chemical use $(0,20)$.

Table 4-6: Farmers' ranking on different environmental criteria

\begin{tabular}{|c|c|c|c|c|c|c|c|c|}
\hline Farmer group & $\begin{array}{l}\text { Chemical } \\
\text { use }\end{array}$ & $\begin{array}{l}\text { Mechan } \\
\text { ization }\end{array}$ & $\begin{array}{l}\text { Food } \\
\text { safety }\end{array}$ & $\begin{array}{l}\text { Crop } \\
\text { manag } \\
\text { ement }\end{array}$ & $\begin{array}{l}\text { Local } \\
\text { Resource } \\
\text { Use }\end{array}$ & $\begin{array}{l}\text { Water\& } \\
\text { air } \\
\text { pollution }\end{array}$ & $\begin{array}{l}\text { Bio } \\
\text { diversity }\end{array}$ & $\begin{array}{l}\text { Incon } \\
\text { sistency }\end{array}$ \\
\hline Conventional & $(0.355)$ & $(0.202)$ & $(0.136)$ & $(0.125)$ & $(0.082)$ & $(0.055)$ & $(0.046)$ & 0.07 \\
\hline $\begin{array}{l}\text { Better } \\
\text { Management }\end{array}$ & $(0.151)$ & $(0.164)$ & $(0.108)$ & $(0.210)$ & $(0.142)$ & $(0.105)$ & $(0.194)$ & 0.09 \\
\hline $\begin{array}{l}\text { High Resource } \\
\text { use }\end{array}$ & $(0.208)$ & $(0.264)$ & $(0.120)$ & $(0.235)$ & $(0.052)$ & $(0.064)$ & $(0.057)$ & 0.04 \\
\hline $\begin{array}{l}\text { Organic } \\
\text { farmers }\end{array}$ & $(0.071)$ & $(0.246)$ & $(0.617)$ & $(1.000)$ & $(0.834)$ & $(0.543)$ & $(0.454)$ & 0.06 \\
\hline
\end{tabular}

Figures in the parenthesis are the corresponding weights from (C) Expert choice software

Regarding the environmental dimension of sustainability it is not surprising that Organic Farmers widely differ from the other three groups in how they rank criteria: Crop management receives the highest priority followed by a very high priority for local resource use. Food safety, water and air pollution and biodiversity are also scoring relatively high when compared to the priorities of the other farmers. Sensitivity analysis in (figure 4-4) portrays that how farmers perceive the various criteria of the environmental dimension of sustainability differently. While food safety and crop management were someway important for all farmers, farmers of different farming systems have very different perceptions about environmental criteria like the role of mechanization, local resource use and the use of chemicals. 


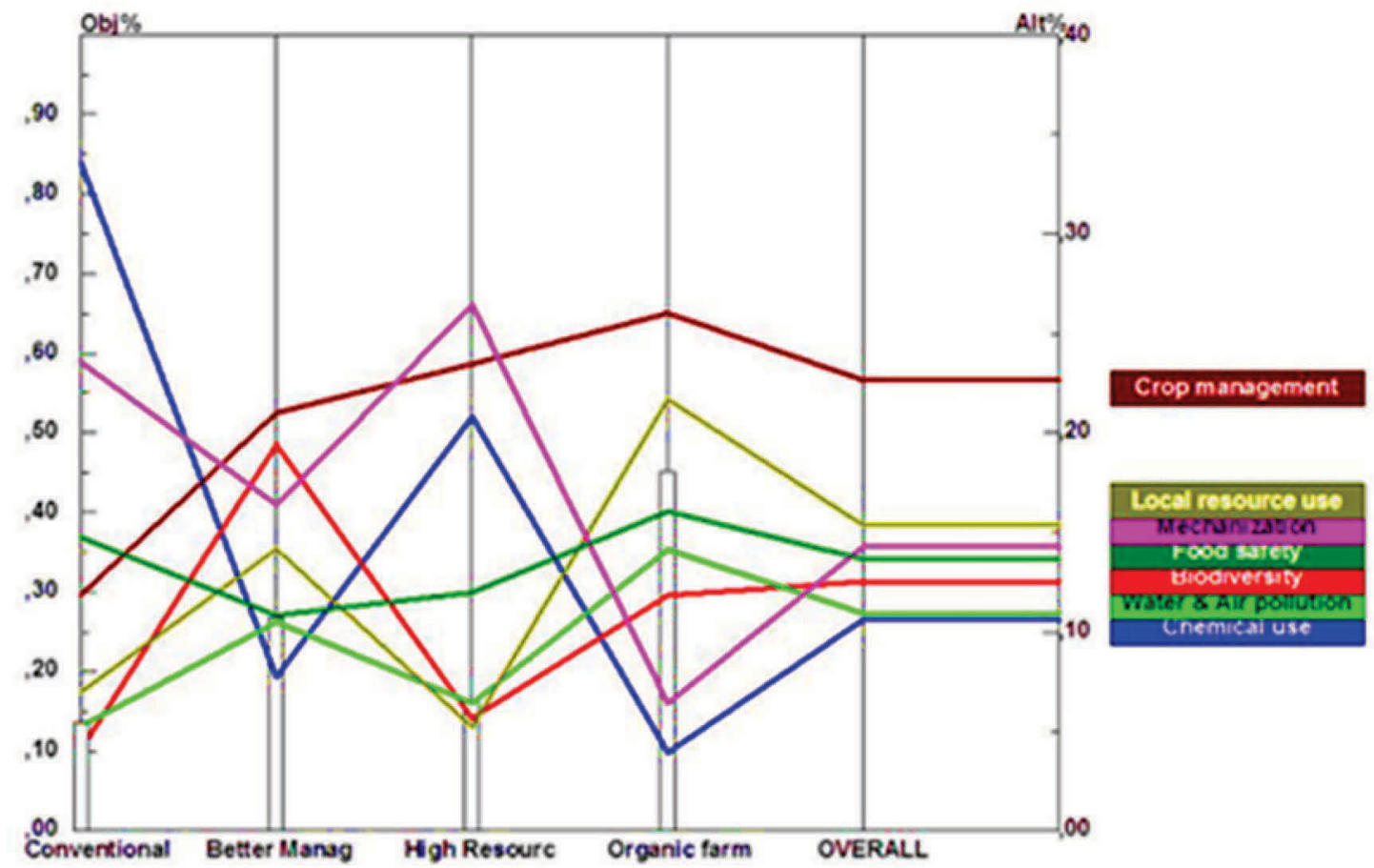

Figure 4-4: Sensitivity analysis of the criteria of environmental dimension

\subsubsection{Farmers' perception on different social criteria}

Social dimension perhaps seems to be a least preferred criteria when compared to the environmental and economic dimensions, while making the decision among the three criteria in the mindset of farmers of Greater Hyderabad Area. However, farmers of different farming systems differ substantially as to what social criteria they give priority. Conventional farmers for example highly prioritize individual farming $(0,337)$ which means that farmers prefer to rather rarely working together with other farmers in co-organizing market access or processing. Conventional farmers prioritize to get informed by professionals like extension officers and input dealers and have low priority for collective action and neighborhood collaboration. The situation is different with Organic Farmers. They prioritize to cooperate with family members, have a preference for being a member in an association of farmers and support collective forms of marketing and processing. They prefer to receive information rather from extensionists than from input dealers. High Resource Use farmers highly prefer to receive information about cropping and marketing from their input dealers. 
Table 4-7: Farmers ranking on different social criteria

\begin{tabular}{llllllllll}
\hline & $\begin{array}{l}\text { Indiv } \\
\text { farming }\end{array}$ & $\begin{array}{l}\text { Family } \\
\text { interaction }\end{array}$ & $\begin{array}{l}\text { Neighbor } \\
\text { interaction }\end{array}$ & $\begin{array}{l}\text { Member } \\
\text { in } \\
\text { organ }\end{array}$ & $\begin{array}{l}\text { Homog. } \\
\text { Farmer } \\
\text { Groups }\end{array}$ & $\begin{array}{l}\text { Tech } \\
\text { advise } \\
\text { EO }\end{array}$ & $\begin{array}{l}\text { Tech. } \\
\text { Advise } \\
\text { Input Agent }\end{array}$ & $\begin{array}{l}\text { Collect } \\
\text { farming }\end{array}$ & $\begin{array}{l}\text { Incons } \\
\text { i } \\
\text { stency } \\
\text { ratio }\end{array}$ \\
\hline$C F$ & $(0.337)$ & $(0.070)$ & $(0.057)$ & $(0.046)$ & $(0.042)$ & $(0.198)$ & $(0.194)$ & $(0.055)$ & 0.09 \\
$B M P$ & $(0.077)$ & $(0.184)$ & $(0.185)$ & $(0.063)$ & $(0.101)$ & $(0.176)$ & $(0.149)$ & $(0.065)$ & 0.08 \\
HRU & $(0.136)$ & $(0.131)$ & $(0.136)$ & $(0.070)$ & $(0.059)$ & $(0.136)$ & $(0.283)$ & $(0.048)$ & 0.06 \\
$\begin{array}{l}\text { Organi } \\
\text { C }\end{array}$ & $(0.095)$ & $(0.187)$ & $(0.181)$ & $(0.152)$ & $(0.104)$ & $(0.115)$ & $(0.065)$ & $(0.101)$ & 0.08 \\
\hline
\end{tabular}

Figures are the weights calculated with (C) Expert choice software

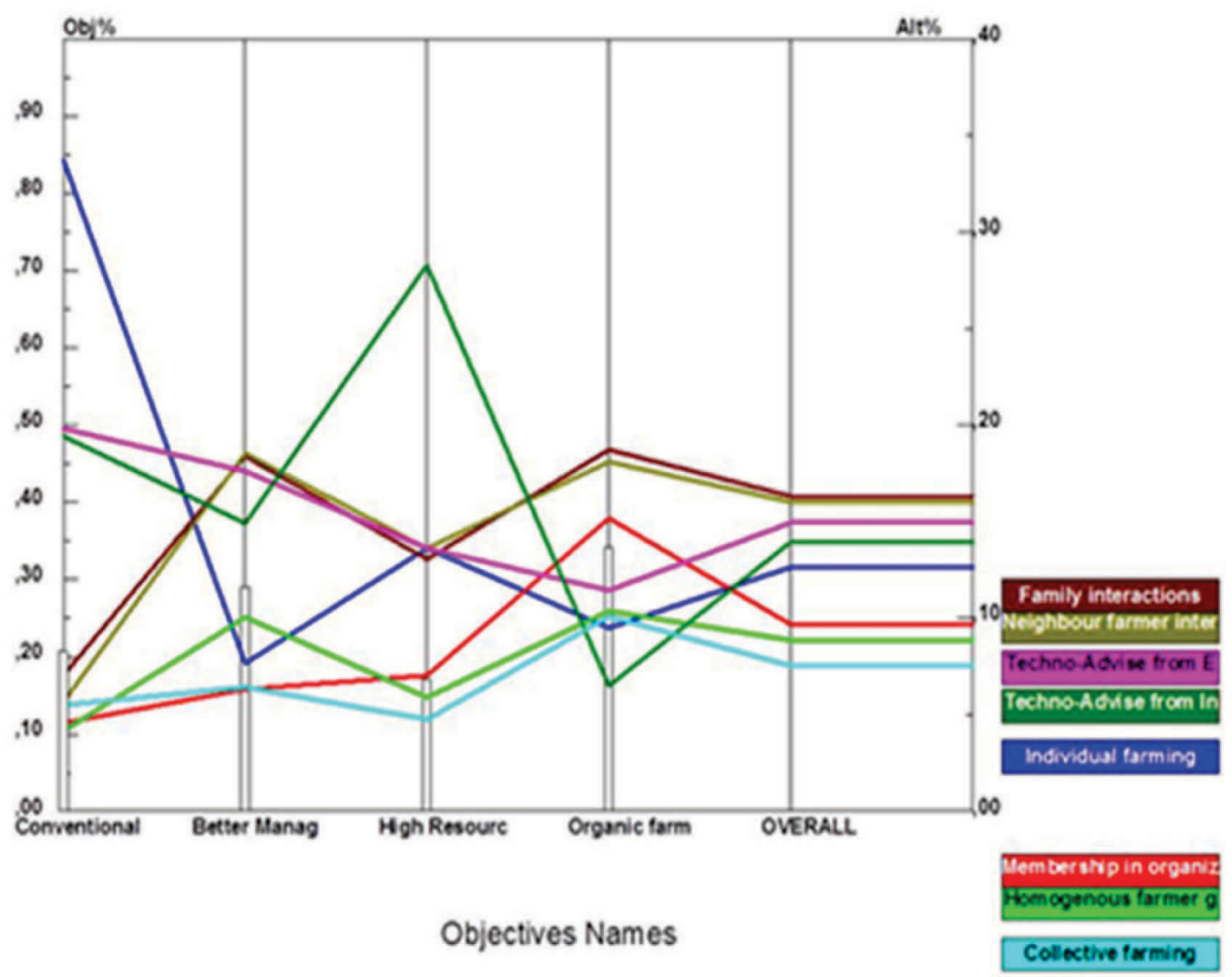

Figure 4-5: Farmers' ranking related to different criteria of social dimension

Sensitivity analysis of graph 4-1 shows that farmers of different farming systems widely differ in terms of priorities for criteria of the social dimension of sustainability: Tradeoffs between the different criteria are highest for High Resource Use Farmers and for 
Conventional Farmers. Better Management Farmers and Organic Farmers seem to give more weight to some of the criteria describing the social dimension of sustainability.

\subsection{Discussion and Conclusion}

Farmers in the Greater Hyderabad Area are exposed to various social discourses on peri-urban farming. Our study analyzes how the farmers themselves rank different criteria of sustainability. Our main hypothesis is that being a farmer of a particular farming system gives notice about what discourses farmers participate in and how they perceive different dimensions of sustainability of agricultural production. We find that in general, farmers of different farming systems weigh the three different dimensions of sustainability differently. Economic criteria of sustainability are given high priority by all groups of farmers but there is a higher priority by Conventional and High Resource Use Farmers than by Better Management and Organic Farmers.

This finding is in line with the findings of other studies measuring sustainability in agriculture (\#have a look and add the relevant sources from literature review here). Environmental criteria are more important for Better Management Farmers and Organic Farmers and less important for the other two groups of farmers. Criteria describing the social dimension of sustainability are given lower priority than the other two dimensions by all farmers. Interestingly, Better Management Farmers and Organic Farmers show higher priorities for particular criteria describing the social dimension.

Our research interest focused on the different perceptions of sustainability and how they come into being. We find that farmers of different farming systems also differ in how they judge the importance of the criteria within each of the three dimensions of sustainability: Better Management Farmers and Organic Farmers ranked crop diversification higher than their colleagues. They also show a higher concern for the use of local resources and give higher priority to biodiversity. Finally, Better Management Farmers and Organic Farmers differ in how they judge criteria of social sustainability: cooperation within and outside the family, the organization in producer groups and collective marketing and processing efforts 
are given higher priorities by these two farmer groups than by Conventional and High Resource Use farmers.

These results demonstrate that the ways in which farmers in the GHA participate in social discourses about agricultural production differ. This difference is beginning to shape how farmers think and act with regard to sustainability. Sensitivity analyses show that for Conventional Farmers and High Resource Use farmers the trade-offs between the three dimensions of sustainability are much higher than is the case with the other two groups. Preferences for economic criteria and for mechanization and heavy chemical use on the one side and preferences for extension and information from input dealers indicate that farmers of these two groups see economic sustainability as a key challenge for peri-urban agriculture and technological fit as a prominent strategy. Farmers of the other two groups (Organic Farmers and Better Management Farmers) show awareness for economic but also for environmental and to a lesser extend social challenges related to the sustainability of periurban agriculture. Preferences towards better crop management, reduced and local input use and cooperation among farmers indicate that these two groups of farmers have a much more integrative and balanced understanding of sustainability challenges. Interestingly, the organization of farmers in producer groups and establishing marketing collectives are likely elements of the future strategies of these farmers. Policies in view of sustainable peri-urban development will have to consider the differences in the perceptions of farmers and the causes for these differences. A point of attack for this policy dialogue is to influence how the farmers themselves think and act towards sustainability. MDA offers important insights into the architecture of farmers ' perceptions of sustainability. Thus MDA results may help to craft necessary policies and incentives to improve an agricultural system that clearly faces problems with sustainability.

\subsection{References}

Abando, L.L and E. Rohnerthielen. (2007) "Different Organic farming patterns within EU25, Statastics in focus". Agriculture and Fisheries: 69.

Alphonce Christian, B. (1997) "Application of the analytic hierarchy process in agriculture in developing countries”. Agricultural Systems, 53, (1): 97-112. 
Annual Report, I.I.T.A. (1997) “Farmers' perceptions of soil degradation. International Institute of Tropical Agriculture”. Lambourn UK. http://www.iita.org/info/ar97/2627.htm

Beaumariage, G.T. (1990) "Investigation of an object oriented modeling Environment for the generation of stimulation models", $\mathrm{PhD}$, diss., Oklahoma State University.

Bennet, J.W. (1968) "Reciprocal economic exchanges among North American agricultural operators". Southwestern Journal of Anthropology, 24: 276-309.

Berger, P.L and Luckmann, T. (1967) "The social construction of reality: A treatise in the sociology of knowledge". London: Penguin.

Bhatta, G.D and Doppler W. (2010) "Farming Differentiation in the Rural-urban Interface of the Middle Mountains, Nepal: Application of Analytic Hierarchy Process (AHP) Modelling". Journal of Agricultural Science, 2 (4): 37-51.

City of Hyderabad Population Census (CHPC), 2011."Hyderabad (Greater Hyderabad) City Census 2011 data”. Available at http://www.census2011.co.in/census/city/392hyderabad.html (Access date: 25th September, 2011)

Collinson, M. P. (2000) “A history of farming systems research”. Rome, Italy, New York: Food and Agriculture Organization of the United Nations.

Chisanto, Maeda. (2010) "Ex-ante impact assessment using Multi-Criteria Decision Analysis for alternative policy options influencing farming practices in two districts of Karnataka, India". M.Sc Thesis, Wageningen University, Netherlands.

Dantsis, T; Douma, C; Giourga, C; Loumou, A. P and Eleni, A. (2010) "A methodological approach to assess and compare the sustainability level of agricultural plant production systems". Ecological Indicators, 10 (2): 256-263.

David, S. (1989) "Sustainable development: theoretical construct on attainable goal?" Environmental conservation, 16: 41-48.

Department of Horticulture, (2010) "Data from Department of Horticulture", available online: www.apshm.ap.nic.in

Diane, P; Belanger, V; Anne, V; Allard, G and Pellerin, D. (2010) "Methods for the evaluation of farm sustainability: The social aspect". A paper presented 9th European IFSA Symposium, Quebec, Canada: 4th-7th July, 2010: 922-930.

Directorate of Economics and Statistics, (2010) "Hand Book Ranga Reddy District, 2010". Hyderabad, Andhra Pradesh.

Directorate of Agriculture, (2011) "Annual Report on crop planning in Andhra Pradesh". Hyderabad, India. 
Drost, D; Gilbert, L and Hales, K. (1997) 'Utah’s vegetable growers: Assessing sustainable agriculture". Hort. Technology, 7(4), 445-450.

Drost, D. (1998) "Targeting extension efforts for the adoption of sustainable agricultural practices". Journal of Extension. (36):5. http://www.joe.org/search.html

Dryzek, J. S. (2005) "The politics of the earth: environmental discourses". Oxford, Oxford University Press.

Eagan, P and Weinberg, L. (1999) "Application of analytic hierarchy process techniques to streamlined life-cycle analysis of two anodizing processes". Environment Science and Technology, 33, 1495-1500.

Elizabeth, M; Sulvian, S; Erickson, D and Raymond, D.E. (1997) "Environmental Awareness, Economic Orientation, and Farming Practices: A comparison of Organic and Conventional Farmers”. Environmental Management, 21 (5): 747-758.

Ethie, C.I. (1989) “An integrated Multi-Objective Decision Model for Industry in a less Developing Country”. PhD. Diss., University of Missouri-Rolla.

Faucault, M. (1972) “The archeology of knowledge”. London, Tavistock.

Fairweather, J. R. (1999) "Understanding how farmers choose between Organic and Conventional production: Results from New Zealand and policy implications". Agriculture and Human Values, 16 (1): 51-63.

Gatzweiler, F and Hagedorn K. (2001) "Sustainable Agriculture in Central and Eastern European Countries (CEESA)”.Discussion Paper No.2/5/2001:1-53.

Gómez Sal, A and González, G.A. (2005) "A comprehensive assessment of multifunctional agricultural land-use systems in Spain using a multi-dimensional evaluative model". Agriculture, Ecosystems \& Environment, 120 (1): 82-91.

Gopal, D.B and Doppler W. (2010) "Farming Differentiation in the Rural-urban Interface of the Middle Mountains, Nepal: Application of Analytic Hierarchy Process (AHP) Modeling". Journal of Agricultural Science, 2 (4): 37-51. Available online at http://ccsenet.org/journal/index.php/jas/article/view/6163/6214

Ghazouane, W; Marlet, S; Meklci, I and Vidal, A. (2009) "Farmers perceptions and engineering approach in the modernization of a community- managed irrigation scheme: A case study from an Oasis of the NEFZAWA (SOUTH TUNISIA)". Irrig. and Drian., 58: 285-296.

Hagedorn, K. (2000) “Institutional arrangements for Environmental Cooperatives: A conceptual framework". Paper presented in 64th Seminar of The European Association of Agricultural Economists, October 27-29, Berlin. 
Hani, F; Braga, F; Stampfli, A; Keller, T; Fischer, M and Porsche, H. (2003) 'RISE, a Tool for Holistic Sustainabiliy Assessment at the Farm Level". International Food and Agribusiness Management Review, 6 (4): 78-90.

Häni F; T. Gerber, F; A. Stämpfli, H; Porsche, C; Thalmann, and C. Studer (2006), "RISE: A Tool for Improving Sustainability in Agriculture. A case study with tea farmers in southern India", in Häni F.J., L. Pintér, and H.R. Herren (Eds.), From Common Principles to Common Practice, Proceedings and Outputs of the first Symposium of the International Forum on Assessing Sustainability in Agriculture (INFASA), International Institute of Sustainable Development and Swiss College of Agriculture, Bern,121-148.

Hanisch, M.; Kimmich, C.; Rommel, J.; Sagebiel, J. (2010) "Coping with Power Scarcity in an Emerging Megacity: A Consumers' Perspective from Hyderabad". International Journal of Global Energy Issues, 33(3/4): 189-204.

Hamza, M.A and Anderson, W. K. (2005) "Soil compaction in cropping systems.A review of the nature, causes and possible solutions". Soil \& Tillage Res, 82: 121-145.

Hansen, J.W. (1996) "Is agricultural sustainability a useful concept?" Agricultural Systems, 50 (2): 117-143.

Harker, P.T. (1989) "The Art and Science of Decision Making: The Analytical Hierarchy Process: Applications and Studies" (Eds.). B.L.Golden, E.A. Wasil, and P.T.Harker. Berlin, Germany: Springer-Verlag.

Harre, R. (1993) “Social being” (IInd Eds.). Oxford: Blackwell.

Hayati., D; Ranjbar., Z and Karami, E. (2010) "Measuring Agricultural Sustainability.Biodiversity, Biofuels, agroforestry and Conservation Agriculture". Sustainable Agriculture Reviews, 5: 73-100.

Heritage, J. (1987) “Ethnomethodology”. (Eds.). Giddens, A. and Turner J. Social theory today, Stanford, California, Stanford University Press.

Hindess, B. (1988) "Choice, rationality and social theory". London and Boston, Unwin Hyman Publishers

Huge, J; Wass, T; Eggermont, G; Farid, Dahdouch-Guebas; Koedam, N and Thomas Block. (2012) "A discourse - analytical perspective on sustainability assessment: interpreting sustainable development in practice". Sustain.Sci, (2), DOI 10.1007/s11625-0120184-2.

Hussain, Z and Hanisch, M. (2013) "Dynamics of peri-urban agricultural development and farmers' adaptive behaviour in the emerging mega-city of Hyderabad, India". Journal of Environmental Planning and Management, DOI:10.1080/09640568.2012.751018.

Kant, I. (1998) “The Critique of Pure Reason”. New York: Cambridge University Press 
Karami, E and Mansoorabadi, A. (2008) "Sustainable agricultural attitudes and behaviors: a gender analysis of Iranian farmers". Environ Dev Sustain, 10 (6): 883-898.

Kennedy, L. (2007) "Regional industrial policies driving peri-urban dynamics in Hyderabad, India". Cities, 24 (2), 95-109.

Kevin O'Toole; Anne Wallis and Brad Mitchell (2006) "Local Perceptions of Sustainability Indicators". Issues of scale and implications for management. Rural Society, 16 (1), $25-46$.

Klostermann, J. E. M and Cramer, J. (2007) "Social construction of sustainability in water companies in the Dutch coastal zone". Journal of Cleaner Production, 15 (16): 15731584.

Knorr-Cetina, (1981) "The manufacture of Knowledge - Constructivist and Contextual knowledge of science”. Oxford. Pergamon Press.

Koeijer, T. J; de Wossink, G. A. A; Struik, P.C and Renkema, J. A. (2002) "Measuring agricultural sustainability in terms of efficiency: the case of Dutch sugar beet growers". Journal of Environmental Management, 66 (1): 9-17.

Latour, Bruno and Woolgar Steve. (1979) "Laboratory Life: The Social Construction of Scientific Facts". USA; Sage Publications.

López-Ridaura, S. (2006) "Multi-scale sustainability evaluation: a framework for the derivation and quantification of indicators for natural resource management systems". Diss. Wageningen University and Reseah Center, Wageningen, TheNetherlands.

Lindsay, P and Norman, D. A. (1977) "Human information processing: An introduction to psychology”. Harcourt Brace Jovanovich, Inc.

Mccann, E; Sulvian, S; Erickson, D and Raymond, D. E. (1997) "Environmental Awareness, Economic Orientation, and Farming Practices: A comparison of Organic and Conventional Farmers". Environmental Management, 21 (5): 747-758.

Morris, C and Winter, M. (1999) "Integrated farming systems: the third way for European agriculture?" Land Use Policy, 16 (4): 193-205.

Mortazavi, M; Ranaei, H and Abbasi, H. (2011) "The Application of Multi Attribute Decision Methods (MADM) on prioritizing Iranian Fisheries Research Project". Iranian Journal of Fisheries Sciences, 10 (1): 47-56.

Mulder, I. (2000) "Soil fertility: QUEFTS and farmers' perceptions". Working Paper. International Institute for Environment and Development, London and Institute for Environmental Studies, Amsterdam 
Munda, G; Nijkamp, P and Rietveld, P. (1994) "Qualitative multi-criteria evaluation for environmental management". Ecological Economics, 10 (2): 97-112.

Mudroch, J.P; Lowe, N; Ward, T and Marsden. (2003) "The Differentiated Countryside”. New York, Routledge.

Mwana, N; Mawapanga and David, L. D. (1996) "Choosing between Alternative Farming Systems: An Application of the Analytic Hierarchy Process". Review of Agricultural Economics, 18(3): 385-401.

Napier, T. L; Thraen, C. S and McClaskie, S.L. (1988) "Adoption of soil conservation practices by farmers in erosion prone areas of Ohio: The application of logit modeling”. The Agricultural systems, 1: 107-109.

Pacini, C; Wossink, A; Giesen, G; Vazzana, C and Huirne, R. (2003) "Evaluation of sustainability of Organic, integrated and Conventional farming systems: a farm and field-scale analysis". Agric. Ecosyst. Environ, 95 (1): 273-288.

Pannell, D.J; Marshall, G.R; Barr, N; Curtis, A; Vanclay, F and Wilkinson, R. (2011) "Adoption of conservation practices by rural landholders" (Eds.): Jennings, J., Packham, R. and Woodside, D., Shaping Change: Natural Resource Management, Agriculture, and the Role of Extension, Australia-Pacific Extension Network, Australia, 72-77.

Parra-López, C; Calatrava-Requena, J and de-Haro-Giménez, T. (2008) “A systemic comparative assessment of the multifunctional performance of alternative olive systems in Spain within an AHP-extended framework". Ecological Economics, 64 (4): $820-834$.

Parra-Lopez, C and Requena, J.C. (2006) "Comparison of farming techniques actually implemented and their rationality in organic and conventional olive groves in Australia and Spain”. Biological Agriculture and Horticulture, 24(1), 35-39.

Pleog, J.D.v.d. (1994) "Styles of farming: An Introductory Note on the Concepts and Methodology. 7-30 In. Born from Within - Practice and Perspectives of Endogenous Rural Development" (Eds): Pleog, J.D.v.d., and A.Long. Holland. Van Gorcum.

Poursaeed, A; Mehdi, M; Iraj, M and Hosseini, J. F. (2010) "The partnership models of agricultural sustainable development based on Multiple Criteria Decision Making (MCDM), Iran”. African Journal of Agricultural Research, 5 (23): 3185-3190.

Pretty, J. N. (1995) "Regenerating Agriculture: policies and practices for sustainability and self-reliance”. Washington, D.C., Joseph Henry Press.

Rao, N.H and Rogers, P. P. (2006) "Assessment of agricultural sustainability". Current Science, 91(4): 439-448. 
Rao, V.S.P and Narayana, P.S. (1998) “Organisation Theory and Behaviour”. Delhi: Konark Publishing Company, 329-330

Rezaei-Moghaddam, K and Karami, E. (2008) "A multiple-criteria evaluation of sustainable agricultural development models using AHP”. Environ Dev Sustain, 10 (4): 407-426.

Reddy, R.V and Reddy S.B. (2007) "Land alienation and local communities: case studies in Hyderabad-Secunderabad". Economic and political weekly, 42 (31), 3233-3240.

Rigby, D; Woodhouse, P; Young, T and Burton, M. (2001) "Constructing a farm level indicator of sustainable agricultural practice". Ecological Economics, 39 (3): 463478.

Rigby, D and Caceres, D. (2001) "Organic Farming and the Sustainability of Agricultural Systems". Agricultural Systems, 68 (1): 21-40.

Robinson, J. (2004) "Squaring the circle? Some thoughts on the idea of sustainable development”. Ecological Economics, 48: 369-384

Rodulescue, C; Stephen, R and Harrison, P. (2010) "The assessment of indictors for sustainability". Ecology and Society, 21(2): 39-45

Saaty, T.L. (1980) “The Analytic Hierarchy Process, Planning, Priority Setting, Resource Allocation”. New York: McGraw-Hill.

Saaty, T.L and Alexander, J. M. (1989) "Conflict Resolution-The Analytical Hierarchy Process". New York: Praeger.

Sadok, W; Angevin, F; Bergez, J; Bockstaller, C; Colomb, Bruno, G and Laurence et al. (2008) "Ex ante assessment of the sustainability of alternative cropping systems: implications for using multi-criteria decision-aid methods". A review.Agron. Sustain. Dev. 28 (1): 163-174.

Sarbin, T.R.and Kitsuse, J. I. (1994) “Constructing the social” .London, Thousand Oaks, Calif: Sage.

Shannon, S and Maccann, E. (1996) "Farmers Attitudes about Farming and the Environment: A Survey of Conventional and Organic Farmers". Journal of Agricultural and Environmental Ethics, 9 (2): 123-143.

Strassert, G and Tony, P. (2002) "Selecting farming systems using a new multiple criteria decision model: the balancing and ranking method". Ecological Economics, 40: 267277.

Tatlidil, F; Boz, İ and Tatlidil, H. (2009) "Farmers' perception of sustainable agriculture and its determinants: a case study in Kahramanmaras province of Turkey". Environ Dev Sustain, 11 (6): 1091-1106. 
Taylor, D; Mohamed, Z; Shamsudin, M; Mohayidin, M and Chiew, E. (1993) "Creating a farmer sustainability index: A Malaysian case study". American Journal of Alternative Agriculture, 8, 175-184.

Tiwari, D.N; Loof, R and Paudyal, G.N. (1999) "Environmental-economic decision-making in lowland irrigated agriculture using multi-criteria analysis techniques". Agricultural Systems, 60 (2): 99-112.

van Calker, K.J; Berentsen, P.B; M. G., Gerard, W. J and Huirne, R. B. M. (2005) "Identifying and ranking attributes that determine sustainability in Dutch dairy farming”. Agric Hum Values, 22 (1): 53-63.

Vanclay, F. (2010) "The impact of deregulation and agricultural restructuring for rural Australia". Australian Journal of Social Issues, 38 (1): 81-94.

World Commission on Environment and Development (WCED). (1987) "Our common future". Report of the World Commission on Environment and Development. Published as an Annex to the General Assembly Document A/42/427. United Nations

Webster, P. (1999) "The challenge of sustainability at the farm level. Presidential address". Journal of Agricultural Economics, 50 (3): 371-38.

Wind, Y and Saaty, T. L. (1980) "Marketing Applications of Analytical Hierarchy Process". Management Science, 26: 644-658

Willams, D.R and Roggenbuck, J.W. (1989) "Measuring place attachment: Some preliminary results”. (Eds.) McAvoy, L., H., \& Howard, Abstracts: 1989 Leisure Research Symposium (p.32). Arlington, VA: National Recreation and Park Association.

Yappa, L. (1996) "What Causes Poverty? A Postmodern View". Annals of the Association of American Geographers, 86 (4): 707-28. 


\title{
5. Sustainability and Social innovation - A case study of the adoption of organic farming in the Greater Hyderabad Area, India
}

\begin{abstract}
Agriculture in the urban fringes of the South Indian megacity of Hyderabad suffers from an enduring crisis. The major drivers for this crisis perhaps seems to be increasing production cost, land and labor scarcity as well as volatile product prices which substantially call for changes including technological and social innovation. This paper analyses the a case of the South Indian village of Enabavi where farmers of an entire village located in the Greater Hyderabad Area have decided to collectively switch to another agricultural production system. The study analyses farmers' decision processes and the factors accompanying the successful collective action out from a social innovation perspective. We find that this case strongly underpins a case in point to formulate better policies in order to construct sustainability in peri-urban agriculture concerned to growing megacities of developing countries.
\end{abstract}

Keywords: Sustainability; peri-urban farming; societal innovations; community participation, Hyderabad; India. 


\section{$5.1 \quad$ Introduction}

“...the emergence and implementation of new ideas about how people should organize interpersonal activities, or social interactions, to meet one or more common goals, as with other forms of innovations may vary with regard to breadth and impact" (Mumford 2002)

Over the last few decades the major policy supports for Indian agriculture are fairly skewed towards technological innovation for example subsidizing energy for irrigation, particular farm inputs like seeds and fertilizers as well as farm credit mostly to the rural farmers. But much of the support systems does not broadly apply to the farmers in the urban fringes which is mainly due to the protuberant space conflict. Instead agriculture in the urban fringes of the South Indian megacity of Hyderabad suffers from an enduring farm crisis. In these urban shadow space the increasing production cost, land and labor scarcity as well as volatile product prices call for strategies of exit or renovation. Various researchers have described bottom up movements and access to social capital as the bedrock of agricultural innovation (Subramaniam and Youndt 2005). The idea is that facilitating peoples' access to assets and enhancing their social capabilities can help them to take their futures in their own hands and self-invent new strategies for overcoming rural crises. (Bebbington 1999). Social innovations are showed to be an isolated solution for such crisis around various parts of the world.

This paper has profoundly shed some light to describe such concepts of social innovation and attempt to formulate hypotheses about the process and success factors shaping social innovation. I will then use concepts and hypotheses to structure a narrative about an eccentric case of social innovation in which farmers in a South Indian village successfully escape agricultural crisis through a complete and collective change of their farming system. Finally I will draw conclusions for the importance of social innovation and collective action for the future of peri-urban agriculture in the GHA. 


\subsection{Social innovation}

The sociologist Ogburn (1964) in his work on "Culture and Social change" has theoretically distinguished technical from social innovations, describing the technology as a "main driver of social change" but accepting that social innovation can accidently happen in the process of technological innovation or even become the prerequisite or objective of innovation (Gillward 2000). Gillward describes social innovations as collective knowledge and know-how achieved by a society in order to achieve some form of cultural and technical change (Gillward 2000). In similar fashion, Volckman (2010) indicates that a social innovation perspective is suitable to assess the transformation potential of a particular collective action. In addition Moulaert et al. (2005) argue that social innovation processes have a higher chance for success when civil society, and community development are integrated. Adams and Hess (2008) foresee that social innovations could be exclusive strategies to confront societal needs with substantial capacity building and potential for change. In general social innovations are described as an outcome of collective and creative learning processes and significantly representing a circular process of learning rather than a linear one (Oreszczyn et al. 2010). For example, if farmers interact with each other in groups which could facilitate a new kind of social learning and may lead to new types of farmer organizations. If farmers and citizens interact this may provoke other types of innovative organizations like Community Based Agriculture Organizations or Multi-Stakeholder Cooperatives. (Lamine 2005).

\subsection{Stages of social innovation}

The literature recognizes three crucial approaches that motivate the development of social innovation. The first approach includes, the process where first -the external actors facilitate development of social innovation (top-down approach), second- the local actors develop the social innovation based on need (bottom-up approach) and the third-involvement of external actors to facilitate the local institutional capacity to be able to mobilize local resources and develop social innovations. All these approaches significantly recognize the role of the "community" as main actor of social innovation and conclude that any successful social innovation depends on the characteristics of the community. The local communities are 
mainly responsible for the reconfiguration of social-spatial relations in the region and may put emphasis on grass-root or place based innovations (Moulaert and Nussbaumer 2005). Furthermore communities provide a level playing field for residents which facilitates learning, institutional mechanisms as central elements and determines the eminence of participation and collaborative governance (Anshell and Gash 2008)

Howaldt and Schwartz (2010) disclose that social innovations do not occur as artifacts but are "bounteous outcomes of social practice". In summary, a review of the relatively young literatures on social innovation reveals that social innovation is believed to rely on 'collective action' are unique outcomes of a collaborative action among the network of actors associated with similar interests and are highly related to the existence of social capital (Putnam 1992).

As a result the need or incentives to change attitudes or behavior trigger the initial impetus and are responsible for the development of social innovations. This initial impetus could be motivated through factors that are either internal or external to the actors involved in the social innovation process. These are relatively built on the features of novelty with massive focus on changes of attitudes and behavior and perception. They do not focus on needs, but they attempts to build the assets (Neumeier 2011).Based on the above theoretical concepts the social innovations could be summarized as follows

Problematization -In this phase a small group of actors (farmers) determines to change from their normal way of doing prompted by need or other problems. The initial impetus for this change could be an idea or identification of a problem by the initial actors or initial group of actors in the community -or it could be due to external influence (development programs by government or NGOs)

Expression of Interest - Through their contacts with the initial actors, other actors hear about the changed behavior and attitudes and become interested. If they see some kind of advantage for themselves in adopting these new forms of practices, they decide to mimic or adopt them

Delineation or coordination - In this phase further negotiations and co-evolutionary learning will happen. Gradually the new form of action becomes shaped or solidifies. If a 
critical mass of actors decide to adopt the new form of action it leads to a tangible social innovation otherwise it fails

Building on the above conceptual models in the subsequent sections I analyze Enabawi a village in the neighborhood of the GHA as a case in point for social innovation towards sustainable peri-urban agricultural development. Enduring consequences of agricultural crisis in Enabawi motivated farmers to explore new opportunities. Social innovation enabled farmers to shift from conventional way of doing farming to a novel approach where farmers in the village completely shifted to organic farming. In line with our review of literature the following hypotheses give structure to our analysis: (1) "The process of social innovation typically happens in stages in which successful innovators have to pass some "point of no return". (2) Participation and collective action are the core elements in the pursuit of social innovation. : Research questions guiding the research process are as follows:

What are the drivers of the process of change in Enabavi, what phases of change can be separated?

What is the role of cooperation and collective action in the process?

What are key motivational incentives/other factors motivating/impeding the sustainable (re-)organization of peri-urban agriculture?

\section{$5.4 \quad$ Research Method}

To explore answers to the above research questions this research relied on a single case-study approach which explains how and why some novel things happens by looking in detail at the inner workings of the case. Therefore the case was chosen because it is broadly interesting and thought to be typical of other types of social innovations in agriculture (Shiffman 2004) My research subject is -a whole village's adoption of organic farming; which broadly includes the prominent key investigating point covering behaviour of the actors, the decision points they faced, the choices they made, why the path has been taken and the manner in which their choices generated events and outcomes (Bates et al. 1998). 
To explore the main causalities and transformation process in this case I adopted a "mixed-method" of research combining both qualitative and quantitative methods. The qualitative methods are basically aimed to understand the process of transformation, historical evolution and the desire to change towards shift in alternative methods of farming practice in this village. For this purpose I conducted in-depth interviews with different stakeholders involved in the process of transformation. Alongside I organized focus group discussions in the village to better understand the perceptions, views and experiences among the community. Similarly to facilitate focus group discussions, I used the "Historical matrices" adopted from Thompson and Freudenberger (1997) to capture the changes in the community during the social innovation process. In addition to this I used the concept of a "Resource Exchange Matrix" adopted from Kuehnast and Dudwick (2004), where my main aim was to get feed- back on day to day interactions during the focus group discussions in order to understand the level of social capital.

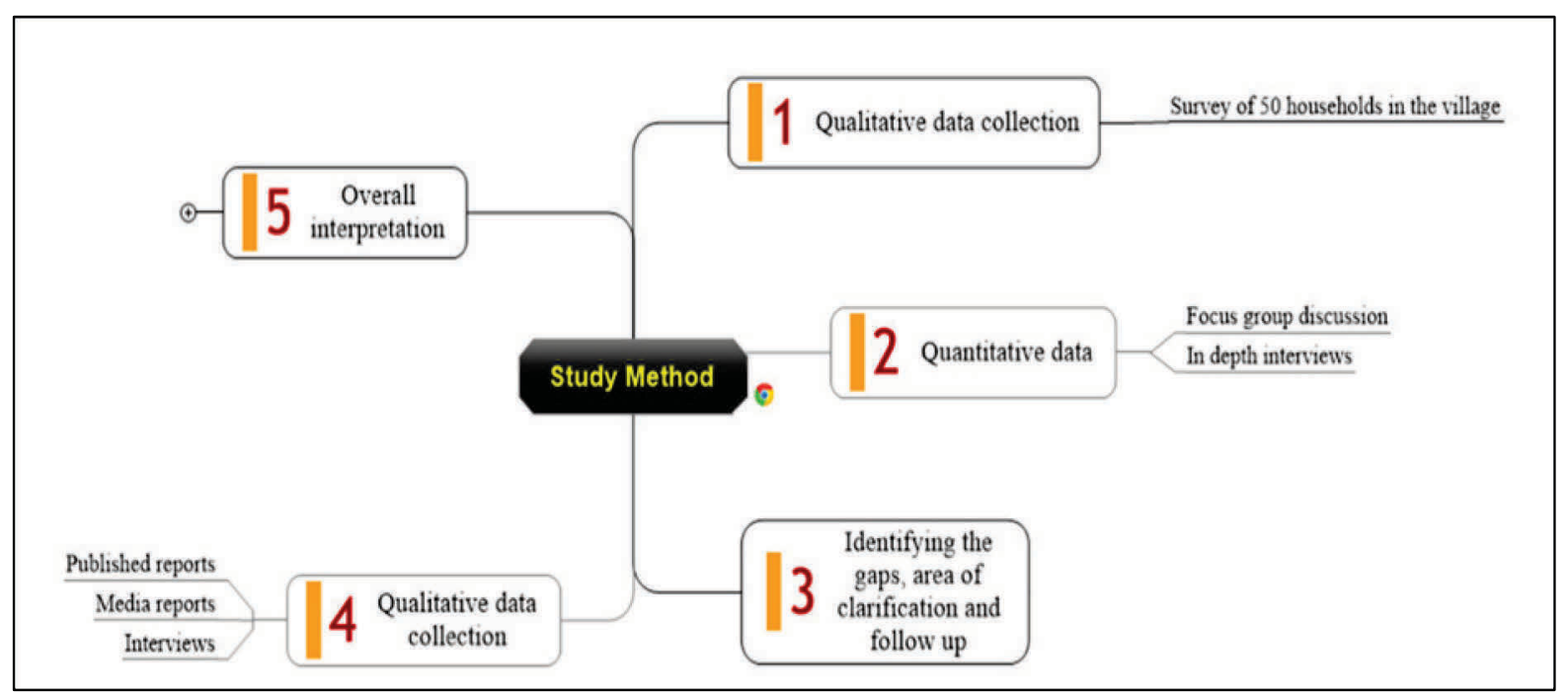

Figure 5-1: Research Method

Source: Adopted from McMohan's (2007) sequential exploratory mixed methods degin

In a similar vein to obtain the insights related to support institutions and their importance for the community I relied on the tools suggested by Narain and Shah (2002) for institutional analysis. Quantitative data was derived from an individual survey with all the 50 household heads through semi-structured interviews. The study has adopted variables like trust, bonding, bridging, group characteristics, generalized norms, togetherness, everyday 
sociability, neighborhood connections, and volunteerism known from the social capital assessment literature (Narain and Cassidy 2001). To explore the most influencing variables for the process of change and the success among the selected variables, I have conducted a Factor analysis with strata. (Barrett \& Kline, 1981), (Aleamoni, 1976). The studies (Mundform and Shaw 2013) indicate the 2 factor extraction with sample size of 40-80 could be a best possible option to achieve excellent level of criterion (0.92). Factor analysis was performed using "principal factor extraction" where I ultimately retained factors with Eigen values higher than 1. Furthermore to underpin and check results, I relied on the information of local newspaper articles and reports prepared by the facilitating organizations.

\subsection{Results}

\subsubsection{Determinants of crisis in-Enabavi}

Farmers in Andhra Pradesh are confronted with escalating crisis due to intensive chemical use in farming of which eventually increases the production cost and largely impact the health. In addition the farmers are highly depend on input dealers who are both acting money lenders for the provision of inputs and at the same time buyers of the farm produce. The substantial increase in production cost with high input use is responsible for farmers' indebtedness in rural and peri-urban areas. Enabavi, a small village with a population of 207 members near $80 \mathrm{Km}$ from North of Hyderabad City, capital of Andhra Pradesh, India is now in limelight and probably the first modern-day organic farming village in Andhra Pradesh.

The farmers of the entire village have collectively decided to evade the use of chemicals in agriculture. They neither use chemical fertilizers nor chemical pesticides in their farming. This kind of transformation in itself meant a tremendous saving for the village in monetary terms. This small village in Warangal district belongs to Lingala Ghanpur mandal shows the way out of agricultural distress that almost all farmers find themselves in today.

Enabavi village is now turned out into a social learning center and standing as a guiding light to farmers in agrarian distress. Enabavi farmers have become champions on sustainable agriculture technologies. Today they teach other farmers about sustainable farm technologies as resource persons. 
Table 5-1: Profile of the village

\begin{tabular}{llllll}
\hline S.NO & Variable & Mean & Min & Max & Std.Dev \\
\hline 1 & Age & 49.5 & 35 & 65 & 7.8095 \\
2 & Male & 1.021 & 1 & 2 & 0.1474 \\
3 & Female & 1.130 & 1 & 2 & 0.3405 \\
4 & Girls & 1.681 & 1 & 3 & 0.716 \\
5 & Boys & 1.433 & 1 & 3 & 0.626 \\
6 & Farming experience & 25.36 & 15 & 45 & 5.930 \\
7 & Experience on organic farming & 11.5 & 7 & 20 & 2.492 \\
\hline
\end{tabular}

$N=50$ Households

It is a small village where the entire community in the village has decided to change the way they do agriculture. The main reason behind this transformation is the distress from intensive chemical use and marginal profits in farming. With just 50 households in the village residents mostly belong to the backward castes, the village started shifting to non-chemical farming about 5 years ago. Then in 2005-06, the entire land of 282 acres was converted to organic farming in the village.The farmers in the village "declared to shift towards organic farming" which represents an innovation by the community to do away with farm crisis. This case is a good example for emergence of bottom-up innovation with strong participation of communities. Though there are no formal guarantee systems established in the village, there is strong social regulation within the community to ensure that there are no 'erring farmers'.

Retrospectively, the village has evolved with a strong desire among few agricultural workers to own and cultivate on their own land. At first, five agriculture labour families purchase certain piece of land from the local Nijam Nawab during 1962.

"...We acquired 133 acres of land for INR 25000 from the nawab and when we saw the field it was just a waste land with a nearby hillock and that's the reason we name this as Enabavi- means a place of open-wells and rocks" says Ponnam Mallaiah (personnel communication with a farmer in the village) recollecting those days. 
There is restless efforts and lot of labour in making the empty land into a village which has started during 1962 initially with 13 farm families. Then agriculture becomes their livelihoods and that took its own transformation in the process. Similar to other villages in India they also shifted to chemical farming and initially harvested better yields. Then after few years they also started intensifying the use of chemicals in farming (from 1975 to 1995) and caught up in debt traps with insects developing resistance to chemicals.

\subsubsection{The beginning of transformation (Problematization)}

During 1995 there was massive outbreak of insect- Red Hairy Caterpillar (RHC) that generally invades the crop in swarms. The hairiness on the insect averts the insecticides to reach the body and kill them. Farmers started spraying very intensively to manage the pest but they could not. In the process they are heavily indebted to the input agencies. In addition to these huge debts along with high production cost shoved them into crisis. They were frustrated to continue farming and were desperately looking for helping hand. Although few farmers approached the local agricultural department but they use to recommend certain high dosage chemical sprays with different formulations which were ineffective on the insects.

\subsubsection{Expression of interest and coordination}

At this time the local NGO; Centre for Rural Operations Program Society (CROPS) was working on a campaign mode on creating awareness about sustainable agricultural practices in those areas. The NGO approached the farmers and advised farmers to collaborate to manage the pest. The Centre for Sustainable Agriculture, a Hyderabad based NGO trained the farmers on different approaches to effectively manage insect, soil management and seed management. Under the guidance of CSA and determined coordination of local NGOCROPS, all the farmers decided to participate and collectively eradicate the insect. This decision has relatively set off the foundation for collective action among the villagers for effective participation and collective action.

\subsubsection{Collective action}

The focus group discussion with the core group in the village reveals the details of collective action where the whole community was involved in change. They report few 
activities collectively done by the community to eradicate the insect through the awareness generated by the NGOs. (1) Installation of light traps in all the fields - All the farmers participated in installing light traps in the fields and community pest surveillance has been done by the farmers. (2) Community bonfires -Farmers after dividing into groups collected the waste debris in the village and put fires every day 6 to $9 \mathrm{pm}$ to attract the adult month and fall in the fire. (3) Shaking of plants- In case of pigeon pea crop farmers divided into groups and they spread some mats under the crops. Further they manually shake the branches so that the caterpillars are forced to fall on the plastic mats. (4) Tank silt application- to abandon the use of chemical fertilizers the entire community invested their labour in collecting, transporting and distributing the tank silt among the farmers. Similar kind of collective action was done in other farming practices related to farming.

"I installed 30 light traps in my field and we use to observe the falling moths into gasoline filled tubs attracted by light and that really made us to believe on the alternatives" (personal interview, Ponnam Paramesham, Enabavi, Dated 20. 09.2012).

\section{Similarly Ettaboina Mallesham proudly reports that}

“....they could efficiently manage boll warms collectively on crops like Pigeon pea, Castor through shaking and hand picking of the insects and completely abandoned using chemicals in their farming"

and further recollecting the days of transformation and he says that

"...the pesticide dealers in Janagam town are surprised about this successful management".

The quest for change in the village has stipulated with massive crop damage by the insects and subsequent ineffectiveness of agrochemicals. At the same time the increasing debts due to indiscriminate use of chemicals has relentlessly incited them to explore the alternatives in order to get rid of farm crisis and move away from crop loss. This phase could be explicitly described as "Problematization" phase in the social innovation process Figure 52). The search for alternatives helped the farmers to build external linkages and acquiring awareness through facilitation of external agents. 


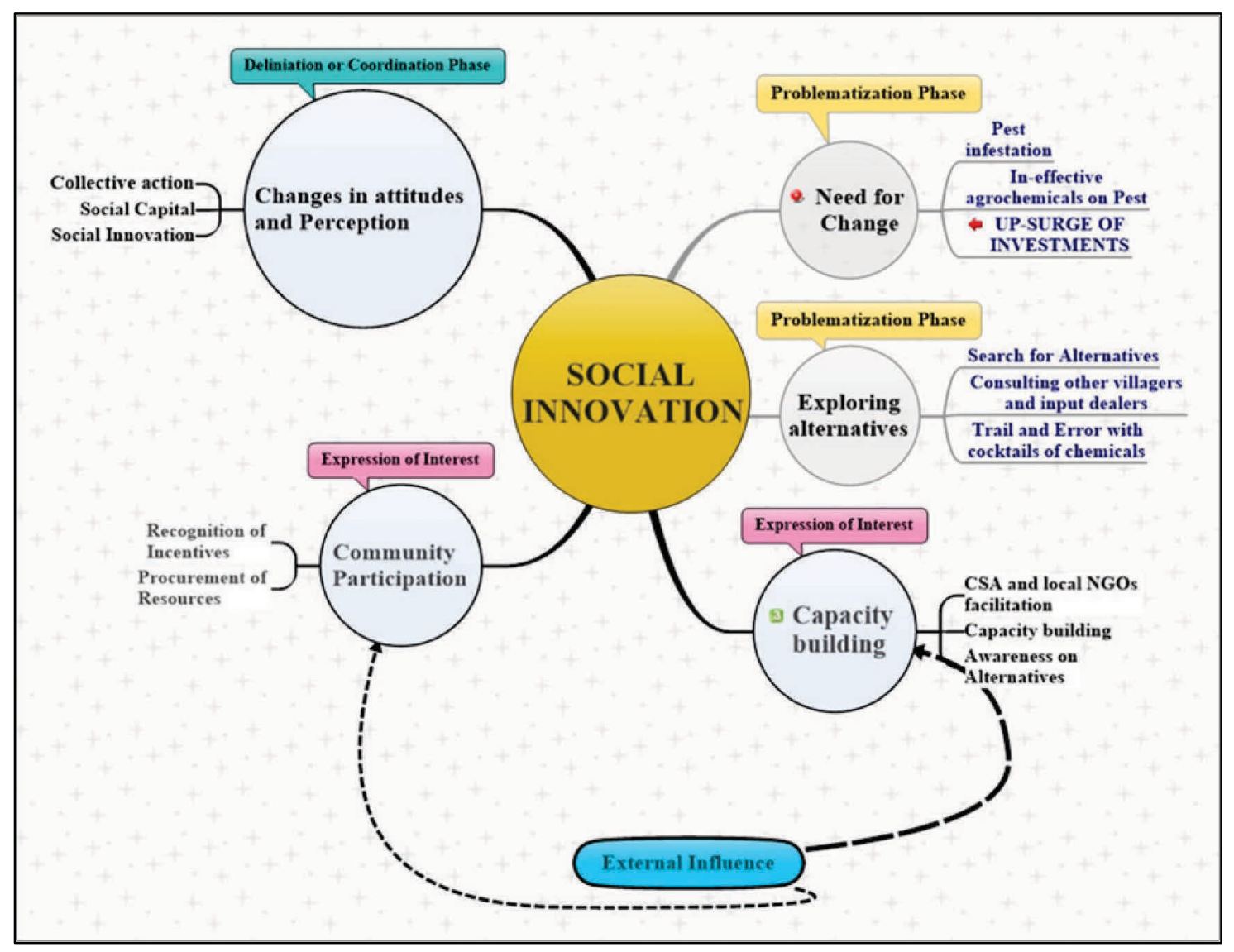

Figure 5-2: The Process of Change

This is the real instigation of transformation in the whole case of social innovation. Subsequently the awareness generation has followed through expression of interest by the community to participate eventually initiated the process of capacity building of the farmers. The further activities of community participation and collective eradication of pest could clearly represent the typical coordination phase. It was followed by recognition of incentives and increase in social bondage leading to scaling up of the social innovation to the whole village.The following table (Table 5-2) indicates increase in participation, collective action, and trust over the years in the process of village evolution. Similarly the data on resource exchange indicates the exchange of farm inputs, farm resources is high and more frequent in the villages compared to other villagers. The experience sharing, trainings, and transport of produce is similar to other villagers. Labour sharing more frequent within the village and neighbor village.

A simple ranking exercise was done with farmers to rank the trust, timely help, ( 
) effective coordination and participation among the various organizations, networks involved in the social innovation process. Results indicate that the farmers avow more weight to local NGO with respect to all the aspects compared to other organizations, followed by organic cooperative in the village. The villagers avow less weight to extension officials, money lenders and similarly to the banking institutions. The capacity building NGO (CSA) along with the seed groups in the village ranked an average weight. The outcome of the focus group discussion indicates the reliability on the local NGO in the entire process of social innovation.

Table 5-2: Historical Matrix of change in the village

\begin{tabular}{|c|c|c|c|c|c|}
\hline $\begin{array}{l}S \\
N \\
o\end{array}$ & Particulars & $\begin{array}{l}\text { When } \\
\text { commu } \\
\text { nity/vill } \\
\text { age } \\
\text { establis } \\
\text { hed }\end{array}$ & $\begin{array}{l}\text { When } \\
\text { farmers } \\
\text { shifted to } \\
\text { organic } \\
\text { farming }\end{array}$ & $\begin{array}{l}\text { When } \\
\text { village } \\
\text { declared } \\
\text { total } \\
\text { organic }\end{array}$ & Present \\
\hline 1 & $\begin{array}{l}\text { Number } \\
\text { Households }\end{array}$ & 13 & 45 & 50 & 50 \\
\hline 2 & $\begin{array}{l}\text { Number of } \\
\text { groups/cooperatives } \\
\text { in the village }\end{array}$ & - & $\begin{array}{l}\text { One woman } \\
\text { group, four } \\
\text { SHGs, four } \\
\text { farmer groups }\end{array}$ & $\begin{array}{l}\text { One } \\
\text { woman } \\
\text { group, } \quad 5 \\
\text { SHGs, } 4 \\
\text { farmer } \\
\text { groups and } \\
\text { one } \\
\text { cooperative }\end{array}$ & $\begin{array}{l}\text { One woman group, } \\
5 \text { SHGs, } 4 \text { farmer } \\
\text { groups and } 1 \\
\text { cooperative }\end{array}$ \\
\hline 3 & $\begin{array}{l}\text { Trust among the } \\
\text { people }\end{array}$ & $* *$ & $* * *$ & $* * * *$ & $* * * *$ \\
\hline 4 & $\begin{array}{l}\text { Peoples } \\
\text { participation }\end{array}$ & $* *$ & $* * *$ & $* * * *$ & $* * * *$ \\
\hline 5 & Collective action & $*$ & $* * *$ & $* * * *$ & $* * * *$ \\
\hline 6 & $\begin{array}{l}\text { Frequency } \\
\text { conflicts }\end{array}$ & $*$ & $*$ & - & - \\
\hline 7 & $\begin{array}{l}\text { Local Agricultural } \\
\text { officials support }\end{array}$ & - & - & - & - \\
\hline 8 & $\begin{array}{l}\text { Support from local } \\
\text { NGO }\end{array}$ & $*$ & $* * *$ & $* * *$ & $* * *$ \\
\hline
\end{tabular}




$\begin{array}{llllll}9 & \begin{array}{l}\text { Support from } \\ \text { Coordinating NGO }\end{array} & - & * * * * & * * * * & * * * \\ 1 & \text { Production cost } & \text { High } & \text { Average } & \begin{array}{l}\text { Drastically } \\ \text { comedown }\end{array} & \begin{array}{l}\text { Drastically } \\ \text { comedown }\end{array} \\ 0 & \text { High } & \text { High } & \text { Better } & \text { Better } \\ 1 & \text { Market issues } & \text { Less } & \text { More } & \text { Less } & \text { More } \\ 1 & \text { Yields } & & & & \\ 1 & & & & & \end{array}$

Source: Focus group discussion in Enabavi village dated 22/09/2012

The focus group discussion unpacks the following reasons behind togetherness in the village. The farmers were informed that when they joined the community they all decided to live together helping each other. They report that they all exchange ideas, respect each other opinion and daily share their experiences in farming, marketing, family issues in the evening get together. They all said that

“... Community control of Red Hairy caterpillar eventually enhanced our mutual trust and helped us to build strong community sense among each other".

Table 5-3: Villagers attribution of importance to various organizations about trust and coordination

\begin{tabular}{llllll}
\cline { 3 - 5 } & \multicolumn{2}{l}{ Total Score 100 } & \\
\hline S.NO & Organizations & Trust & Timely help & $\begin{array}{l}\text { Effective } \\
\text { Coordination }\end{array}$ & $\begin{array}{l}\text { Participation } \\
\text { in village } \\
\text { issues }\end{array}$ \\
\hline 1 & & & 60 & 90 \\
2 & Organic cooperative & 90 & 90 & 90 & 80 \\
3 & Seed groups & 80 & 70 & 100 & 90 \\
4 & Local NGO & 100 & 100 & 80 & 70 \\
5 & Capacity building & 50 & 60 & 10 & 5 \\
6 & Extension officials & 10 & 20 & 20 & 0 \\
7 & Money lender cum & 20 & 20 & 40 & 10 \\
\hline
\end{tabular}

Source: Focus group discussion in the village dated 22/09/2012 


\subsubsection{The household level factor analysis}

At the household level in depth interview were conducted with the 50 individual households in the village and segregated the variables into two sets of data. The results are analyzed using principal factor analysis in stata 10.2. One set of observations (Table 5-4) include intensity of participation, individual interest in collective action, and feeling of togetherness, social cohesion and identity among the villagers at various levels. Similarly the second set of observation includes variables related to reciprocity, community norms, community enforcement and trust. The number of factors retained based on the stipulation where the Eigen value is more than one.

Table 5-4: Factor results on participation and collective action

\begin{tabular}{lll} 
Description & Factor Eigen value \\
\hline Variable & $1(1.9951)$ & $2(1.1932)$ \\
\hline $\begin{array}{l}\text { Frequency of participation in community } \\
\text { activities }\end{array}$ & 0.2329 & 0.5469 \\
Participation in village meeting & 0.0224 & -0.5891 \\
Participation in trainings & 0.9627 & -0.0879 \\
Participation in policy platforms & 0.0614 & 0.1009 \\
Participation as community resource person & -0.0006 & -0.4315 \\
Individual participation in collective action & 0.9584 & -0.1651 \\
Community planning & -0.1043 & -0.0054 \\
Volunteerism among the villagers & 0.2343 & 0.4981 \\
Social cohesion & 0.1580 & -0.0064 \\
Togetherness & 0.0227 & 0.2598 \\
\hline
\end{tabular}

Unrotated

For obtaining a clear picture we have rotated the factors with 'varimax' rotation inbuilt in the factor analysis. The data indicates that two factors exclusively Factor 1 and 2 have fairly influenced the participation in the village. 


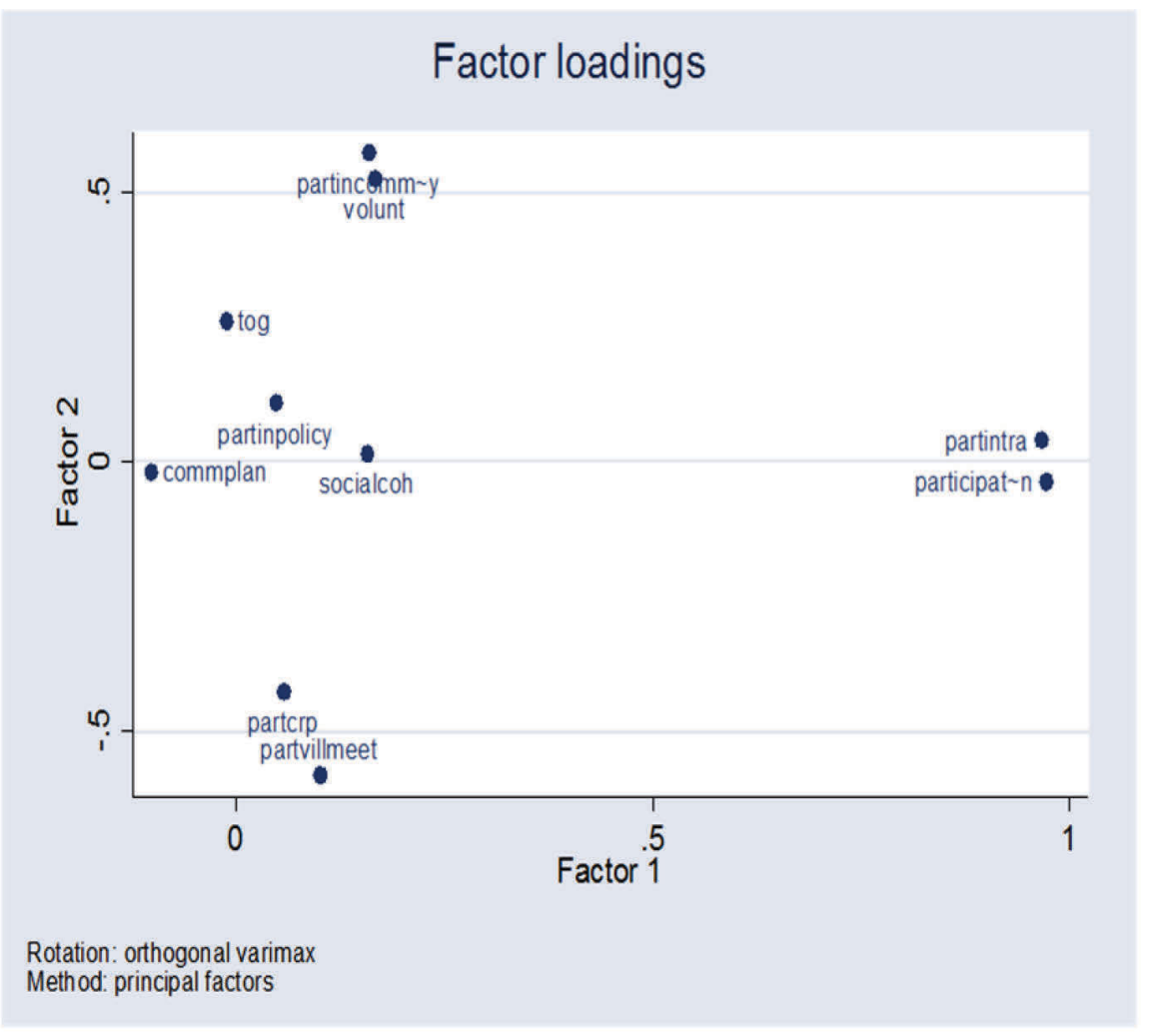

Figure 5-3: Factor loading graph of participation factors

Two important variables have shown their maximum loading on Factor 1 with Eigen value more than 0.7$)$ of (1.9951). Those variables include participation in trainings (0.9627) and participation in collective action (0.9584).

The frequency of participation in community activities has loaded on Factor 2 (0.5469) and followed by volunteerism among the villagers $(0.4981)$ but these factors have not densely represented as the other two variables in the Factor 1. The above analysis strongly underpins (Figure 5-3) that the Factor 1 has strongly influenced the whole process of social innovation and the success in the village related to the first set of observations and the Factor1- could be named as (Participation in trainings + Individual participation in collective action). The above graph clearly indicates the loading of various factors at the factors with Eigen value more than 1. In the same manner the Factor 2 represents the combination of frequency of participation in community activities + volunteerism among the villagers which has certain influence on the process of change loading at low level 
Subsequently in the second set of observations describes the variables related to community norms, group interactions along variables concerned to trust dimension. We have extracted two factors using principal factor analysis in stata 10.2 and the results reveal that the Factor 1 is compactly loaded with community enforcement (0.9303), trust on local NGO (0.8776) together with a distinguished influence of commitment to community decision making in the village (0.5269). The results explicitly indicate that the Factor 1 denotes (a combination of variables influencing Community enforcement together with a high level of trust to the local NGO. The factor loading graph (Figure 5-4) provides us with a clear picture about the level of influence of different variables. For example on Factor 1 the community enforcement and trust on local NGO is loaded beyond 0.8 points and the commitment to community decision by the villagers has loaded at the range of 0.6 and all other factors are loaded at the lower range indicating the lower influence.

Table 5-5: Factor results of Trust and community interactions

Factor Eigen value

\begin{tabular}{lll}
\hline Variable & $1(2.255)$ & $2(1.459)$ \\
\hline Commitment to community decision & 0.5269 & -0.1885 \\
Respect to community norms & 0.1747 & 0.2333 \\
Community enforcement & 0.9303 & -0.0102 \\
Group interactions & 0.2480 & 0.6448 \\
Inter-group interactions & 0.2286 & 0.3385 \\
Intra-group interactions & -0.2114 & 0.0618 \\
People getting along each other & 0.3117 & 0.3034 \\
Help in case of need & -0.1431 & 0.3644 \\
Trust on villagers & -0.0165 & 0.5594 \\
Trust on leaders & -0.1809 & 0.0048 \\
Trust on local NGO & 0.8776 & -0.1996 \\
Trust on nodal NGO (CSA) & -0.0000 & 0.4114 \\
Trust on fellow farmers & -0.0181 & 0.0556 \\
Trust on neighbors & 0.0008 & -0.1255 \\
Trust on technology adopted & -0.0468 & 0.2636 \\
\hline
\end{tabular}

Unrotated 


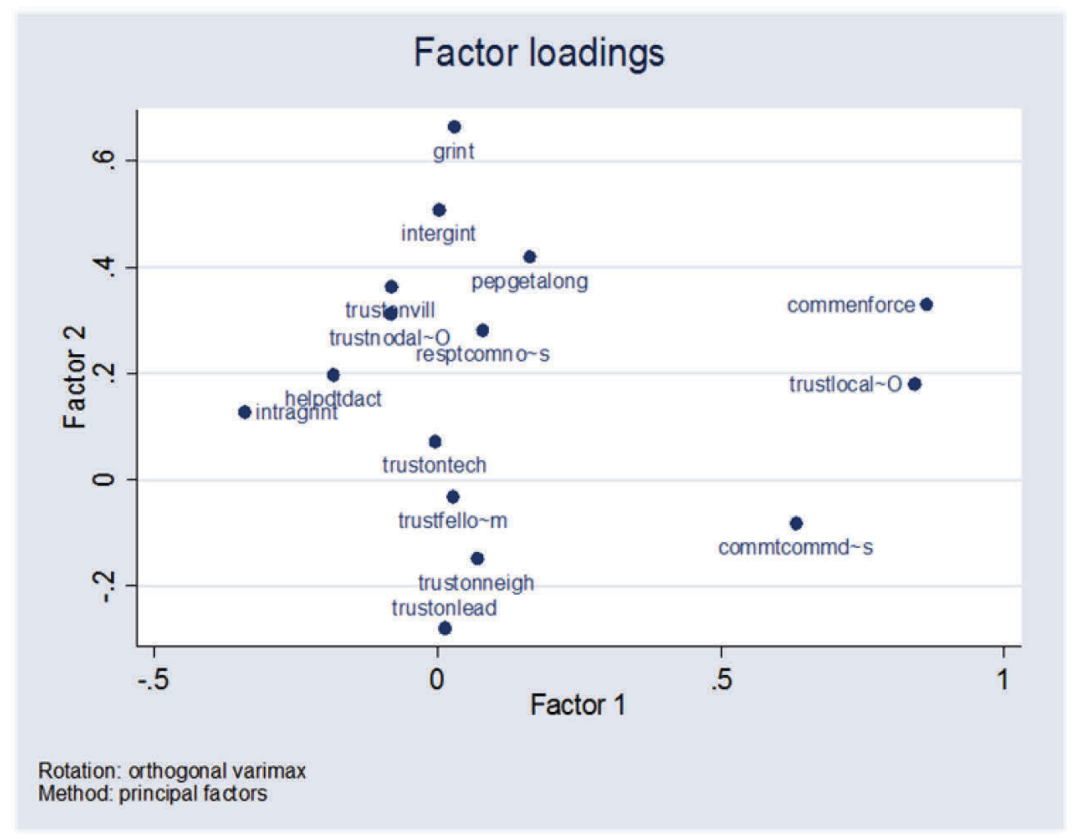

Figure 5-4: Factor loading graph on trust and community enforcement

Similarly the factor 2 represents group interactions at higher range loading (0.6448) followed by trust on villagers $(0.5595)$ and trust on nodal NGO $(0.4114)$ that embodies the relative strength of this factor. Similar pattern of loading could be seen on the factor loading graph portrayed above.

\subsection{Incentives for conversion}

The data on the motivational incentives for conversion indicates that reduction in cost of production as the main driver for conversion (50\% of the respondents). About $20 \%$ of them indicated healthy food as well. Similarly a $22 \%$ of the respondents reveal that better market access. Only $10 \%$ of the villagers indicate that better environment .The data on average yields performance in farming during the last five years from the household analysis disclose that only 18 percent of the farmers in the village indicated abrupt increase (very high). Furthermore farmers around 30 percent of the household report that the yields have gone up during last 5 years indicating high rank. In addition 46 percent of the households reveal that the yields remain same. At the end only 4 percent of the households inform that there is slight decrease in yields. 


\subsubsection{Exchange of goods and services among the villagers}

The data based on the focus group discussion related to exchange of goods and services indicates very high frequency of input exchange among the villagers compared to the frequency of exchange with other villagers. The exchange of better seeds is facilitated by the organizations involved in transformation through establishing seed banks in the village. They preserve the good seed and use their own seed instead of depending on external agencies. The diffusion of technology is more between the NGOs, and the villagers and then laterally spread to other villagers. In this process few farmers are especially regarded as (community resource persons) have become champions in explaining, training other farmers on technological front

Table 5-6: Resource exchange matrix

\begin{tabular}{|c|c|c|c|c|c|}
\hline $\begin{array}{l}S . \\
N \\
O\end{array}$ & $\begin{array}{l}\text { Goods/servi } \\
\text { ces being } \\
\text { transacted }\end{array}$ & $\begin{array}{l}\text { Among the } \\
\text { villagers/co } \\
\text { mmunity }\end{array}$ & $\begin{array}{l}\text { Neighbor } \\
\text { villagers }\end{array}$ & $\begin{array}{l}\text { Organization } \\
\text { s/network of } \\
\text { organizations }\end{array}$ & Other villagers \\
\hline 1 & $\begin{array}{l}\text { Farm inputs, } \\
\text { Tank silt }\end{array}$ & $* * *$ & $* *$ & $*$ & $* *$ \\
\hline 2 & $\begin{array}{l}\text { Irrigation } \\
\text { water }\end{array}$ & $* * *$ & $*$ & - & - \\
\hline 3 & Seed & $* * *$ & $* *$ & $* * *$ & $*$ \\
\hline 4 & $\begin{array}{l}\text { Technology } \\
\text { Know-how }\end{array}$ & $* * *$ & $* *$ & $* * *$ & $* *$ \\
\hline 5 & $\begin{array}{l}\text { Market } \\
\text { information }\end{array}$ & $* * *$ & $*$ & $* * *$ & $* *$ \\
\hline 6 & Trainings & $* * *$ & $* *$ & $* * *$ & $* * *$ \\
\hline 7 & $\begin{array}{l}\text { Transport of } \\
\text { produce }\end{array}$ & $* * *$ & $* *$ & $* * *$ & $* * *$ \\
\hline 8 & $\begin{array}{l}\text { Labour } \\
\text { sharing }\end{array}$ & $* * *$ & $* * *$ & - & $*$ \\
\hline 9 & $\begin{array}{l}\text { Farm } \\
\text { implements, } \\
\text { livestock }\end{array}$ & $* * *$ & $* *$ & $* * *$ & $* *$ \\
\hline 10 & $\begin{array}{l}\text { Experience } \\
\text { sharing }\end{array}$ & $* * *$ & $* * *$ & $* * *$ & $* * *$ \\
\hline
\end{tabular}

Source: Focus group discussion 22/11/2012,

Note: frequently $(* * *)$, occasionally $(* *)$, rarely $(*)$, never $(-)$ 
Finally the agriculture in the village has become a low budget after the villagers adopted organic farming. The village received "Krishi Gaurav" Award for the Patanjali Trust and has become a buzz word showing a path way for transformation. So far 100.000 people visited the village to learn about organic agriculture.

\subsection{Discussion}

Villagers of Enabavi have transformed their farming system towards organic agriculture. The process resembles the process of social innovation described by a growing number of theoretical contributions on the role of social innovation for agricultural development. Agricultural crisis in Enabavi was present long before the initiation of change. Crisis had culminated with the occurrence of a plaque which challenged the economic viability of the existing farming system. In a phase of problematization villagers started to look for the causalities' of the crisis in their village and for alternative ways of agricultural production. With the help of two NGOs already working in the region a few farmers pioneered the transformation of the farming system towards the conduct of organic farming while the NGOs convinced other interested farmers of the feasibility and advantages of organic farming. The process of social innovation following the initial phase was accompanied by the mobilization of collective action and community participation both closely coordinated by local NGOs. Factor analysis demonstrates the main determinants of endurance and the success of the process of sociol innovation. Participation in trainings, collective action of farmers defeating the plague, trust Vis a Vis the local NGO and the support of the village community as a whole all are important variables contributing to success. Interestingly it is not the environmental aspect which dominates the perception about organic farming. The case underpins theoretical claims that collective action and effective community participation are core elements of social innovation. Likewise the role of social pacemakers and facilitators as has been described by Neumeier (2012) can be observed in the case of Enabavi. 


\subsection{Conclusion}

Remarkably, farmers in Enabavi justify their decision to adopt organic farming mainly with economic reasoning: Savings in input cost due to independence from input dealers, increased networking among farmers and better yields and access to new markets are main arguments supporting their decision. This observation is important because in the literature the initial impetus for organic farming is often described as one of environmental sustainability. For small farmers in the South of India the economic dimension of sustainability seems to be the convincing argument to switch to a more sustainable farming system. This line of argumentation deserves more attention in future research on agricultural development as well as on the future political agenda for more sustainable peri-urban agriculture.

\subsection{References}

Adams, D and M. Hess. (2008) "Social innovation as a new public administration strategy". 12 th annual conference of the International Research Society for Public Management. Brisbane, 26-28 March.

Aleamoni, L. M. (1976) "The relation of sample size to the number of variables in using factor analysis techniques". Educational and Psychological Measurement, 36, 879883.

Anshell, C and Gash, A. (2008) "Collaborative governance in theory and practice". Journal of Public Administration Research and Theory, 18 (4): 543-571.

Armony, Ariel C. (2004) "The dubious link: Civic engagement and democratization". Stanford, Calif: Stanford University Press.

Ayer, H.W. (1997) “Grass Roots Collective Action: Agricultural Opportunities”. Journal of Agricultural and Resource Economics, 22 (1):231-235.

Barrett, P.T and Kline, P. (1981) "The observation to variable ratio in factor analysis". Personality Study and Group Behaviour, (1): 22-33.

Bates, R. H; Avner, G; Margaret, Levi and Jean-Laurent, R. (1998) “Analytic narratives”. Princeton, N.J, Princeton University Press.

Bebbington, A. (1999) "Capitals and Capabilities: A framework for Analyzing Peasant Viability”. World Development, 27(12): 2021-2044 
Bettina, K; Anett, K.W; Bokelmann Alexandr; D. W.Schwerdtner and Maria B. et al. (2012) "Analysing agricultural innovation system: a multilevel mixed methods approach". 131 EAEE seminar.

Bock, B. (2012) "Social innovation and sustainability: how to disentangle the buzzword and its application in the field of agriculture and rural development". Stagec, 114 (2): 5763.

Bowling, D.R; D.E.Pataki and J.T Randerson. (2008) "Carbon isotopes in terrestial ecosystem pools and CO2 fluxes". New Phytol. 178 (1): 24-40.

Defra. (2005) "Securing the future" Delivering UK sustainable development strategy. Available online at http://www.defra.gov.uk/publications/files/pb10589-securing-thefuture-050307.pdf.

Edwards-Schachter; Mónica E. M; Cristian E and Alcántara, E. (2012) "Fostering Quality of Life through Social Innovation: A Living Lab Methodology Study Case" Review of Policy Research.29 (6):672-692.

European Commission. (2011) "Europe.2020 Flagship Initiative Innovation Union". European Union, Luxemburg office. Available online at http://ec.europa.eu/research/innovation-union/pdf/innovation-union-communicationbrochure en.pdf.

Firdaus, G and Ahmad, A. (2011) "Impact analysis of urbanization on rural livelihood - an empirical study of an urban centre of Delhi, India". International Journal of Urban Sciences 15 (3): 147-160.

Franz, H.W; Josef, H and Hochgerner, J. (2012) "Challenge Social Innovation: An Introduction". (Eds.). Challenge Social Innovation, Berlin-Heidelberg, Springerverlag.

Gianluca, B and A.Rossi.(2000) "Synergy and Coherence through Collective Action: Some Insights from Wine Routes in Tuscany". Sociologia Ruralis, 40 (4): 409-423.

Godin, B. (2006) "The linear model of innovation: the historical construction of an analytical framework”. Science Technology Human Values, 31 (6): 639-666.

Godman, D. (2004) "Rural Europe Redux? Reflections on Alternative Food Networks and Paradigm Change”. Sociologia Ruralis, 44(1): 3-16.

Howaldt, J and Schwarz, M. (2010) "SI: Concepts, research fields and international trends". Report of ESF.EU: Dortmund, Aachen University.

Hubert, A. (2010)."Empowering the people, driving change. Social innovations in Europe”. Bureau of European Policy Advisors. European Union, Luxemburg office. Available online athttp://ec.europa.eu/bepa/pdf/publications_pdf/social_innovation.pdf. 
Khavul, S and Bruton, G.D. (2013) "Harnessing Innovation for Change: Sustainability and Poverty in Developing Countries". Journal of Management Studies, 50 (2), 285-306.

Kuehnast, K and Nora D. (2004) "Be Better a hundred friends than a hundred rubles? Social networks in transition". World Bank. The Kyrgyz Republic, Environmentally and Socially Sustainable Development (ESSD) Division. Wahinghton, D.C.

Lamine, C. (2005) "Settling Shared Uncertainties: Local Partnerships between Producers and Consumers". Sociologia Ruralis, 45 (4):324-345.

MacCallum, R.C; Widaman K.F; K.J Preacher and S, Hong. (2001) "Sample Size in Factor Analysis: The Role of Model Error". Multvariate Behavioral Research, 36 (4): 611637.

McMahon, S. (2007) "Understanding Community-Specific Rape Myths: Exploring Student Athlete Culture". Affilia 22 (4): 357-370.

Morse, J. M. (2010) "Simultaneous and Sequential Qualitative Mixed Method Designs". Qualitative Inquiry, 16 (6): 483-491.

Moulaert, F and J. Nussbaurner. (2005) "The social region: beyond the territorial dynamics of the learning economy". European Urban and Regional Studies, 12(1): 45-64.

Moulaert, F; Martinelli, F; Swyngedouw, E and González, S. (2005) "Towards alternative model(s) of local innovation”. Urban Studies, 42 (11): 1969-1990.

Murry, S .F and Elston M A. (2005) "The promotion of private health insurance and its implications for the social organization of health care: a case study of private sector obstetric practice in chile". Socialogy of Health and Illness, 27(6): 701-721.

Mundfrom, D.J and Shaw, D.G. (2013) "Minimum sample size recommendations for conducting factor analysis". International Journal of Testing, 5(2): 159-168.

Narayan, D and Cassidy, M. F. (2001) “A Dimensional Approach to Measuring Social Capital: Development and Validation of a Social Capital Inventory". Current Sociology, 49 (2): 59-102.

Narayan, D and P.L.Petesch. (2002) "From many lands". Washington, DC, World Bank, Oxford University Press.

Neumeier, S. (2012) "Why do Social Innovations in Rural Development Matter and Should They be Considered More Seriously in Rural Development Research? - Proposal for a Stronger Focus on Social Innovations in Rural Development Research". Sociologia Ruralis, 52 (1):48-69.

Ogburn, W. (1964) “On culture and social change”. Chicago: University of Chicago Press. 
Oreszczyn, S; Lane, A and Carr, S. (2010) "The role of networks of practice and webs of influencers on farmers' engagement with and learning about agricultural innovations". Journal of Rural Studies, 26 (4): 404-417.

Putnam, R. (2000) "Bowling Alone: The Collapse and Revival of American Community". New York, Simon \& Schuster.

Revi, A. (2008) "Climate change risk: an adaptation and mitigation agenda for Indian cities". Environment and Urbanization, 20 (1): 207-229.

Shiffman, J. (2004) "Political Management in the Indonesian Family Planning Program". International Family Planning Perspectives.30 (1): 27-33.

Subramaniyam, M and Youndt M.A. (2005) "The Influence of Intellectual Capital on the Types of Innovative Capabilities". Academy of Management Journal, 48 (3): 450463.

Thomas, G. (2011) "A Typology for the Case Study in Social Science Following a Review of Definition, Discourse, and Structure”. Qualitative Inquiry, 17 (6): 511-521.

Thomson, J.T and K.S.Freudenberger. (1997) "Participatory Rural Appraisal Tools that may be useful in an institutional analysis: Crafting institutional arrangements for community forestry," Food and Agriculture Organisation of the United Nations. Rome.Available online at http://www.fao.org/docrep/w7483e/w7483e0a.htm.

Volckmann, R. (2010) “Integral leadership” (Eds): R.A.Couto. Political and Civic leadership Los Angels, CA: Sage Publication.

Walter, C.N. (1985) "Indian Community Development, Local Government: Local Planning, and Rural Policy since 1950". Economic Development and Cultural Change, 33 (4):677-698. 


\section{Conclusion and Research outlook}

“Cities are complex adaptive systems comprising multitudes of actors, firms, and other organizations forming diverse relationships and evolving together. Frequent face-toface contact and other cooperative and competitive interactions enabled by proximity help to increase people's knowledge and skills, to improve their capacity to respond creatively to economic challenges, and to develop new improved products, processes and services. Other places cannot easily replicate these conditions" (Turok 2009)

The recent shift in focus at global level due to upsurge of food prices has fairly manifested to emphasize on food security in the urban areas. In relation to this there is growing interest to address the issue of sustainability and sustainable peri-urban agricultural development in the urban peripheries. Connected to these changes this dissertation has broadly made an extensive effort to understand the manner in which the farm adaptations crystalize in the urban peripheries due to drivers of urbanisation (Heimlich and Anderson. 2001).Considering these issues this research has significantly investigated the pace of farmers' adaptations in response to urbanisation along with the farmers' perceptions on continuity and profitability of peri-urban agriculture in GHA. While the research has significantly motivated to understand how the farmers in these areas relatively think and perceive about various sustainability dimensions and how far the enduring discourses play a key role in the adoption of farming systems in these areas. Since farmers cannot be separated from the farming systems, the adoption and development of a particular kind of development trajectory fairly depends on the socially constructed views on that particular technology or sustainability among them. Furthermore these areas significantly represent the loss of community sense and fading of land use ethics. Exploring sustainability in these contested spaces could be an excavation which indicates that sustainability is always a process of searching and learning. Further looking from this dimension in this research I attempted to analyze a case that strongly supports the need for designing societal involvement and collective action in order to achieve sustainability in the farming. Related to this the research has explored the emergence of social innovations where societies in case of need join hands together in order to achieve sustainable development pondering a case in the suburb of 
Hyderabad city. Disentangling such cases highly illustrates the need for fabricating such kind of societal innovations in order to achieve sustainability in these areas.

In the following section, I summarize the key findings of the research in the various chapters mentioned in this dissertation. Further I also draw attention to summarize the contribution of each paper to the empirical literature related to peri-urban agricultural development and the theories of farm adaptations in the urban fringe. Then, I discuss what policy recommendations could better formulated for the sustainable peri-urban agricultural development. Furthermore, I will describe the limitations of the dissertation. Finally I would indicate certain key areas that can be explored for future research concerned to peri-urban agricultural development.

\subsection{Key results and contributions}

Chapter 1 mainly focuses on literature review draws particular attention to the various developments of peri-urban agriculture in different parts of the world, such as Europe, North America, South East Asia and South Africa. It explores the ramification of rapid urbanization on food production at the urban periphery. At the same time it also provides for an overview of typical changes which farmers adapt in response to urbanization in various parts of the world. In addition it highlights the multiplicity of dynamics concerned to peri-urban agriculture development; concepts, approaches across the world. Subsequently the paper has comparatively provided better insights related to the dynamics of peri-urban agriculture, various drivers of structural change explicitly nuanced in literature by various researchers across the world. Further it has provided a brief summary of various concepts, approaches and diversities around the world. This review is intended to understand and summarize about various insights about the dynamics, development patterns, various diversities and concepts across the world.

The extensive literature review in various peer-reviewed articles published in a wide range of journals emphasizing peri-urban agriculture broadly provided me a vast range of theories, concepts, and approaches starting from urbanisation, peri-urban agriculture and farmers' adaptations. In addition to this I found a growing interest among the scholars 
considering the value perception on peri-urban farming and research related to examining the various constructed views among the consumers, urbanites on farming in the urban vicinities. Further, the review has profoundly provide me a direction to extend my focus on farmers' perception on sustainability after examining studies related to the social construction views of environment, sustainability in the peri-urban area, from the perspective of urbanities. While looking at the fabrication of sustainability in these areas, I found a wider strand of literature that has strongly built on the community development approaches and the need for the fabrication of social capital in the hinterlands (Sharp and Smith 2003). Furthermore I found distinct drivers of urbanization with a range of thrust areas in various parts of the world related to the peri-urban agriculture development.

Studies indicate that there is growing interest in crafting the sustainability of these areas in Europe and USA with much emphasis on recognizing the multiple roles of agriculture. At the same time the pace of development in China and other Asia- Pacific region is much more relayed on amenity driven approach along with promoting multifunctionality in agriculture. In contrast the pace of development in Sub Saharan Africa is highly driven by donor implemented projects to address the food security in these areas. Perhaps the emphasis in India seems to be much neglected to consider farming in the peri-urban areas and the thrust seems to be promotion of world class cities with industrial enclaves.

Over and above there is substantial neglect to address the specific needs and challenges of peri-urban populations especially in agriculture dependent populations around the world. They tend face huge risks due to overlapping trends of development in terms of socio-economic changes together with biophysical degradation and climate change impacts (Garscahngen et al. 2012). In addition the review recognizes that urban fringe has relatively received little attention from the perspective of local community shaping development process despite of their particular importance in emerging new economy in other areas (Bryant 1995). He argues that over the past 20 years literature has only some pointers about the role for local agency into urban fringe agriculture while summarizing the role of individual farmer and the farm family. Yet, little progress has been made to comprehend the locality, or socially constructed localized action space, values and beliefs in the urban fringe, particularly in its manifestations through the actions of local groups, organized communities (Bryant 1995) 
The review clearly illustrates that the research on sustainability assessment in periurban agriculture so far has poorly addressed (Binder et al. 2010). Some studies moderately indicates that the structural components of peri-urban areas are tend to be more resilient than the socio-economic system especially declining number of full time farmers and increasing number of farmers engaged in off-farm activities in these areas (Anne and Busck 2006). Related to this another study indicates the need to study the degree at which the interest in sustainability exists among the peri-urban farmers, and weather structural factors and farmers personal characteristics are more or less significant than social network factors to explain the farmers view of possible sustainable farming methods (Jussaume and Glenna 2009). Few studies in the literature emphasizes that the issue of land degradation is a "social construction" with different meanings for different individuals and there is more critical evaluation is needed on how the knowledge, understanding and the perception of local actors drive behavior and affect land use decisions at the micro-level in order to initiate sustainable environmental policies for the peri-urban areas (Macconiche and Binns 2006).

This literature review provided us a better insight to further investigate the drivers of urbanisation related to megacity development of Hyderabad. Further to explore the dynamics associated with farming in the Hyderabad peri-urban area and possible trajectories of agricultural development along with the underlying farmer adaptations.

Based on the insights from the literature for example few studies indicated land degradation is a social construction, similarly environmental concerns are social construct. These thoughts motivated us to thinks about social construct of sustainability among the periurban farmers of GHA. Further, a broad review on various group based approaches, community involvement in solving the natural resource problems fuelled us to explore the case of social innovations in the peri-urban Hyderabad which has its roots on collective action. Finally I found underrepresentation of research on peri-urban agriculture in Indian sub-continent.

In similar vein Chapter 2: Dynamics of peri-urban agricultural development and farmers' adaptive behaviour in the emerging megacity of Hyderabad, India This chapter is based on a field work study describes about the strategies of peri-urban farmers to react on 
the transformations taking place in the urban fringes of Hyderabad. ${ }^{9}$ The data indicates that along with the increasing cost of agricultural inputs like machines, water, fertilizer, pesticides and herbicides, environmental problems like the fall of the ground water table, soil degradation increase as well. To lower the costs farmers also expanded family labour, or had to resort to part time farming. Also agriculturists sometimes had to resort to different farming patterns. In general, current developments in the land use of agriculturists indicate an unsustainable use of natural resources, small scale farms disappearing, number of medium size growing.

In other words the findings indicate that the megacity development of Hyderabad has been affecting the crop choice, intensity of production and technologies in use in peri-urban farming. The study reports the absence of typical scenarios of structural change in agriculture characterized by increase in farm size, collective marketing, and on-farm investment in storage and quality (Reardon et al. 2004) in the GHA. The farm types can be classified as 'traditional farm types' (Heimlich and Anderson 2001) which broadly characterized by limited factor mobility and slow adaptation capacity to changing environments. During the last decade, the more 'sensitive' forms in GHA have closed down and have obviously sold their land.

Apart from "persistence and decline", Smithers and Johnson (2004) describe "growth" and "intensification" as typical farm-level trajectories scenarios. But our results indicate that very high land prices inhibit structural change towards larger and more efficient farm structures in the GHA. "Intensification", "diversification" and experimenting with more valuable crops thus remain the only feasible strategies for farmers who are increasingly threatened by income reduction. The adaptation processes we have observed fit into diversification scenarios described by Bryant and Johnston (1992), where farmers often rely on what has been called "off-farm diversification". Off-farm employment in government schemes and urban construction work compensates for income losses in agricultural production. "On-farm diversification" can also be observed, as farmers are changing their production practices towards those involving more machinery, fertilizer, water and chemical use, as well as engaging in neighborhood organisation for farm labour sharing. As we have

\footnotetext{
${ }^{9}$ Thanks to Professor Michael Mann to summarize the results
} 
mentioned above, the increases in pesticide use have been dramatic. The investigation has provided certain interesting insights related to continuity and profitability in the peri-urban farming where $>94 \%$ of the farmers want to continue farming despite of the conflicting forces of urbanisation on the long term sustainability of the farming in urban fringe of Hyderabad.

Our findings support the thesis that current developments in agriculture in the GHA are being accompanied by unsustainable use of natural resources and problematic levels of chemical residues in drinking water, fruits and vegetables, caused by intense small-scale agricultural production. Weakly capitalized agriculturalists cannot afford necessary investments in quality, training and on-farm infrastructure. This, together with growing demand for best-quality vegetables at the city markets, makes farmers in GHA risk-averse, because they cannot afford crop losses or quality-reducing crop damage. They react by drilling more and deeper bore wells and applying excessive dosages of fertilizers and agrochemicals.

The problematic connection between the deterioration of the economics of agricultural production in the GHA and the increase of agricultural externalities has, thus far, not resulted in a well-suited strategy for coordinating and accompanying structural change in Hyderabad's peri-urban agriculture. Such a comprehensive strategy may be necessarily complex. It should include elements connecting agricultural energy delivery with water-preserving measures to be carried out by farmers, elements of a more sustainability-oriented rural extension service targeting the knowledge base and capacities of agricultural stakeholders, as well as elements in support of healthy development of agricultural land rents and the division of risks in contract-farming arrangements. An important element here is the support of agricultural investments. Modern food systems are driven by the increasing demand of urban dwellers for healthy, high-quality products, known to induce heavy on-farm investments and a more direct and transparent system of retail. Policies in support of peri-urban farmers should not try to slow down on-going structural change at the cost of the environment. They should, instead, couple economic and environmental incentives and secure higher farm incomes for those farmers who are willing and able to prepare for a market in which a fair farm income is accompanied by sustainable resource use. 
Foster collective action, enable switches to more sustainable farming by highlighting the economic advantages of farming organically, and the independence from Monsanto and other high intensity supplies.

The results of the chapters 1 and 2 summarizes that there with managing to make farmers themselves the advocates of environmental, social and economic sustainability of peri urban farming i.e. taking the consumers as natural allies in a coalition which defends peri urban agriculturism as a necessary land use pattern but as well as one which protects the green belts and healty food providing character of agriculture so necessary for future megacities.

The analytical results (Chapter 3) based on the Analytical Hierarchy Process (AHP) indicate that the majority of the farmers evidently prioritize the criteria of economic development over the social and environmental criteria among the sustainability aspects. Thus in farmers opinion of peri-urban Hyderabad, technology (machines), biology (seeds) and chemistry (chemicals) are more important when compared to other criteria. Only Organic farmers, rather unsurprisingly, give priority to environmental sustainability whilst all agriculturist regard social sustainability least important. At the same time profit maximization is a top priority of all interviewed farmers, followed by yield maximization.

The findings of the study unpack the fact that the constant discourses of the farmers with the other actors in the society has something to do that substantially resulted into the adoption of the kind of production system and their preferences towards the dimension of sustainability. The differences in attitudes and opinions related to farming has stipulated various trade-offs between the three dimensions of sustainability. Majority of the farmers prefer economic dimension (Conventional, Better Management and High Resource use group) with an exception of Organic group of farmers which has relatively supported the findings of Napier et al. (1988), who argues that economic dimension is more important in farmers' decision making and farmers' use their own frameworks, their own views of "reality" while making a choice. The access to market in the urban areas drive the farmers to meander around the prioritization of factors like profit, yield, input use and market orientation 
Despite of the importance of factors like cropping intensity, crop diversification and specialization, farmers avow much priority to the factors like profits, yield, and input use which are relatively high priority for small and marginal farmers who are much credit constrained in the peri-urban areas. These situations underpin the argument of Hindess (1988) who states that the farmers' intensions, consequently actions arise from beliefs and desires among the farmers which are socially constructed.

The farmers in this area impart a high value to the mechanization which deliberately illustrates the verbalized discourse on scarcity of labor in the urban vicinities. In other wards the severe scarcity of labour in the peri-urban areas has prompted them to consider high priority to the mechanization despite itdoes not better fit as an element considering the environmental sustainability.

Similarly the results on the social dimension indicates the less social integration where majority of the farmers are individual oriented and they vow less weight for collective farming and participation. These findings strengthen the arguments of heterogeneous population and low social integration in the urban fringe argued in the literature. This weak "social pillar" in peri-urban context debunks the necessary to intervene at organizing farmers and strengthen the human capital for participation and collective action in light of sustainable development.

The results clearly demonstrate that sustainability dimensions in this context are antagonistic instead of complementary. The closer observation reveals the existence of a considerable trade-offs among and within three dimensions of sustainability. Considering the "reality" from the farmers' perceptions, the "fact" to achieve sustainable development in any given context is that all these three dimensions should be complementary and counteract.

The results disclose that farming practices in the urban fringe are shaped by several factors that entirely depend on demographic structure, market demand, objectives and motivations of farm families in these areas. The preference for chemical use in Conventional farmers is mainly due to interaction and discourse with other economic actors that has created a reality among them. Similarly the more interaction of Better Management and Organic group with actors concerned about environmental sustainability has socially constructed their 
attitude towards environmental concerns. The prominent belief of high water use in paddy farmers is also socially constructed where they believe that if they don't use more water and inputs for paddy they could not harvest better yields. That's reason they have ranked "input use" in economic dimension. The beliefs about "reality" by farmers on farming played an important role in construction of institutions and persons reflecting co-existence of different production patterns in the peri-urban context. This analysis provides a better understanding to promote policies and try to implement strategies for achieving the goal of sustainability in agriculture in peri-urban context.

Similarly Chapter 4 summarizes that when urbanization has substantially erode the land use ethics in peri-urban areas and shifts the value in land use from farming to other nonindustrial uses. Furthermore these areas considerably represent the blurring community sense along with fading social capital. To anticipate sustainable peri-urban farming it is necessary to fabricate societal innovations with enhanced participation and collective actions of the communities. When we seek to explore social innovations in these areas the exploration eventually abridge the construction of social capital, where social capital is presumed to be the bed-rock of innovations (Subramaniam and Youndt 2005).

This paper gives an example on finding on the preceding chapter. This is based on case study on the adoption of organic farming in a village in the urban fringe of Hyderabad. This case demonstrates that the mounting uncertainties in farming at the same time could propel the farmers to participate, innovate and do novel approaches in farming through rationalizing efficient external relationship with various actors in the society. After a great calamity (plague) which had seriously threatened the village's agriculture and survival of the village community, and with the assistance of two NGOs the entire village decided to adopt organic farming. This decision was based on economic rather than environmental grounds. Another finding is that the ecological challenge procured community (collective) action and thus promoted environmental sustainability as well as social sustainability. This confirms the thereotical claim that collective action and community participation are core elements of social innovation which might help to shape future politics in Hyderabad's urban fringes.

The case study analysis illustrates that in order to craft such innovations in peri-urban areas it is necessary to design strong community sense and collective action among the 
farmers in the urban fringes. The farmers in this case have successfully manipulated the crisis in farming through collective management of natural resources. Social innovation analysis has devoted particular attention to the local and regional territories. Urban neighborhoods are privileged spatial focus of territorial development based on social innovations (Moulaert and Nussbaurner 2005). In this study the innovation is put on par with collective learning and learning by doing. At the same this case should be exclusively designates beyond innovation in the sense of new skills attained by farmers, access to information, asset building at the community level through enhanced social relation between farmers and external actors (NGOs).Our analysis in this case evidently reveals that villagers' participation in collective action, participation in trainings, and strong community enforcement together with the solid trust on the local facilitating NGOthat hasevolved during the transformation process are responsible for the evolution of a resilient community. Promotion of this kind of innovations has many explanations where Moulaert describes them as erosion of community sense in the urban vicinity manifests need for such innovations. Finally to promote sustainability in urban fringes -these areas often become loci for instigating new types of social relations and new drivers of alternative agendas.

The uncertainty of the status of urban neighbourhoods as breeding grounds of socially innovative development is well known in the literature. On the one hand these territories very often have lived long histories of 'disintegration': being cut off from prosperous economic dynamics, fragmentation of local social capital, breakdown of traditional and often beneficial personnel relations, loss of quality of policy delivery systems, and so on (Moulaert et al. 2000). Crafting these kinds of social innovations into the policy design could ultimately enhance the abilities of the farmers to withstand and act collectively to recoup from the negative effects of urbanisation.

\subsection{Limitations of the thesis and indications for further research}

This dissertation itself disentangles the pace of farm development influenced by urbanisation in GHA. Based on these various trajectories of development (Pierce John 1994) the dissertation attempted to explore various farmers' perceptions connected to sustainability dimensions in these contemporary spaces. I found the existence of various trade-offs amongst 
farmers on various sustainability dimensions. These findings are very crucial in order to understand how farmers think of relative sustainability of what they do in farming. The investigation to demonstrate the farmers' perceptions could support the philosophical stand which is nothing but an emic perspective (Thompson 1994). From this perspective we are observing the farmers perceptions as an outsider of the system. This kind of analysis accentuates a basis to formulate effective strategies and policies to better integrate sustainability in these areas. Furthermore in order to infuse the sustainability agenda the farmers need an intensive capacity building that could eventually change the farmers' perceptions and instigate adoption of sustainable farming practices. In addition the excavation of sustainability in peri-urban farming relatively corresponds to exploring community based adaptations with strong social capital. Taking forward this idea I have explored a case based on community adaptations in the suburb of GHA and investigated the cause and effect relations along with the main factors responsible for the transformation. This analysis provided a better insight to fabricate such kind of innovations in the farming community in the vicinity of urban areas in order to emphasize community participation towards sustainable peri-urban development.

Concerned to the empirical strategies encouraged in this dissertation much of the investigation has been carried out through incorporating both qualitative and quantitative approaches. The dissertation has highly relied on the 'mixed methods' of research in order to capture various dimension connected to dynamics of development, farmer adaptations in the urban periphery of GHA. Despite of the various normative approaches proposed to evaluate sustainability only few of them could be well suited to analyze the farmers' perceptions on sustainability.

Yet a closer examination of various normative studies gives us an impression that only a couple of them have considered the three dimensions of sustainability and majority of them have extensively focused on measuring environmental indicators (Hani et al. 2006). Closely connected to this, Hyati (2010) recognizes three major challenges related to measurement of sustainability where first, the measures fall in short of pursuing trade-offs and complementarities among these three sustainability dimensions. Second, many of the indicators are not particularly useful to farmers and time consuming. Third, different 
indicators do not represent the actual cause-effect relationship among these dimensions. In the end after rigorous review we could able to adapt

Analytical Hierarchy Process (AHP). AHP is a well suited tool among Multi-criteria Decision analysis that better outfit for analyzing the problems where complex dimensions are involved. While evaluating the farmers' perceptions on sustainability dimensions despite of various methods proposed for evaluating sustainability. The only difficulty with this method is collecting data based on pair-wise ranking exercise that is pre-requisite for obtaining weighing the farmers' perception. It is oppressive to get the data on each pair-wise ranking and needs constant probing with the farmers to obtain ranks for various dimensions. Yet at the end it provides a very good picture on the sensitivity analysis and weights imparted to different sustainability dimensions. Simultaneously there are certain difficulties to explore the software as there is much diversity in the designs of the software available to analyze the data on AHP. Furthermore, the software purchase or getting license to use involves a mindnumbing process. In addition to this the researcher should get acquainted with various designs of diverse software available to carryout AHP analysis.

In similar vein while exploring the main casual factors for the entire process of social innovation in paper 4 along with qualitative approaches, I have adopted factor analysis. It was rather tedious to interpret the factor analysis model with small sample size $(N=50)$. Yet the precise literature review on the use of factor sample size and its application has directed me to effectively manage factor analysis with small sample size (Mundform and Shaw 2013). In the end I could finally demarcate the most influencing factors which have significantly represented high factor weight $(>0.8$ to 0.9$)$ in the entire process of societal transformation in the village. Besides these I did not face further constraints in the empirical analysis of the research.

In the end to indicate the further research areas in the context of peri-urban agriculture in India, it seems there is a whole bunch of areas that needs further in depth analysis. The research on peri-urban farming and its viability has been significantly underrepresented in Indian context. There are various problems in the peri-urban areas that are in relentless quest for a comprehensive analysis and further policy reforms. In this research I made an attempt to formulate the research basically to understand the dynamics of change in these areas 
explicitly due to megacity development in the Indian context. I have drawn theoretical understanding based on various studies in various parts of the world and attempted to explore them on farming impacts connected to megacity development of Hyderabad. Based on the range of research problems the research can address are limited arenas in the impacts of urbanisation on farming in the peri-urban areas.

Further, these areas need much more comprehensive strategies and approaches to explore the sustainability in the peri-urban areas. Nevertheless of our efforts to understand the dynamics and farmer adaptations in the urban fringe farmers, yet there is a vast list of issues in these areas that have not seen light in the research domain. Few things to ponder for example farmers vulnerability to the weather changes in the peri-urban areas, changing livelihoods and income diversification patterns, impacts of pollution on agriculture are quite a few that needs further comprehensive evaluation. In similar vein the studies ontenant farmers and their issues concerned with access to various support structures in urban hinterlands. Similarly the influence of property rights on farmers'adaptations and development. In addition there is underrepresentation of research on varioushealth impacts connected to use of urban wastewater especially for farming in peri-urban areas.

Furthermore the peri-urban farming itself is dynamic entity and they deliberately illustrate the need for better integration and planning by the urban authorities that constitutes a missing element in urban development agencies. Relate to this the urban development agencies and various stakeholders concerned to agriculture should seriously consider these loci and incorporate the farming issues into the territorial development approach. In order to further fulfill this research gap, these areas manifests wide-ranging studies related to farmers and farming in these contemporary spaces. These areas significantly manifest studies related to urban governance and environmental planning where the traditional approaches have largely failed to address these challenges.

\subsection{References}


Anne G; Busck. Soren, P; Kristensen, S. P; Anette R and T. Primdhal. (2006) "Land system changes in the context of urbanization: Examples from the peri-urban area of Greater Copenhagen". Danish Journal of Geography, 106, (2): 21-34.

Bryant, C.R and Johnston, T.R.R. (1992) “Agriculture in the city's countryside”. University of Toronto Press.

Bryant, Christopher R. (1995) "The role of local actors in transforming the urban fringe". Journal of Rural Studies, 11 (3): 255-267.

Garschagen, Matthias; Renaud Fabrice, G and Birkmann, Jörn. (2011) "Dynamic Resilience of Peri-Urban Agriculturalists in the Mekong Delta under Pressures of SocioEconomic Transformation ,Environmental change and Agriculture in Mekong Delta”. Advances in Global Change Research, 45:141-163.

Hani, F; Braga, F; Stampfli, A; Keller, T; Fischer, M and Porsche H. (2003) 'RISE, a Tool for Holistic Sustainability Assessment at the Farm Level". .International Food and Agribusiness Management Review, 6 (4): 78-90.

Hayati, D; Ranjbar, Z and Karami, E. (2010) "Measuring Agricultural Sustainability. Biodiversity, Biofuels, agroforestry and Conservation Agriculture" .Sustainable Agriculture Reviews, 5: 73-100.

Hindess, B. (1988) "Choice, rationality and social theory". London and Boston, Unwin Hyman Publishers.

Jussaume Jr; Raymond A and Glenna, Leland. (2009) "Considering Structural, Individual and Social Network Explanations for Ecologically Sustainable Agriculture: An Example Drawn from Washington State Wheat Growers". Sustainability 1 (2): 120-132.

Maconachie, R. A and Binns, T. (2006) "Sustainability under threat? The dynamics of environmental change and food production in peri-urban Kano, northern Nigeria". Land Degrad. Dev. 17 (2):159-171.

Moulaert, F and Nussbaurner, J. (2005) "The social region: beyond the territorial dynamics of the learning economy”. European Urban and Regional Studies, 12(1): 45-64.

Moulaert, F. et al. (2000) "Globalization and Integrated Area Development in European Cities”. Oxford: Oxford University Press.

Mundfrom, D.J and Shaw, D.G. (2013) "Minimum sample size recommendations for conducting factor analysis". International Journal of Testing, 5(2): 159-168.

Napier, T. L; Thraen, C. S and McClaskie, S.L. (1988) "Adoption of soil conservation practices by farmers in erosion prone areas of Ohio: The application of logit modeling". Society and Natural Resources, (1): 107-109. 
Pierce, John T. (1994) "Towards the Reconstruction of Agriculture: Paths of Change and Adjustment". The Professional Geographer, 46 (2): 178-190.

Reardon, T; Timmer, P and Berdegue, J. (2004) "The rapid rise of supermarkets in developing countries: induced organizational, institutional, and technological change in agri-food systems". Electronic journal of agricultural and development economics (eJADE), 1 (2):168-183.

Subramaniyam, M andYoundt, M.A. (2005) "The Influence of Intellectual Capital on the Types of Innovative Capabilities". Academy of Management Journal, 48 (3): 450463.

Sharp, J.S and Smith, M.B. (2003) "Social capital and farming at the rural-urban interface: the importance of non-farmer and farmer relations". Agricultural systems, 76 (3): 913-927.

Smither, J and Jhonson, P. (2004) "The dynamics of family farming in North Huron County, Ontarion.Part 1. Development Trajectories". The Canadian Geographer, 48(2), 191208.

Turok, I. (2009) "The distinctive city: pitfalls in the pursuit of differential advantage". Environment and Planning A, 41(1): 13-30.

Zollinger, Brett; Krannich and Richard, S. (2002) "Factors Influencing Farmers' Expectations to Sell Agricultural Land for Non-Agricultural Uses". Rural Sociology, 67 (3):442463. 


\section{Annexures}

Table 6-1: Summary of various studies related to peri-urban agriculture

\begin{tabular}{|c|c|c|c|c|c|}
\hline Author(s) & $\begin{array}{l}\text { Yea } \\
\mathbf{r}\end{array}$ & Place & Theory & Method & Remarks \\
\hline $\begin{array}{l}\text { Aguilar et } \\
\text { al. }\end{array}$ & $\begin{array}{l}200 \\
3\end{array}$ & $\begin{array}{l}\text { Latin } \\
\text { America, } \\
\text { Mexico }\end{array}$ & $\begin{array}{l}\text { Polarization } \\
\text { reversal, } \\
\text { Geographical } \\
\text { theory has been } \\
\text { largely unable } \\
\text { to incorporate } \\
\text { the nature of } \\
\text { evolving } \\
\text { settlements }\end{array}$ & Case study & $\begin{array}{l}\text { The study } \\
\text { indicates } \\
\text { peri-urban } \\
\text { should be } \\
\text { named as } \\
\text { the } \\
\text { "extended- } \\
\text { periphery" } \\
\text { for any given } \\
\text { mega-city. }\end{array}$ \\
\hline Busck et al & $\begin{array}{l}200 \\
8\end{array}$ & $\begin{array}{l}\text { Greater } \\
\text { Copenhage } \\
\mathrm{n}\end{array}$ & $\begin{array}{l}\text { Porous } \\
\text { landscapes }\end{array}$ & Case study & $\begin{array}{l}\text { Importance of } \\
\text { agricultural } \\
\text { land declined, }\end{array}$ \\
\hline Dinham, B & $\begin{array}{l}200 \\
3\end{array}$ & $\begin{array}{l}\text { Developin } \\
\text { g countries }\end{array}$ & $\begin{array}{l}\text { Farmer } \\
\text { adaptations to } \\
\text { urbanisation }\end{array}$ & Survey & $\begin{array}{l}\text { High } \\
\text { demand, } \\
\text { Better access } \\
\text { to market, } \\
\text { Farmers have } \\
\text { only limited } \\
\text { or no access } \\
\text { to advice on } \\
\text { the } \\
\text { complicated } \\
\text { management } \\
\text { of pesticides }\end{array}$ \\
\hline
\end{tabular}




\begin{tabular}{|c|c|c|c|c|c|}
\hline Trauger & $\begin{array}{l}200 \\
9\end{array}$ & USA & $\begin{array}{l}\text { Actor-Network } \\
\text { theory }\end{array}$ & Case Study & $\begin{array}{l}\text { The study } \\
\text { indicates } \\
\text { peri-urban } \\
\text { should be } \\
\text { named as the } \\
\text { "extended- } \\
\text { periphery" } \\
\text { for any given } \\
\text { mega-city. }\end{array}$ \\
\hline Douglas & $\begin{array}{l}200 \\
8\end{array}$ & $\begin{array}{l}\text { Latin } \\
\text { America, } \\
\text { and Asia }\end{array}$ & $\begin{array}{l}\text { Urbanisation } \\
\text { pressure on } \\
\text { ecosystem } \\
\text { environmental } \\
\text { pollution }\end{array}$ & $\begin{array}{l}\text { Comparative } \\
\text { study }\end{array}$ & $\begin{array}{l}\text { Interplay } \\
\text { between } \\
\text { economy, } \\
\text { society, land } \\
\text { and } \\
\text { ecosystems in } \\
\text { peri-urban } \\
\text { areas }\end{array}$ \\
\hline Dinham, B & $\begin{array}{l}200 \\
3\end{array}$ & $\begin{array}{l}\text { Developin } \\
\text { g countries }\end{array}$ & $\begin{array}{l}\text { Farmer } \\
\text { adaptations to } \\
\text { urbanisation }\end{array}$ & Survey & $\begin{array}{l}\text { High } \\
\text { demand, } \\
\text { Better access } \\
\text { to market, } \\
\text { Farmers have } \\
\text { only limited } \\
\text { or no access } \\
\text { to advice on } \\
\text { the } \\
\text { complicated } \\
\text { management } \\
\text { of pesticides }\end{array}$ \\
\hline $\begin{array}{l}\text { Ducrot et } \\
\text { al }\end{array}$ & $\begin{array}{l}200 \\
9\end{array}$ & USA & $\begin{array}{l}\text { Actor-Network } \\
\text { theory }\end{array}$ & Case Study & $\begin{array}{l}\text { The study } \\
\text { indicates } \\
\text { peri-urban } \\
\text { should be } \\
\text { named as the } \\
\text { "extended- } \\
\text { periphery" } \\
\text { for any given } \\
\text { mega-city. }\end{array}$ \\
\hline
\end{tabular}




\begin{tabular}{|c|c|c|c|c|c|}
\hline $\begin{array}{l}\text { Dufour et } \\
\text { al }\end{array}$ & $\begin{array}{l}200 \\
7\end{array}$ & France & $\begin{array}{l}\text { Multifunctional } \\
\text { ity of } \\
\text { agriculture in } \\
\text { peri-urban } \\
\text { development }\end{array}$ & $\begin{array}{l}\text { Multidisciplina } \\
\text { ry survey }\end{array}$ & $\begin{array}{l}\text { Agriculture is } \\
\text { closely } \\
\text { connected to } \\
\text { professional } \\
\text { identity, thus } \\
\text { helping in } \\
\text { understandin } \\
\mathrm{g} \text { attitudes to } \\
\text { multifunction } \\
\text { al nature }\end{array}$ \\
\hline $\begin{array}{l}\text { Francisco } \\
\text { and Ali }\end{array}$ & $\begin{array}{l}200 \\
6\end{array}$ & $\begin{array}{l}\text { Manila } \\
\text { peri-urban } \\
\text { context }\end{array}$ & $\begin{array}{l}\text { Innovations in } \\
\text { vegetable } \\
\text { farming }\end{array}$ & $\begin{array}{l}\text { Multi-object } \\
\text { Programming }\end{array}$ & $\begin{array}{l}\text { The higher } \\
\text { income } \\
\text { offered by the } \\
\text { costly } \\
\text { technology } \\
\text { will only be } \\
\text { acceptable if } \\
\text { farmers are } \\
\text { willing to } \\
\text { take on the } \\
\text { higher risk. }\end{array}$ \\
\hline $\begin{array}{l}\text { Haregewe } \\
\text { yn et al }\end{array}$ & $\begin{array}{l}201 \\
2\end{array}$ & $\begin{array}{l}\text { Bahir Dar, } \\
\text { Northwest } \\
\text { Ethiopia }\end{array}$ & $\begin{array}{l}\text { Urbanisation } \\
\text { impacts on } \\
\text { farming }\end{array}$ & $\begin{array}{l}\text { Aerial } \\
\text { photographs, } \\
\text { Field Mapping } \\
\text { using GPS }\end{array}$ & $\begin{array}{l}\text { Intensificatio } \\
\mathrm{n} \text { at the } \\
\text { expense of } \\
\text { agricultural } \\
\text { areas. } \\
\text { Ownership } \\
\text { system. }\end{array}$ \\
\hline $\begin{array}{l}\text { Hornis and } \\
\text { van Eck }\end{array}$ & $\begin{array}{l}200 \\
8\end{array}$ & $\begin{array}{l}\text { Netherland } \\
\mathrm{s}\end{array}$ & $\begin{array}{l}\text { Urban network } \\
\text { theory }\end{array}$ & Case study & $\begin{array}{l}\text { Ommeland } \\
\text { referes to } \\
\text { peri-urban } \\
\text { area. Almost } \\
40 \% \text { of the } \\
\text { Dutch } \\
\text { national } \\
\text { population } \\
\text { lives in peri- } \\
\text { urban area. }\end{array}$ \\
\hline
\end{tabular}




\begin{tabular}{|c|c|c|c|c|c|}
\hline & $\begin{array}{l}200 \\
5\end{array}$ & Australia & $\begin{array}{l}\text { Changing land } \\
\text { use patterns } \\
\text { and rural } \\
\text { livelihoods }\end{array}$ & $\begin{array}{l}\text { Spatial frame } \\
\text { and } \\
\text { Agricultural } \\
\text { census }\end{array}$ & $\begin{array}{l}\text { Results } \\
\text { indicate that } \\
25 \% \text { of the } \\
\text { Australia's } \\
\text { total Gross } \\
\text { value of } \\
\text { production is } \\
\text { from peri- } \\
\text { urban areas }\end{array}$ \\
\hline $\begin{array}{l}\text { Huang et } \\
\text { al }\end{array}$ & $\begin{array}{l}201 \\
1\end{array}$ & Taiwan & $\begin{array}{l}\text { Systems } \\
\text { Ecology theory }\end{array}$ & Impact Matrix & $\begin{array}{l}\text { The results } \\
\text { indicate that } \\
\text { the soil } \\
\text { component of } \\
\text { forest } \\
\text { ecosystem, } \\
\text { play a crucial } \\
\text { role for } \\
\text { agricultural } \\
\text { productivity }\end{array}$ \\
\hline $\begin{array}{l}\text { Christophe } \\
\mathrm{r} \text { and } \\
\text { Kendal }\end{array}$ & $\begin{array}{l}201 \\
3\end{array}$ & $\begin{array}{l}\text { Melborne, } \\
\text { Australia }\end{array}$ & $\begin{array}{l}\text { Peoples } \\
\text { underlying } \\
\text { values and } \\
\text { attitudes } \\
\text { towards } \\
\text { landscapes }\end{array}$ & $\begin{array}{l}\text { Exploratory } \\
\text { Factor } \\
\text { Analysis; } \\
\text { Regression } \\
\text { analysis }\end{array}$ & $\begin{array}{l}\text { This result } \\
\text { demonstrates } \\
\text { that peri- } \\
\text { urban } \\
\text { agricultural } \\
\text { landscapes } \\
\text { are perceived } \\
\text { as } \\
\text { multifunction } \\
\text { al systems by } \\
\text { the urban } \\
\text { public and } \\
\text { are valued for } \\
\text { a range of } \\
\text { functions }\end{array}$ \\
\hline Kombe & $\begin{array}{l}200 \\
5\end{array}$ & $\begin{array}{l}\text { Dar es } \\
\text { Salaam, } \\
\text { Tanzania }\end{array}$ & $\begin{array}{l}\text { Informal } \\
\text { settlements; } \\
\text { URBAN } \\
\text { FORM }\end{array}$ & $\begin{array}{l}\text { Focus group } \\
\text { interviews, } \\
\text { survey }\end{array}$ & $\begin{array}{l}\text { Migrants } \\
\text { search for a } \\
\text { location } \\
\text { where they } \\
\text { can meet } \\
\text { their basic } \\
\text { needs. }\end{array}$ \\
\hline
\end{tabular}




\begin{tabular}{|c|c|c|c|c|c|}
\hline $\begin{array}{l}\text { Dupont et } \\
\text { al. }\end{array}$ & $\begin{array}{l}200 \\
7\end{array}$ & India & $\begin{array}{l}\text { Peri-urban } \\
\text { areas as } \\
\text { "mixed-spaces. } \\
\text { Degenerated } \\
\text { peripheralisatio } \\
\text { n }\end{array}$ & Case studies & $\begin{array}{l}\text { The } \\
\text { arbitration } \\
\text { and } \\
\text { management } \\
\text { of PUA are } \\
\text { rendered } \\
\text { problematic } \\
\text { when they are } \\
\text { situated } \\
\text { beyond } \\
\text { administrativ } \\
\text { e limits. } \\
\text { "degenerated } \\
\text { peripheralisat } \\
\text { ion" }\end{array}$ \\
\hline $\begin{array}{l}\text { Firdaus } \\
\text { and } \\
\text { Ahamed. }\end{array}$ & $\begin{array}{l}201 \\
1\end{array}$ & India & $\begin{array}{l}\text { Changing land } \\
\text { use patterns } \\
\text { and rural } \\
\text { livelihoods }\end{array}$ & $\begin{array}{l}\text { Multiple Linear } \\
\text { Regression } \\
\text { Model }\end{array}$ & $\begin{array}{l}\text { Results } \\
\text { indicate } 63 \% \\
\text { of the } \\
\text { households } \\
\text { shift their } \\
\text { occupation } \\
\text { from } \\
\text { agriculture to } \\
\text { non- } \\
\text { agriculture, in } \\
\text { Delhi }\end{array}$ \\
\hline $\begin{array}{l}\text { Nsongkhla } \\
\text { amd } \\
\text { Sintusingh } \\
\text { a }\end{array}$ & $\begin{array}{l}201 \\
2\end{array}$ & $\begin{array}{l}\text { Mae Hong } \\
\text { Town }\end{array}$ & $\begin{array}{l}\text { Social } \\
\text { construction of } \\
\text { Green planning }\end{array}$ & $\begin{array}{l}\text { Participatory } \\
\text { approach }\end{array}$ & $\begin{array}{l}\text { The study } \\
\text { argues that } \\
\text { the } \\
\text { participatory } \\
\text { process opens } \\
\text { up planning } \\
\text { and resource } \\
\text { management } \\
\text { to more } \\
\text { sustainable, } \\
\text { democratic } \\
\text { and equitable } \\
\text { practices, }\end{array}$ \\
\hline
\end{tabular}




\begin{tabular}{|c|c|c|c|c|c|}
\hline $\begin{array}{l}\text { Isgin } \\
\text { Foster and }\end{array}$ & $\begin{array}{l}200 \\
6\end{array}$ & Ohio & $\begin{array}{l}\text { Real option } \\
\text { pricing theory }\end{array}$ & $\begin{array}{l}\text { Parsimonious } \\
\text { empirical } \\
\text { hedonic } \\
\text { models }\end{array}$ & $\begin{array}{l}\text { Both land-use } \\
\text { conversion } \\
\text { probability } \\
\text { and urban } \\
\text { influences } \\
\text { have been } \\
\text { important } \\
\text { factors }\end{array}$ \\
\hline $\begin{array}{l}\text { Hayes et } \\
\text { al. }\end{array}$ & $\begin{array}{l}199 \\
7\end{array}$ & Gambia & $\begin{array}{l}\text { To investigate } \\
\text { the role of } \\
\text { tenure security } \\
\text { on farm } \\
\text { investments } \\
\text { and input use } \\
\text { and thereby on } \\
\text { yield. }\end{array}$ & $\begin{array}{l}\text { Amemiya's } \\
\text { generalized } \\
\text { probit }\end{array}$ & $\begin{array}{l}\text { The tenure } \\
\text { security is } \\
\text { found to } \\
\text { enhance long- } \\
\text { term } \\
\text { investments, }\end{array}$ \\
\hline $\begin{array}{l}\text { Lanno et } \\
\text { al. }\end{array}$ & $\begin{array}{l}201 \\
2\end{array}$ & & $\begin{array}{l}\text { To investigate } \\
\text { the level of } \\
\text { social capital in } \\
\text { rural-urban } \\
\text { areas }\end{array}$ & $\begin{array}{l}\text { Multilevel } \\
\text { modeling } \\
\text { techniques }\end{array}$ & $\begin{array}{l}\text { The social } \\
\text { capital } \\
\text { appears to be } \\
\text { higher among } \\
\text { students from } \\
\text { municipalitie } \\
\mathrm{s} \text { in central } \\
\text { agglomeratio } \\
\text { ns than } \\
\text { among those } \\
\text { from more } \\
\text { rural } \\
\text { municipalitie } \\
\text { s. }\end{array}$ \\
\hline Chen et al & $\begin{array}{l}200 \\
9\end{array}$ & $\begin{array}{l}\text { Chaina and } \\
\text { India }\end{array}$ & $\begin{array}{l}\text { The kinds of } \\
\text { relationships } \\
\text { between the } \\
\text { state and other } \\
\text { urban } \\
\text { development } \\
\text { actors it entails, } \\
\text { ranging from } \\
\text { conflict to } \\
\text { collaboration, } \\
\text { from protest to } \\
\text { partnerships, } \\
\text { and from } \\
\text { contestation to }\end{array}$ & $\begin{array}{l}\text { field-based } \\
\text { observations, } \\
\text { and informal } \\
\text { discussions and } \\
\text { interviews with } \\
\text { official town } \\
\text { planners, } \\
\text { architects, and } \\
\text { private } \\
\text { planners }\end{array}$ & $\begin{array}{l}\text { Growing } \\
\text { social and } \\
\text { spatial } \\
\text { polarization } \\
\text { of the rich } \\
\text { and the poor } \\
\text { becomes } \\
\text { evident as the } \\
\text { peripheries } \\
\text { proceed to } \\
\text { become } \\
\text { inhabited and } \\
\text { revalorized } \\
\text { through new }\end{array}$ \\
\hline
\end{tabular}




\begin{tabular}{|c|c|c|c|c|c|}
\hline & & & collaboration & & $\begin{array}{l}\text { circuits of } \\
\text { capitals. of } \\
\text { large } \\
\text { numbers of } \\
\text { poor urban } \\
\text { inhabitants } \\
\text { describing the } \\
\text { caseas } \\
\text { "splintering } \\
\text { urbanism." }\end{array}$ \\
\hline $\begin{array}{l}\text { Glowacki- } \\
\text { Dudka et } \\
\text { al }\end{array}$ & $\begin{array}{l}201 \\
3\end{array}$ & $\begin{array}{l}\text { Midwest } \\
\text { United } \\
\text { States }\end{array}$ & $\begin{array}{l}\text { How can local } \\
\text { food systems } \\
\text { contribute to } \\
\text { the } \\
\text { development of } \\
\text { social capital in } \\
\text { a community } \\
\text { and how does } \\
\text { the social } \\
\text { capital } \\
\text { contribute to } \\
\text { the } \\
\text { development of } \\
\text { the local food } \\
\text { system? }\end{array}$ & $\begin{array}{l}\text { Grounded } \\
\text { Theory }\end{array}$ & $\begin{array}{l}\text { The study } \\
\text { theorizes that } \\
\text { social capital } \\
\text { expands in a } \\
\text { community } \\
\text { as a } \\
\text { consequence } \\
\text { of the } \\
\text { connections } \\
\text { and } \\
\text { reciprocity } \\
\text { that emerge } \\
\text { with the } \\
\text { development } \\
\text { of a locally } \\
\text { grown food } \\
\text { system when } \\
\text { facilitated by } \\
\text { trust and } \\
\text { unified goals } \\
\text { among the } \\
\text { participants }\end{array}$ \\
\hline
\end{tabular}

